\title{
A Multi-Layer Approach to the Equation of Motion Coupled-Cluster Method for the Electron Affinity
}

Soumi Haldar, Achintya Kumar Dutta

Submitted date: 14/02/2020 Posted date: 17/02/2020

Licence: CC BY-NC-ND 4.0

Citation information: Haldar, Soumi; Dutta, Achintya Kumar (2020): A Multi-Layer Approach to the Equation of Motion Coupled-Cluster Method for the Electron Affinity. ChemRxiv. Preprint.

https://doi.org/10.26434/chemrxiv.11853399.v1

We have presented a multi-layer implementation of the equation of motion coupled-cluster method for the electron affinity, based on local and pair natural orbitals. The method gives consistent accuracy for both localized and delocalized anionic states. It results in many fold speedup in computational timing as compared to the canonical and DLPNO based implementation of the EA-EOM-CCSD method. We have also developed an explicit fragment-based approach which can lead to even higher speed-up with little loss in accuracy. The multi-layer method can be used to treat the environmental effect of both bonded and non-bonded nature on the electron attachment process in large molecules.

File list (2)

Multilayer_EA_Soumi.pdf (2.10 MiB)

view on ChemRxiv • download file

SI_ChemRxiv.pdf (361.37 KiB)

view on ChemRxiv • download file 


\title{
A Multi-layer Approach to the Equation of Motion Coupled-Cluster Method for the Electron affinity
}

\author{
Soumi Haldar and Achintya Kumar Dutta* \\ Department of Chemistry, Indian Institute of Technology Bombay, Powai, Mumbai 400076
}

We have presented a multi-layer implementation of the equation of motion coupled-cluster method for the electron affinity, based on local and pair natural orbitals. The method gives consistent accuracy for both localized and delocalized anionic states. It results in many fold speedup in computational timing as compared to the canonical and DLPNO based implementation of the EA-EOM-CCSD method. We have also developed an explicit fragment-based approach which can lead to even higher speed-up with little loss in accuracy. The multi-layer method can be used to treat the environmental effect of both bonded and non-bonded nature on the electron attachment process in large molecules.

*achintya@chem.iitb.ac.in 


\section{Introduction:}

Electron attachment plays an essential role in many of the biological processes, which include photosynthesis, respiration, and radiation damage to biomolecules. Theoretical simulations can play a significant role in understanding the physics and the chemistry of the electron attachment induced biological processes.

The quantum chemical methods available for the study of electron affinity can be classified into two broad categories. The first one is the so-called $\Delta$-based method, in which one needs to perform two separate calculations on the neutral and the electron attached state. Consequently, the electron affinity is calculated as the difference between the two separately calculated energies. Now, the quantum chemical calculations on the anionic state may suffer from problems like spin contamination and symmetry breaking in the wave-function. Moreover, the reference Hartree-Fock wave-function of the anionic state may suffer from variational collapse. Jordan and co-workers ${ }^{1}$ have recently shown that a variational collapse of the reference wave-function cannot be cured by even a $\operatorname{CCSD}(\mathrm{T})$ treatment of the correlation effect. On the other hand, the direct difference energy based methods, which calculate the electron affinity directly as the energy of transition from the neutral to the anionic state, is free from the problems mentioned above and can calculate electron affinity corresponding to multiple states in a single calculation. The method based on Green's function ${ }^{2}$, propagator based methods ${ }^{3,4}$, linear response method ${ }^{5}$, and equation of motion $(\mathrm{EOM})^{6}$, all fall under this category. Among all the direct difference energy based methods, the equation of motion coupled cluster $(\mathrm{EOM}-\mathrm{CC})^{7-11}$, is considered to be the most accurate and systematically improvable one. The EOM-CC is generally used in singles and doubles approximation (EOM-CCSD), which scales as iterative $\mathrm{O}\left(\mathrm{N}^{6}\right)$ power of the basis set and has an error bar ${ }^{12}$ of 0.01 to $0.03 \mathrm{eV}$ for the electron attachment problem. The steep computational scaling and high storage requirement restrict the use of the canonical EOM-CCSD method beyond small molecules unless one has access to supercomputing facilities. Various strategies have been described in the literature ${ }^{13}$ to reduce the scaling of the EOM-CCSD calculations. Starting from perturbative approximation ${ }^{14-19}$, density fitting ${ }^{20-26}$ and semi-numerical approximation $^{27-29}$ to the state of the art implementations $\mathrm{s}^{30-39}$ based on local orbital and natural orbitals has been reported in the literature. However, the reports of lower scaling approximation to electron attachment variant of the EOM-CCSD method (EA-EOM-CCSD) are rather limited ${ }^{40,41}$. Recently, Neese and coworkers have developed a domain-based pair natural implementation $\left(\right.$ DLPNO $\left.^{42-50}\right)$ of the EA-EOM-CCSD method $^{51}$, which can be applied to large molecules. However, most of the existing implementation of the EA-EOM-CCSD method is restricted to isolated gas-phase molecules only. The surrounding environment can have a significant impact on the electron attachment process as the incoming electron is often 
delocalized. Therefore, it is a challenging task to develop theoretical models that can describe environmental effects on the electron attachment process.

The theoretical models that are usually used to describe environmental effects on quantum chemical calculations are of two types: (i) implicit model and (ii) explicit model. The implicit solvation models ${ }^{52,53}$ treat the whole environment as a uniform polarisable continuous medium, with a specific dielectric constant. The polarizable continuum model (PCM) ${ }^{54}$ and conductor-like screening model (COSMO $)^{55}$ are among the most popular implicit models that are used to study the environmental effects introduced by the solvents. However, such implicit models cannot include specific short-range interactions like H-bonding, charge delocalization ${ }^{56}$. The best way to include these short-range interactions is to use an explicit model where each molecule constituting the environment is treated explicitly. However, the explicit treatment of the environment in a quantum chemical method can lead to a high computational cost, even for a mediumsized system. The way-out is to choose a multilayer model in which the entire system is divided into some hypothetical fragments: i) the main system, where the reaction or any chemical change of interest takes place, (ii) the environment, and (iii) the interaction zone between these two fragments. Instead of treating the whole system at a uniform level of theory, different levels of theories can be employed for the different regions depending upon their importance in the chemical process. The multi-layer approach can provide a proper balance between the computational cost and the accuracy of results. Generally, quantum chemical methods (QM) are used to perform the calculation on the main fragments and molecular mechanics (MM) is used for the environment. The treatment of the interaction region varies in different methods. To get a quantitative agreement with the experimental value, one needs to include an accurate treatment of the interfragment using the electronic embedding technique.

Additional complications arise when the partitioning between the main system and environment involves cutting of covalent bonds. The most widely used approach is the link atom method ${ }^{57}$, in which the raptured covalent bonds are saturated with a hydrogen atom. However, this can lead to the introduction of additional degrees of freedom in the system and can also lead to the problem of over-polarization of the QM region by the MM region. Various techniques have been developed to account for the over polarization errors $^{58}$. Alternatively, one can replace the boundary atom by parameterized pseudopotentials ${ }^{59,60}$. This approach is free from the problem of over polarization. On the downside, the pseudopotentials need to be reparameterized individually on every basis set and for each kind of bond.

The traditional QM/MM methods work reasonably well in describing the environmental effect on the ground state. However, it fails to give a consistent performance for the ionized, electron attached or excited states, especially where the electron density over the environment undergoes significant change 
during the transition process ${ }^{61}$. Krylov and co-workers have reported some original progress on simulating environmental effects for excited states using a non-empirical polarizable force field in the form of the effective fragment potential method ${ }^{62-68}$.

The models based on density embedding approaches ${ }^{69-71}$, on the other hand, are free from the problem mentioned above. It does not require any explicit cutting of bonds and can describe the environmental effects in both ground and excited state. The recent development in the local correlation methods has made it possible to treat the main fragment in a highly accurate wave-function based method and embed it in the density of the environment calculated at a lower-level method (generally Hartree-Fock or the DFT). As there is no semi-empirical parameter involved, the density embedding scheme can be applied to ground and excited states of any arbitrary chemical or biological system. Recent years have seen a surge of interest in the development of coupled cluster based density embedding methods ${ }^{72}$. Manby and co-workers have recently used a projector-based embedding scheme $\mathrm{e}^{73,74}$ to include environmental effects in EOM-CCSD based excited-state calculations. Kohn and co-workers ${ }^{75}$ have reported a subtractive embedding based approach for the multi-reference coupled-cluster method. Kallay and co-workers ${ }^{76,77}$ have used a Huzinaga equation-based local self-consistent field approach to develop an efficient scheme for the embedding of higher level density functional theory (DFT) and wave function theory (WFT) methods into lower-level DFT or WFT approaches. The multi-layer DLPNO scheme ${ }^{78}$ of Neese and co-workers provides an alternative approach of treating environmental effects in the coupled-cluster based method. In this approach, the localized orbitals are used to distinguish between the central fragment and the environment. Such a localized description of the orbitals allows one to treat different fragments with different levels of accuracy. Straatsma and co-workers ${ }^{79}$ have implemented the multi-layer approach of Divide-ExpandConsolidate (DEC) coupled-cluster method. Folkestad and Koch have also described a multi-layer implementation of excited state coupled-cluster methods based on the correlated natural transition orbitals $^{36,80}$. Recently, we have extended the multi-layer DLPNO scheme to ionized states ${ }^{81}$. The method can describe the environmental effect, of both bonded and non-bonded nature, on the ionization process with systematically controllable accuracy. However, the single ionization is generally localized on a particular part of the molecule and Koopmans' approximation generally provides a decent estimate of the ionization energy for the valence state. However, the situation is entirely different for the electron attachment, as many of the electron attached states can be non-local and the incoming electron can be delocalized on the entire molecule. Moreover, the Hartree-Fock method gives an inadequate description of electron attached states and inclusion of electron correlation is essential to get even a qualitative accuracy in EA value. Therefore, the use of any localized orbital based multi-layer modeling approach to describe the environmental effect on electron attachment can be rather complicated. To the best of our knowledge 
no density embedding or multi-layer approach for the direct calculation of electron affinitiy is available in the literature.

This paper aims to develop a multi-layer DLPNO scheme for electron affinity variant of EOMCCSD, which can treat the environment effects on the electron attachment to molecules of unprecedented size with systematically controllable accuracy.

\section{Theoretical Background:}

\subsection{Canonical EA-EOM-CCSD:}

In the canonical EA-EOM-CCSD method the target electron-attached state is obtained by the diagonalization of the coupled cluster (CC) similarity transformed Hamiltonian

$$
\bar{H}=e^{-\hat{T}} H_{N} e^{\hat{T}}
$$

in a space spanned by 1-particle and 2-particle1-hole determinants. The cluster operator $\hat{T}$ is formed out of the ground state CC amplitudes

$$
T=T_{1}+T_{2}+\ldots+T_{N}=\sum_{n}^{N} T_{n}
$$

with

$$
T_{m}=\frac{1}{(m !)^{2}} \sum_{\substack{i j \ldots . \\ a b \ldots}}^{a b \ldots . . .} a_{a}^{\dagger} a_{b}^{\dagger} \ldots a_{j} a_{i}
$$

where the indices $i, j \ldots$ refer to the occupied orbitals while the indices $a, b \ldots$ indicate the virtual ones. The $\mathrm{T}$ amplitudes are obtained by the iterative solution of the following non-linear equations

$$
\left\langle\Psi_{i j \ldots}^{a b \ldots}|\bar{H}| \Psi_{0}\right\rangle=0
$$

The EOM-CCSD equation for the $\mathrm{k}^{\text {th }}$ target state is given by

$$
\bar{H} \hat{R}_{k}\left|\Psi_{0}\right\rangle=E_{k} \hat{R}_{k}\left|\Psi_{0}\right\rangle
$$

where $\hat{R}_{k}$ is the linear excitation operator and $E_{k}$ is the energy of the $\mathrm{k}^{\text {th }}$ target state. The energy difference of the ground and $\mathrm{k}^{\text {th }}$ target state $\left(\omega_{k}=E_{k}-E_{0}\right)$ can be directly obtained from the commutator form of the equation,

$$
\left[\bar{H}, \hat{R}_{k}\right]\left|\Psi_{0}\right\rangle=\omega_{k} \hat{R}_{k}\left|\Psi_{0}\right\rangle
$$


The explicit expression of the $\hat{R}_{k}$ operator for electron attachment in the CCSD approximation is given by,

$$
\hat{R}_{k}^{E A}=\sum_{a} r_{a} a^{\dagger}+\sum_{a} r_{a b}^{i} b^{\dagger} a^{\dagger} i
$$

Equation 6 is solved by the modified Davidson iterative diagonalization method, which involves the contraction of the similarity transformed Hamiltonian with suitably chosen guess vectors to generate the so-called sigma vectors. The explicit expressions for the EA-EOM-CCSD sigma vectors are

$$
\begin{aligned}
& \sigma_{a}=\underbrace{\tilde{\tilde{F}}_{d}^{a} r_{d}+\tilde{F}_{d}^{l} \tilde{r}_{a d}^{l}}_{F}+\hat{g}_{e d}^{l a} \tilde{r}_{d e}^{l} \\
& \sigma_{a b}^{j}=\underbrace{\tilde{\tilde{F}}_{d}^{a} r_{d b}^{j}+\tilde{\tilde{F}}_{d}^{b} r_{a d}^{j}-\tilde{\tilde{F}}_{j}^{l} r_{a b}^{l}-t_{a b}^{m j} \tilde{F}_{d}^{m} r_{d}}_{F}+\underbrace{\tau_{a b}^{m n}\left(g_{d e}^{m n} r_{d e}^{j}\right)+\tilde{\tilde{K}}_{b d}^{j l} r_{a d}^{l}-\tilde{K}_{b d}^{j l} \rho_{d a}^{l}-\tilde{J}_{d a}^{j l} \rho_{d b}^{l}}_{2 e} \\
& +\tilde{g}_{b a}^{j d} r_{d}+\underbrace{K\left(\rho^{j}, r^{j}\right)_{a b}}_{4 e}-\underbrace{\tilde{r}_{f e}^{m} g_{f e}^{n m} t_{a b}^{n j}}_{3 b}
\end{aligned}
$$

Where $\tilde{r}_{a b}^{j}=2 r_{a b}^{j}-r_{b a}^{j}$ and $\rho_{a b}^{j}=r_{a b}^{j}+r_{a} t_{b}^{j}$. The $g_{r s}^{p q}$ are two-electron integrals. $\tilde{F}, \tilde{\tilde{F}}, \tilde{g}, \tilde{K}, \tilde{\tilde{K}}$ and $\tilde{J}$ are standard $\bar{H}$ intermediates. The implementational details of the canonical EOM-CCSD in ORCA can be found in reference ${ }^{28}$.

\subsection{DLPNO Implementation of EA- EOM-CCSD:}

The implementation of the EA-EOM-DLPNO-CCSD method is based on the idea of local correlation $^{42,45,78,82-89}$ i.e. dynamic correlation is a short-range effect. In the DLPNO approach, the occupied space is expanded in terms of localized orbitals and the virtual space is expanded in correlation domains using projected atomic orbitals. The correlation domains are further truncated using pair natural orbitals $(\mathrm{PNOs})^{90}$. The steps involved in the EA-EOM-DLPNO-CCSD calculations are as follows.

After the solution of the Hartree-Fock equations, we first localized the occupied molecular orbitals to generate localized molecular orbitals (LMO). Any of the standard localization methods like Pipek-Mezey ${ }^{91}$, or Foster-Boys ${ }^{92}$ can be used for that purpose.

After localizing the occupied MOs, a linearly dependent (redundant) set of projected atomic orbitals $(\mathrm{PAOs})^{84}$ is constructed for the virtual space. 


$$
|\tilde{\mu}\rangle=\sum_{\mu} \tilde{P}_{\mu \tilde{\mu}}|\mu\rangle
$$

where the PAO coefficient matrix is given by,

$$
\tilde{P}=1-C^{o c c} C^{o c c^{\dagger}} S
$$

The $S$ is the overlap matrix of atomic orbitals, and $C^{o c c}$ represents the occupied block of LMO coefficient matrix.

The advantage of constructing the virtual space PAOs is that the local nature of the orbitals introduced in the occupied space is still retained. A non-redundant set of PAOs ( $\left.\tilde{\mu}^{\prime}\right)$ can then be formed using standard orthonormalization techniques.

In the next step, all these PAOs are assigned to the orbital domains of the occupied LMOs. The domains are defined by a sparse map $L\left(i \rightarrow \tilde{\mu}_{A}\right)$ which includes all the PAOs whose differential overlap integral (DOI)

$$
D O I_{i \tilde{\mu}}=\sqrt{\int|i(r)|^{2}|\tilde{\mu}(r)|^{2}}
$$

with a particular occupied LMO ${ }^{i}$ is above some predefined threshold value (TCutDO in ORCA). The subscript $A$ indicates that if the PAO $\tilde{\mu}_{A}$ is centered on the atom $A$, then all other PAOs which are also centered on the atom $A$ will be included in the orbital domain of occupied LMO $i$. The pair domains for $i j$ pair are constructed from the union of orbital domains of LMOs $i$ and $j$. All the required integrals in the DLPNO method is calculated using the density fitting approximation ${ }^{20,22-24,93}$. Therefore, one also needs to construct a fitting domain of the auxiliary basis for each occupied orbital and is controlled by the keyword TCutMKN in ORCA.

After the construction of the orbital domains, the pairs which will be treated in the coupled-cluster level are determined by a three-step procedure based on a semi-canonical MP2 estimate of the pair energy. The process is controlled by the keyword TCutPairs in ORCA. The semi-canonical first order amplitudes for closed-shell species are defined as

$$
t_{\tilde{\mu}_{i j}^{\prime} \tilde{v}_{i j}^{\prime}}^{i j}=\frac{\left(i \tilde{\mu}_{i j}^{\prime} \mid j \tilde{v}_{i j}^{\prime}\right)}{F_{i i}+F_{j j}-\varepsilon_{\tilde{\mu}_{i j}^{\prime}}-\varepsilon_{\tilde{v}_{i j}^{\prime}}}
$$


where $\tilde{\mu}_{i j}^{\prime}$ represents the set of non-redundant and linearly independent PAOs in the pair domain for the pair ij. The $F_{i i}$ are the diagonal elements of the Fock matrix in the LMO basis and $\varepsilon_{\tilde{v}_{i j}^{\prime}}$ are the orbital energies in the redundant PAO basis.

In the first step, an MP2 estimate of the pair energy for every pair with $D O I_{i j}<T C u t D O_{i j}$ is calculated using a dipole-dipole approximation of the 2-external exchange integrals. The pairs which have the pair energy less than the threshold TCutPre are discarded from the further calculation and the sum of their energies is saved as the weak pair correction. The default values of TCutDO $O_{i j}$ and TCutPre are controlled by the keyword TCutPair and is defined as TCutDO $O_{i j}=$ TCutPair/10 and TCutPre=TCutPair/100. In the second step, the semi-canonical MP2 energy is calculated for the remaining pairs in a much smaller domain defined by $2 \times T C u t D O$ and $10 \times T C u t M K N$ and pairs which have energy smaller than TCutPairs/10 are discarded from the pair list. The pair energies of the dropped pairs are added to the existing weak pair correction. In the third step, semi-canonical MP2 energy is calculated for the surviving pairs using larger domains defined by $T C u t D O_{i j}$ and TCutMKN. The pairs with pair energy larger than TCutPairs (strong pairs) are passed on for the coupled-cluster treatment. The remaining pairs are discarded and their energy is added to the already existing weak pair corrections. The MP2 energy of the strong pair is also saved to be used as a correction for the PNO truncation.

In the next step, pair densities are constructed as

$$
D_{\tilde{\mu}^{\prime} \tilde{v}^{\prime}}^{i j}=\frac{2}{1+\delta_{i j}}\left(\tilde{t}_{\tilde{\mu}^{\prime} \tilde{v}^{\prime} \tilde{t}^{i j}}^{i j \dagger} \tilde{t}_{\tilde{\mu}^{\prime} \tilde{v}^{\prime}}^{i j}-\tilde{t}_{\tilde{\mu}^{\prime} \tilde{v}^{\prime}}^{i j \dagger} \tilde{t}_{\tilde{\mu}^{\prime} \tilde{v}^{\prime}}^{i j}\right)
$$

with

$$
\tilde{t}_{\tilde{\mu}_{i j}^{\prime} \tilde{r}_{i j}^{\prime}}^{i j}=2 t_{\tilde{\mu}_{i j}^{\prime} \tilde{\nu}_{i j}^{\prime}}^{i j}-t_{\tilde{v}_{i j}^{\prime} \tilde{\mu}_{i j}^{\prime}}^{i j}
$$

The pair density $D^{i j}$ is then diagonalized

$$
\sum_{\tilde{v}^{\prime}} D_{\tilde{\mu}^{\prime} \tilde{v}^{\prime}}^{i j} d_{\tilde{v}^{\prime} \tilde{a}_{i j}}^{i j}=n_{\tilde{a}_{i j}}^{i j} d_{\tilde{\mu}^{\prime} \tilde{a}_{i j}}^{i j}
$$

to obtain the PNO occupation numbers $n_{\tilde{a}_{i j}}^{i j}$ and PNO expansion coefficients $d_{\tilde{\mu}^{\prime} \tilde{a}_{i j}}^{i j}$. All the PNOs with PNO occupation number $n_{\tilde{a}_{i j}}^{i j} \leq T C u t P N O$ are discarded and the remaining ones are canonicalized by diagonalizing the virtual-virtual block of the Fock matrix. The MP2 energy is calculated for the strong pairs in the 
truncated PNO basis and the difference of it with the MP2 energy in the non-redundant PAO basis is saved as a correction for the PNO truncation.

The next step is to solve the ground state CCSD equations in the truncated PNO basis. Both the singles and doubles amplitudes are expanded in the PNO basis. However, the singles amplitudes are expanded on a PNO basis corresponding to diagonal pairs (singlesPNO) and a tighter threshold $(0.3 \times$ TCutPNO) is used for the singles. The total DLPNO-CCSD correlation energy is thus the sum of the correlation energies for the strong pairs, correction energies for the weak pairs, and the PNO truncation correction. The accuracy of the DLPNO-CCSD method is essentially controlled by four cutoff parameters TCutPNO, TCutPair, TCutMKN and TCutDO, as all the other truncation parameters are defined in terms of these four parameters. Neese and co-workers ${ }^{94}$ have defined a balanced truncation scheme where a single keyword can control all the four truncation parameters. They are called LOOSEPNO, NORMALPNO and TIGHPNO and gives the progressively more accurate results at the expense of higher computational cost. Werner and co-workers ${ }^{83,95-100}$, as well as, Hattig and co-workers ${ }^{101-108}$ have reported similar developments in the PNO based coupled cluster methods.

In the DLPNO formulation of EA-EOM-CCSD, the singles block of the similarity transformed Hamiltonian is kept untruncated and doubles block is expanded in terms of the singlesPNOs basis. The steps involved in the EA-EOM-DLPNO-CCSD method are as follows.

After the solution of the ground state DLPNO-CCSD equations, one needs to construct the transformation matrix from doublesPNOs $\left(S_{a_{i j}, a}^{i j}\right)$ and singlesPNOs $\left(S_{\tilde{a}_{i}, a}^{i}\right)$ to the canonical basis. In the next step, the virtual-virtual block of the dressed Fock matrix and is constructed as

$$
\tilde{\tilde{F}}_{a}^{d}=F_{a}^{d}-S_{a, \tilde{a}_{m n}}^{m n} \tau_{\tilde{a}_{m n} \tilde{e}_{m n}}^{m n} \overline{\bar{g}}_{\tilde{d}_{m n} \tilde{c}_{m n}}^{m n} S_{\tilde{d}_{m n}, d}^{m n}+S_{a, \tilde{a}_{m}}^{m} \overline{\bar{g}}_{\tilde{d}_{m} \tilde{e}_{m}}^{a_{m} m} t_{e_{m}}^{m} S_{\tilde{d}_{m}, d}^{m}-S_{a, \tilde{a}_{m}}^{m} t_{a_{m}}^{m} F_{d_{m}}^{m} S_{\tilde{d}_{m}, d}^{m}
$$

The dressed 2 external integrals are as follows

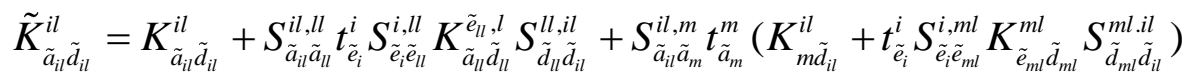

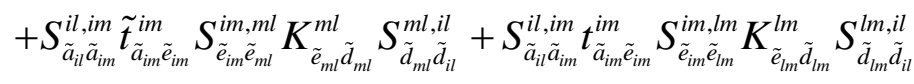

$$
\begin{aligned}
& J_{\tilde{d}_{i l} \tilde{a}_{i l}}^{i l}=J_{\tilde{d}_{i l} \tilde{a}_{i l}}^{i l}+S_{\tilde{d}_{i l} \tilde{d}_{l l}}^{i l, l} t_{\tilde{e}_{i}}^{i} S_{\tilde{e}_{i} \tilde{e}_{l l}}^{i, l l} K_{\tilde{e}_{l l} \tilde{a}_{u l}}^{l \tilde{d}_{l l}} S_{\tilde{a}_{l l} \tilde{a}_{i l}}^{l l, i l}-S_{\tilde{a}_{i l} \tilde{a}_{m}}^{i l, m} t_{\tilde{a}_{m}}^{m}\left(J_{m \tilde{d}_{i l}}^{i l}+t_{\tilde{e}_{i}}^{i} S_{\tilde{e}_{i} \tilde{e}_{m l}}^{i, l m} K_{\tilde{e}_{l m}}^{l m} \tilde{d}_{l m} S_{\tilde{d}_{l m}}^{l m, i l} \tilde{d}_{i l}\right) \\
& -S_{\tilde{a}_{i l} \tilde{a}_{i m}}^{i l, i m} \tilde{t}_{\tilde{e}_{i m}}^{i m} \tilde{a}_{i m} S_{\tilde{e}_{i m} \bar{e}_{l m}}^{i m, l m} K_{\tilde{e}_{l m} \tilde{d}_{l m}}^{l m} S_{\tilde{d}_{l m}}^{l m, i l} \tilde{d}_{i l} \\
& \tilde{\tilde{K}}_{a_{i l} d_{i l}}^{i l}=2 \tilde{K}_{\tilde{a}_{i l} \tilde{d}_{i l}}^{i l}-\tilde{J}_{\tilde{d}_{i l} \tilde{a}_{i l}}^{i l}
\end{aligned}
$$

The EA-EOM-DLPNO-CCSD equations are solved using the modified Davidson iterative diagonalization algorithm. The EA-EOM-DLPNO-CCSD sigma equations are as follows 


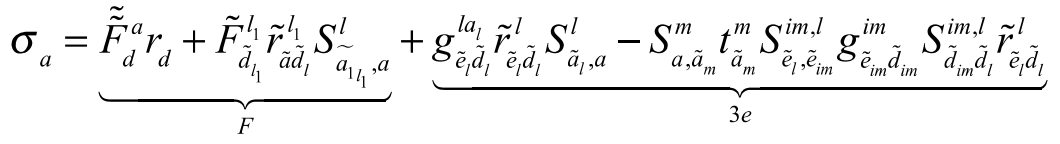

$$
\begin{aligned}
& \sigma_{\tilde{a}_{j} \tilde{b}_{j}}^{j}=\underbrace{S_{\tilde{a}_{j}, a}^{j} \tilde{F}_{d}^{a} S_{d, \tilde{d}_{j}}^{j} r_{\tilde{d}_{j} \tilde{b}_{j}}^{j}+S_{\tilde{b}_{j}, b}^{j} \tilde{\tilde{F}}_{d}^{b} S_{d, \tilde{d}_{j}}^{j} r_{\tilde{a}_{j} \tilde{d}_{j}}^{j}-\tilde{\tilde{F}}_{j}^{l} S_{\tilde{a}_{j}, \tilde{a}_{l}}^{j, l} r_{\tilde{a}_{l} \tilde{b}_{l}}^{l} S_{\tilde{b}_{l}, \tilde{b}_{j}}^{l, j}-S_{\tilde{a}_{j}, \tilde{a}_{m j}}^{j, m j} t_{\tilde{a}_{m j} \tilde{b}_{m j}}^{m j} S_{\tilde{b}_{m j}, \tilde{b}_{j}}^{m j, j} \tilde{F}_{\tilde{d}_{m}}^{m} S_{\tilde{d}_{m}, d}^{m} r_{d}}_{F} \\
& +\underbrace{S_{\tilde{a}_{j}, \tilde{a}_{m n}}^{j, m n} \tau_{\tilde{a}_{m n} \tilde{b}_{m n}}^{m n} S_{\tilde{b}_{m n}, \tilde{b}_{j}}^{m n, j}\left(g_{\tilde{d}_{m n} \tilde{e}_{m n}}^{m n} S_{\tilde{d}_{m n}, \tilde{d}_{j}}^{m n, j} r_{\tilde{d}_{j} \tilde{e}_{j}}^{j} S_{\tilde{e}_{j}, \tilde{e}_{m n}}^{j, m n}\right)}_{2 e}
\end{aligned}
$$

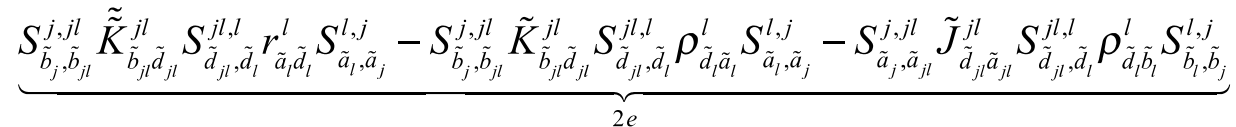

$$
\begin{aligned}
& +\underbrace{g_{\tilde{b}_{j} \tilde{a}_{j}}^{j \tilde{d}_{j}} S_{\tilde{d}_{j}, d}^{j} r_{d}+S_{\tilde{a}_{j}, \tilde{a}_{j m}}^{j, j m} \tilde{t}_{\tilde{a}_{j m} \tilde{m}_{j m}}^{j m} S_{\tilde{e}_{m j}, \tilde{e}_{m}}^{j m, m} K_{\tilde{e}_{m} \tilde{b}_{m}}^{m \tilde{b}_{m}} S_{\tilde{d}_{m}, d}^{m} r_{d} S_{\tilde{b}_{m}, \tilde{b}_{j}}^{m, j}}_{3 e} \\
& -\underbrace{S_{\tilde{a}_{j}, \tilde{a}_{j m}}^{j, j m} \tilde{t}_{\tilde{a}_{j m} \tilde{e}_{j m}^{j m}}^{j m} S_{\tilde{e}_{m j}, \tilde{e}_{m}}^{j m, m} J_{\tilde{b}_{m} \tilde{e}_{m}}^{m \tilde{d}_{m}} S_{\tilde{d}_{m}, d}^{m} r_{d} S_{\tilde{b}_{m}, \tilde{b}_{j}}^{m, j}-S_{\tilde{b}_{j}, \tilde{b}_{j m}}^{j, j m} \tilde{t}_{\tilde{e}_{j m} \tilde{b}_{j m}^{j m}}^{j m} S_{\tilde{e}_{m j}, \tilde{e}_{m}}^{j m, m} J_{\tilde{a}_{m} \tilde{e}_{m}}^{m \tilde{d}_{m}} S_{\tilde{d}_{m}, d}^{m} r_{d} S_{\tilde{a}_{m}, \tilde{a}_{j}}^{m, j}}_{3 e} \\
& +\underbrace{S_{\tilde{a}_{j}, \tilde{a}_{m n}}^{j, m n}\left(2 t_{\tilde{a}_{m n} \tilde{b}_{m n}}^{m n}-\tau_{\tilde{a}_{m n} \tilde{b}_{m n}}^{m n}\right) S_{\tilde{b}_{m n}, \tilde{b}_{j}}^{m n, j}\left(K_{i \tilde{d}_{m n}}^{m n}+t_{\tilde{e}_{j}}^{j} S_{\tilde{d}_{j}, \tilde{d}_{m n}}^{j, m n} K_{\tilde{e}_{m n} \tilde{d}_{m n}}^{m n}\right) S_{\tilde{d}_{m n}, d}^{m n} r_{d}}_{3 e} \\
& +\underbrace{K\left(\rho^{j}, \mathbf{r}^{j}\right)_{\tilde{a}_{j} \tilde{b}_{j}}}_{4 e}+\underbrace{S_{\tilde{e}_{n n}, \tilde{e}_{m}}^{n m, m} \tilde{r}_{\tilde{f}_{m} \tilde{e}_{m}}^{m} S_{\tilde{f}_{m}, \tilde{f}_{n m}}^{m, n m} g_{\tilde{f}_{n m} \tilde{e}_{n m}}^{n m} S_{\tilde{a}_{j}, \tilde{a}_{n j}}^{j, n j} t_{\tilde{a}_{n j} \tilde{b}_{n j}}^{n j} S_{\tilde{b}_{n j}, \tilde{b}_{j}}^{n j, j}}_{3 b} .
\end{aligned}
$$

where

$$
\begin{aligned}
& \tau_{\tilde{a}_{i j} \tilde{b}_{i j}}^{i j}=t_{\tilde{a}_{i j} \tilde{b}_{i j}}^{i j}+t_{\tilde{a}_{i j}}^{i} t_{\tilde{b}_{i j}}^{j} \\
& \tilde{t}_{\tilde{a}_{i j} \tilde{b}_{i j}}^{i j}=2 t_{\tilde{a}_{i j} \tilde{b}_{i j}}^{i j}-t_{\tilde{b}_{i j} \tilde{a}_{i j}}^{i j} \\
& \tilde{r}_{\tilde{a}_{j} \tilde{b}_{j}}^{j}=2 r_{\tilde{a}_{j} \tilde{b}_{j}}^{j}-r_{\tilde{b}_{j} \tilde{a}_{j}}^{j} \\
& \rho_{\tilde{a}_{j} \tilde{b}_{j}}^{j}=r_{\tilde{a}_{j} \tilde{b}_{j}}^{j}+S_{\tilde{a}_{j}, a}^{j} r t_{\tilde{b}_{j}}^{j} .
\end{aligned}
$$

The term containing the four external integrals is constructed as

$$
\begin{aligned}
& K\left(\rho^{j}, \mathbf{r}^{j}\right)_{\tilde{a}_{j} \tilde{b}_{j}}=S_{\tilde{a}_{j}, \tilde{a}_{i j}}^{j, j j} g_{\tilde{c}_{j j} \tilde{d}_{j j}}^{\tilde{a}_{j j} \tilde{b}_{j j}} S_{\tilde{b}_{j j}, \tilde{b}_{j}}^{j j, j} S_{\tilde{c}_{j j}, \tilde{c}_{j}}^{j j, j} \rho_{\tilde{c}_{j} \tilde{d}_{j}}^{j} S_{\tilde{d}_{j}, \tilde{d}_{j j}}^{j, j j} \\
& -\left(S_{\tilde{a}_{j}, \tilde{a}_{m}}^{j, m} t_{m}^{\tilde{a}_{m}} g_{\tilde{c}_{m m} \tilde{d}_{m m}}^{m \tilde{m}_{m m}} S_{\tilde{b}_{m m}, \tilde{b}_{j}}^{m m, j}-S_{\tilde{b}_{j}, \tilde{b}_{m}}^{j, m} t_{m}^{\tilde{b}_{m}} g_{\tilde{c}_{m m} \tilde{a}_{m m}}^{\tilde{a}_{m m}^{m}} S_{\tilde{a}_{m m}, \tilde{a}_{j}}^{m m, j}\right) S_{\tilde{c}_{m m}, \tilde{c}_{j}}^{m m} r_{\tilde{c}_{j} \tilde{d}_{j}}^{j} S_{\tilde{d}_{j}, \tilde{d}_{m m}}^{j, m m}
\end{aligned}
$$


For more details on the implementation of EA-EOM-DLPNO-CCSD, authors can consult reference 51.

From equations 21 and 22, one can see that the different terms in EA-EOM-DLPNO-CCSD method are treated with different levels of accuracy. The singles contribution to singles block, which has the zeroth-order contribution to the electron affinity, is kept untruncated. The singles contribution to doubles, doubles contribution to singles and doubles contribution to doubles block, whose contributions are at least up to second-order in perturbation, are treated in terms of singlesPNOs basis. The terms which are higher than the second-order are calculated in terms of doublesPNOs basis and transformed back to the singlesPNOs basis on the fly. In addition to the four standard truncation parameters for DLPNO-CCSD method, the singlesPNOs truncation parameter (TCutPNOSingles in ORCA) plays a crucial role in determining the accuracy of the calculated electron affinity. We have used a default value of $10^{-12}$ for the TCutPNOSingles in this paper, which is slightly larger than that used in the original EA-EOM-DLPNOCCSD implementation paper $^{51}$.

\subsection{Multi-layer EA-EOM-DLPNO-CCSD:}

The multi-layer DLPNO method uses localized orbitals to partition the system into multiple hypothetical fragments and the fragmentation scheme is based on the chemical intuition of the users. The incoming electron must be localized in one of the fragments (main fragment denoted by 1 in Figure 1) for the applicability of the multi-layer EA-EOM-DLPNO-CCSD method. The other fragments can be considered as the environment which participates in the electron attachment process. The fragments may or may not be covalently bonded with each other.

In the multi-layer EA-EOM-DLPNO-CCSD method, the Hartree-Fock (HF) calculation is performed on the entire system at first. After the HF step, the occupied orbitals are localized and assigned to a particular fragment based on their Mulliken populations. Next, the orbital domains and PNOs for the different sets of fragments are constructed using different truncation thresholds. The sigma equations for multi-layer EA-EOM-DLPNO-CCSD methods are as follows

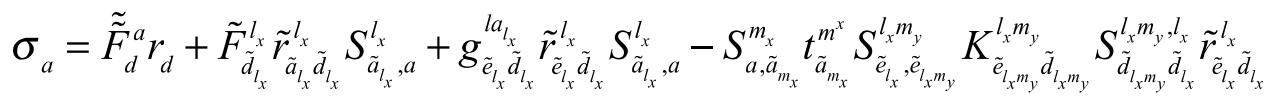




$$
\begin{aligned}
& \sigma_{\tilde{a}_{j} \tilde{b}_{j}}^{j}=S_{\tilde{a}_{j_{x}}, a}^{j_{x}} \tilde{\tilde{F}}_{d}^{a} r_{d} S_{d, \tilde{d}_{j_{x}}}^{j_{x}} r_{\tilde{d}_{j_{x}} \tilde{j}_{j_{x}}}^{j_{x}}+S_{\tilde{b}_{j_{x}}, b}^{j_{x}} \tilde{\tilde{F}}_{d}^{b} S_{d, \tilde{d}_{j_{x}}}^{j_{x}} r_{\tilde{a}_{j_{x}} \tilde{d}_{j_{x}}}^{j_{x}}+\tilde{\tilde{F}}_{j_{x}}^{l_{y}} S_{\tilde{a}_{j_{x}}}^{j_{x}, l_{y}} \tilde{a}_{l_{y}} r_{a_{y y} b_{l_{y}}}^{l_{y}} S_{\tilde{b}_{l_{y}}, \tilde{b}_{j_{x}}}^{l_{y}, j_{x}}
\end{aligned}
$$

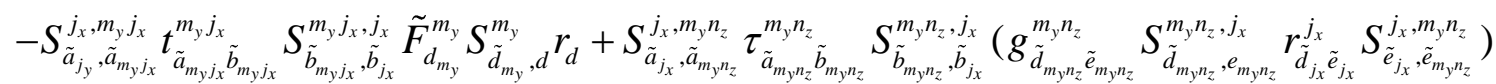

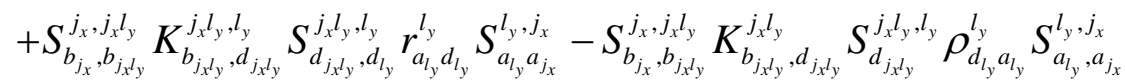

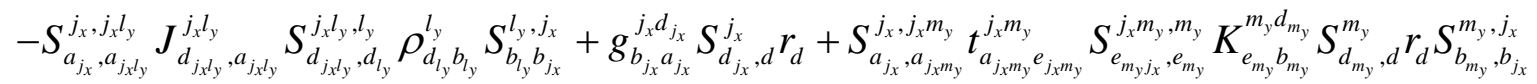

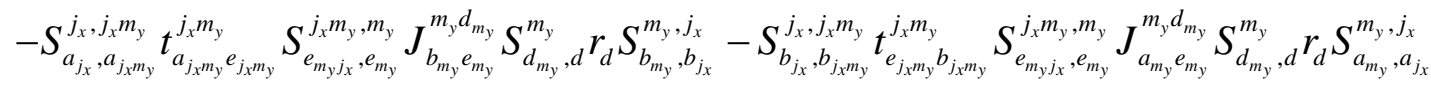

$$
\begin{aligned}
& +S_{a_{j_{x}}, a_{m_{y} n_{z}}}^{j_{x}, m_{y} n_{z}}\left(2 t_{a_{m_{y} n_{z}} m_{m_{y} n_{z}} n_{n_{z}}}^{m_{n_{2}}}-\tau_{a_{m_{y} n_{z}} b_{m_{y} n_{z}}}^{m_{y} n_{z}}\right) S_{b_{m_{y} n_{z}}, b_{j_{x}}}^{m_{y} n_{z}, j_{x}}\left(K_{i d_{m_{y} n_{z}}}^{m_{y} n_{z}}+t_{e_{j_{x}}}^{j_{x}} S_{e_{j_{x}}, e_{m_{y} n_{z}}}^{j_{x}, m_{y} n_{z}} K_{e_{m_{y} n_{z}} d_{m_{y} n_{z}}}^{m_{y} n_{z}}\right) S_{d_{m_{y} n_{z}}, d}^{m_{y}, n_{z}} r_{d}+K\left(\rho^{j_{x}}, r^{j_{x}}\right)_{a_{j_{x}} b_{j_{x}}}
\end{aligned}
$$

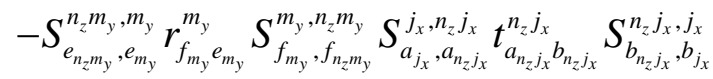

The virtual-virtual block of the dressed Fock matrix in the multi-layer DLPNO formulation is given by,

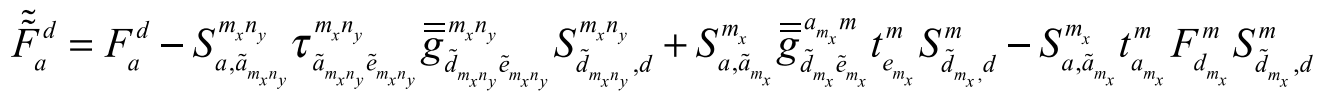

The dressed two external integrals are as follows

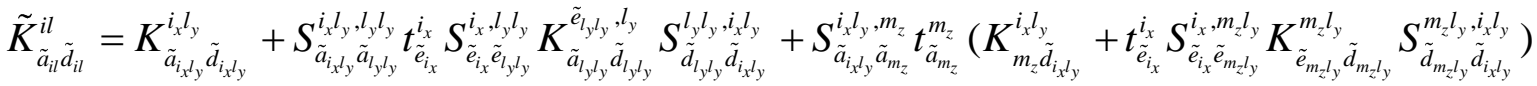

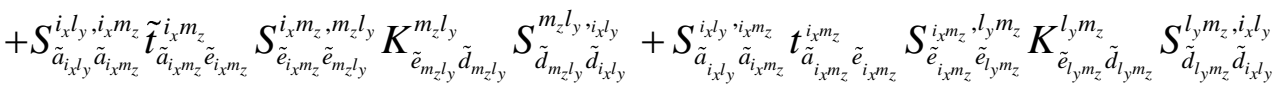

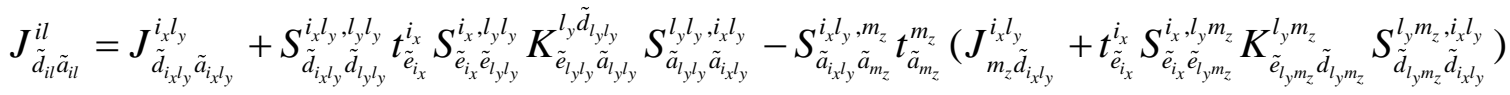

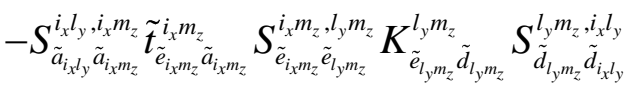

$$
\begin{aligned}
& \tilde{\tilde{K}}_{a_{i l} d_{i l}}^{i l}=2 \tilde{K}_{\tilde{a}_{i_{x} l_{y}} \tilde{d}_{x^{\prime} l_{y}}}^{i_{x^{\prime}} l_{y}}-\tilde{J}_{\tilde{d}_{i_{x} l_{y}} \tilde{a}_{i_{x} l_{y}}}^{i l_{y}}
\end{aligned}
$$

The four external term (4e) in the multi-layer DLPNO method is constructed as

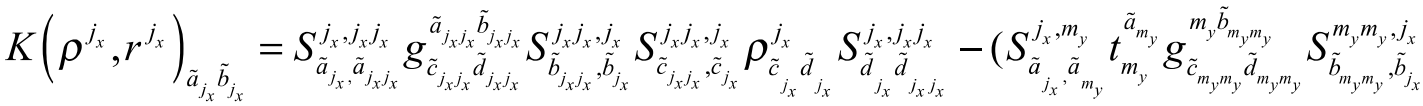

$$
\begin{aligned}
& \left.-S_{\tilde{b}_{j_{x}}, \tilde{b}_{m_{y}}}^{j_{x}, m_{y}} t_{m}^{\tilde{b}_{m_{y}}} g_{\tilde{c}_{m_{y} m_{y}} \tilde{a}_{m_{y} m_{y}}}^{\tilde{a}_{m_{y} m_{y}} m_{y}} S_{\tilde{a}_{m_{y} m_{y}} \tilde{a}_{j_{x}}}^{m_{y} m_{y}, j_{x}}\right) S_{\tilde{c}_{m_{y} m_{y}}, \tilde{c}_{j_{x}}}^{m_{y} m_{y}, j_{x}} r_{\tilde{c}_{j_{x}} \tilde{d}_{j_{x}}}^{j_{j_{x}}} S_{\tilde{d}_{j_{x}}, \tilde{d}_{m_{y} m_{y}}}^{j_{j_{x}, m_{y} m_{y}}}
\end{aligned}
$$

The various dressed amplitudes are defined as 


$$
\begin{aligned}
& \tau_{\tilde{a}_{i_{x} j_{y}} \tilde{b}_{i_{x} j_{y}}}^{i_{x} j_{y}}=t_{\tilde{a}_{i_{x} j_{y}} \tilde{b}_{i_{x} j_{y}}}^{i_{x} j_{y}}+t_{\tilde{a}_{i_{x} j_{y}}}^{i_{x}} t_{\tilde{b}_{i_{x} j_{y}}}^{j_{y}} \\
& \tilde{t}_{\tilde{a}_{i_{x} j_{y}} \tilde{b}_{i_{x} j_{y}}}^{i_{x} j_{y}}=2 t_{\tilde{a}_{i_{x} j_{y}} \tilde{b}_{i_{x} j_{y}}}^{i_{x} j_{j}}-t_{\tilde{b}_{i_{x} j_{y}} \tilde{a}_{i_{x} j_{y}}}^{i_{x} j_{j}} \\
& \tilde{r}_{\tilde{a}_{j_{x}} \tilde{b}_{j_{x}}}^{j}=2 r_{\tilde{a}_{j_{x}} \tilde{b}_{j_{x}}}^{j}-r_{\tilde{b}_{j_{x}} \tilde{a}_{j_{x}}}^{j} \\
& \rho_{\tilde{a}_{j_{x}} \tilde{b}_{j_{x}}}^{j}=r_{\tilde{a}_{j_{x} \tilde{b}_{j_{x}}}}^{j}+S_{\tilde{a}_{j_{x}}, a}^{j} r_{a} t_{\tilde{b}_{j_{x}}}^{j}
\end{aligned}
$$

In all the above cases, if the occupied orbitals $\mathrm{x}$ and $\mathrm{y}$ both are localized on the main fragment, the terms containing $\mathrm{x}$ and $\mathrm{y}$ should be treated with the highest possible accuracy (preferably TIGHTPNO or NORMALPNO). If orbital $\mathrm{x}$ is localized on the main fragment and the orbital $\mathrm{y}$ is localized on the environment, then the term should be treated with the intermediate accuracy. The least accuracy is required when both $\mathrm{x}$ and $\mathrm{y}$ orbitals are localized on the environment.

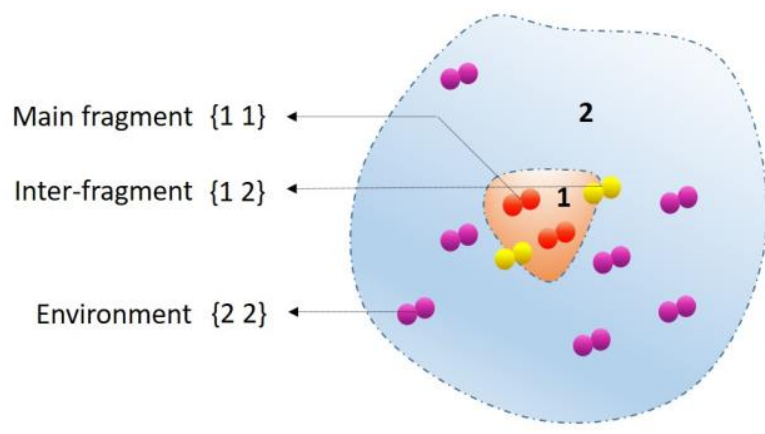

(a)

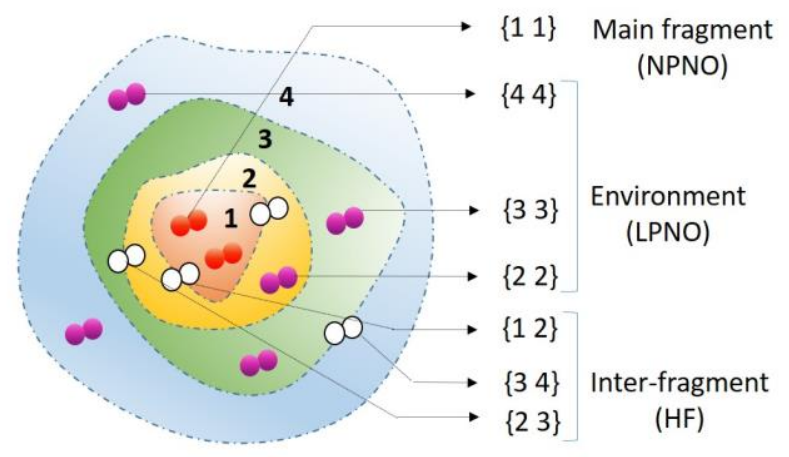

(b)

Figure 1: A schematic representation of the (a) multi-layer EA-EOM-DLPNO-CCSD method and (b) EFDLPNO method

The truncation of the singlesPNO basis (TCutPNOSingles) plays a major role in determining the accuracy of the EA-EOM-DLPNO-CCSD method. The value of the TCutPNOsingles for the inter-fragment or environmental interactions is determined from two parameters, the TCutPNO defined for that particular interaction and TCutPNOSingles defined for the main fragment.

\section{TCutPNOSingles $=\mathrm{C} \times \mathrm{TCu} P \mathrm{PNO}$}

where $C=\frac{\text { TCutPNOSingles main fragment }}{\text { TCutPNO }_{\text {main }} \text { fragment }}$

One should not completely neglect (treating at the HF level) the intra-fragment interaction from any of the fragments. In the DLPNO implementation of EA-EOM-CCSD method, the doubles block is 
truncated using singlesPNO. It ensures that if a particular occupied orbital is localized on the fragment treated at HF level, then all the contributions up to second-order involving that particular orbital get automatically neglected even when one includes the inter-fragment interaction terms for that occupied orbital. The terms containing inter-fragment interaction contributes above second order in perturbation and generally has a small contribution to the total EA. Therefore, one needs to treat the terms up to second order in perturbation at least at LOOSEPNO level to get quantitative accuracy. This leads us to the idea that one can divide the molecule into multiple fragments. The main fragment is treated with NORMALPNO and the rest of the fragments are treated with LOOSEPNO setting. The inter-fragment interactions will be neglected among all the fragments, which will lead to a drastic reduction in the computational cost. The method can give sufficient accuracy as the terms up to second-order are treated at least at LOOSEPNO level even when one neglects all the inter-fragment interactions. We call this new method explicitly fragmented domain based pair natural orbital method (EF-DLPNO) for electron affinity and it is similar in spirit to the cluster in the molecule (CIM) approach of Li and co-workers ${ }^{109,110}$.

All the EA-EOM-DLPNO-CCSD, DFT and QM/MM calculations are performed using a development version of the software package $\mathrm{ORCA}^{111}$. The computational timings are obtained by performing the calculations on two cores of a work station with two hexacore Intel Xeon(R) CPU E5-2643 v4 CPU with $3.40 \mathrm{GHz}$ clock speed and $256 \mathrm{~GB}$ total RAM.

\section{Results and Discussion:}

In this paper, we have mainly focused on the vertical detachment energy (VDE), vertical electron affinity (VEA), and adiabatic electron affinity (AEA). They are defined as follows

$$
\begin{aligned}
& \left.\mathrm{VDE}=\mathrm{E}_{\text {neutral }} \text { (at anion geometry }\right)-\mathrm{E}_{\text {anion }} \text { (at anion geometry) } \\
& \left.\mathrm{VEA}=\mathrm{E}_{\text {neutral }} \text { (at neutral geometry }\right)-\mathrm{E}_{\text {anion }} \text { (at neutral geometry) } \\
& \left.\mathrm{AEA}=\mathrm{E}_{\text {neutral }} \text { (at neutral geometry }\right)-\mathrm{E}_{\text {anion }} \text { (at anion geometry). }
\end{aligned}
$$

The energy of the $\mathrm{k}^{\text {th }}$ anionic state is defined as

$\mathrm{E}_{\text {anion }}=\mathrm{E}_{\mathrm{HF}}+\mathrm{E}_{\mathrm{Cor} \mathrm{r}^{-}} \mathrm{EA}_{\mathrm{k}}$

where $\mathrm{E}_{\mathrm{HF}}$ is the $\mathrm{HF}$ energy for the neutral species, $\mathrm{E}_{\mathrm{Corr}}$ is DLPNO strong pair correlation energy for the neutral species and $\mathrm{EA}_{\mathrm{k}}$ is the EOMCC electron affinity for that particular state. The energy of the neutral state is defined as

$\mathrm{E}_{\text {neutral }}=\mathrm{E}_{\mathrm{HF}}+\mathrm{E}_{\mathrm{Corr}}$ 
The AEA is determined by separately calculating the energies of the neutral and anion and taking the energy difference. The VDE and VEA values can be directly obtained from the EOM-CCSD output file. The ZPE corrections are not included in any of the EA values.

All the molecules treated in the multi-layer EA-EOM-DLPNO-CCSD method are divided into two fragments: the main fragment and the environment. The various interactions between the two fragments are denoted in the following order: main fragement interaction- inter-fragment interaction- environmental interaction. For example, TPNO-NPNO-LPNO denotes that the main fragment interactions are treated at TIGHTPNO level, the inter-fragment interactions are treated at NORMALPNO level and environmental interactions are treated at LOOSEPNO level.

\subsection{Vertical Detachment Energy:}

\subsubsection{Microsolvated Uracil:}

To check the accuracy and efficiency of the multilayer EA-EOM-DLPNO-CCSD method we have chosen a monohydrated uracil system as a simple test case. The initially optimized anion-geometry has been taken from ref ${ }^{112}$. The multilayer EA-EOM-DLPNO-CCSD method is an approximation to the standard EA-EOM-DLPNO-CCSD method. Therefore, results from the standard EA-EOM-DLPNO-CCSD calculation on the entire system can be used as the benchmark values for the multilayer EA-EOM-DLPNOCCSD. This single layer EA-EOM-DLPNO-CCSD calculation on the whole system has been performed using the TIGHTPNO settings.
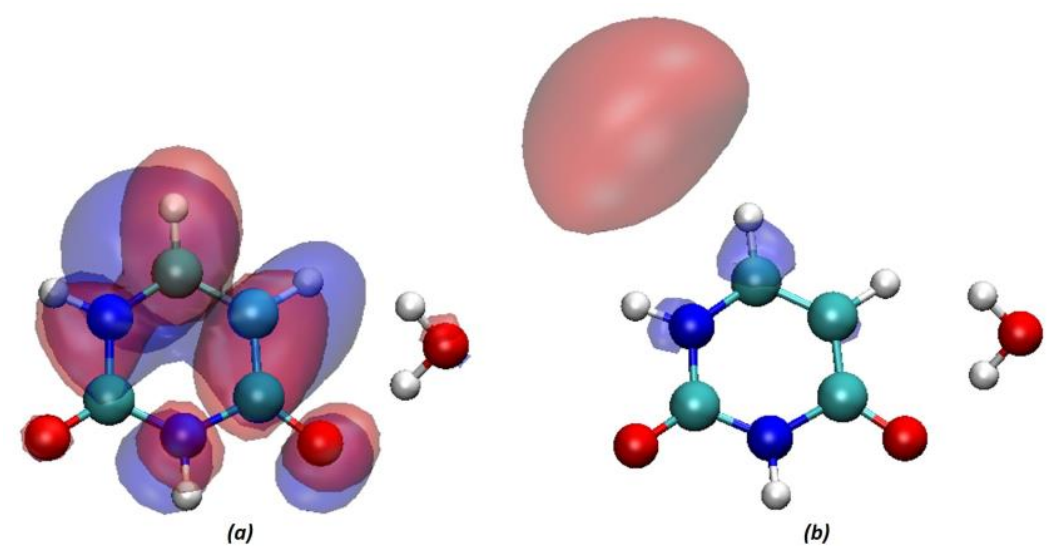

Figure 2: The natural orbitals corresponding to the (a) valence bound and (b) dipole bound state of monohydrated uracil anion 
In this paper, we have focused only on the bound anionic states and we found the existence of two bound states for monohydrated uracil. In the first state, the additional electron density is found to be localized on the nuclear framework of uracil. The extra electron in the second state is away from the nuclear framework and is bound by charge dipole interaction (Figure 2). They are the valence and dipole bound anionic states respectively. We have performed a series of multilayer calculations assuming the uracil moiety as the main fragment and the water molecule as its environment. Different combinations of settings have been used for the main fragment, environment-fragment and the inter-fragment region. Possible lower level treatment includes EA-EOM-DLPNO-CCSD with less tight threshold or the simple HF method neglecting all the correlation contribution. The results obtained from different multilayer methods are presented in Table 1. All the calculations are performed using aug-cc-pVDZ basis set with additional $5 \mathrm{~s} 5 \mathrm{p} 4 \mathrm{~d}$ functions added to the positive end of the dipole.

Table 1: VDE of monohydrated uracil obtained from different settings of multi-layer EA- EOM-DLPNO-

\section{CCSD method}

\begin{tabular}{ccc}
\hline Basis set: $a$ aug-cc- $p V D Z$ & Valence bound & Dipole bound \\
\hline Full TPNO & 0.866 & 0.163 \\
TPNO-TPNO-HF & 0.850 & 0.160 \\
TPNO-NPNO-HF & 0.849 & 0.160 \\
TPNO-LPNO-HF & 0.847 & 0.160 \\
TPNO-HF-HF & 0.846 & 0.160 \\
QM-MM & 0.847 & 0.174 \\
\hline
\end{tabular}

The VDE of valence bound (VB) and dipole bound (DB) anions from the full EA-EOM-DLPNOCCSD calculation on the monohydrated system are found to be $0.866 \mathrm{eV}$ and $0.163 \mathrm{eV}$, respectively. The VDE of VB and DB anion slightly dicreases when we describe the water molecule at HF level, keeping the main fragment and inter-fragment interaction fixed at TIGHTPNO. The change in the VDE for both the $\mathrm{VB}$ and DB state is negligible as the inter-fragment description progressively goes down from TIGHTPNO to NORMALPNO to LOOSEPNO and then to HF.

We also performed a QM/MM calculation for the VDE of the monohydrated uracil system where the uracil moiety has been treated quantum mechanically and the water molecule is treated as a TIP3P point charge. For the VB state, it gives almost the identical result as that obtained from the multilayer calculations. The error in QM/MM method is slightly larger for the DB state. However, it should be noted that the errors 
in both multi-layer EA-EOM-DLPNO-CCSD and QM/MM calculations for this particular example are within the error bar of the canonical EA-EOM-CCSD method itself.

\subsubsection{DNA Model System:}

In the previous subsection, we have investigated the accuracy of the multilayer EA-EOM-DLPNOCCSD on micro-solvated uracil, a system with only fifteen atoms. We have seen from our previous experience on the multi-layer method for ionization potential ${ }^{81}$ that the conclusions drawn from the small molecules are often not transferable to the large systems, where the use of a multilayer method will be of actual importance. Moreover, in the previous model system, the environment fragments are not covalently bonded to the main fragment. To investigate the performance of the multilayer EA-EOM-DLPNO-CCSD method for bonded systems, we have chosen a DNA subunit with three base-pairs in the order A-G-A in one chain and the corresponding complementary bases T-C-T in the other chain. The model was created using software Avogadro ${ }^{113}$ and the additional negative charges were neutralized by adding hydrogen to the unsaturated phosphate group. The anion geometry is optimized using XTB method ${ }^{114}$, where only the cytosine coordinates are allowed to relax and the rest of the molecule is kept frozen. The final geometry of the model system is provided in the supporting information.

Electron attachment to nucleobases is a crucial step in the secondary radiation damage ${ }^{115-118}$ pathway of genetic materials. However, accurate wave-function based simulation of the electron attachment to genetic material is restricted at most to the base-pairs owing to the high computation cost of the calculations ${ }^{119,120}$.

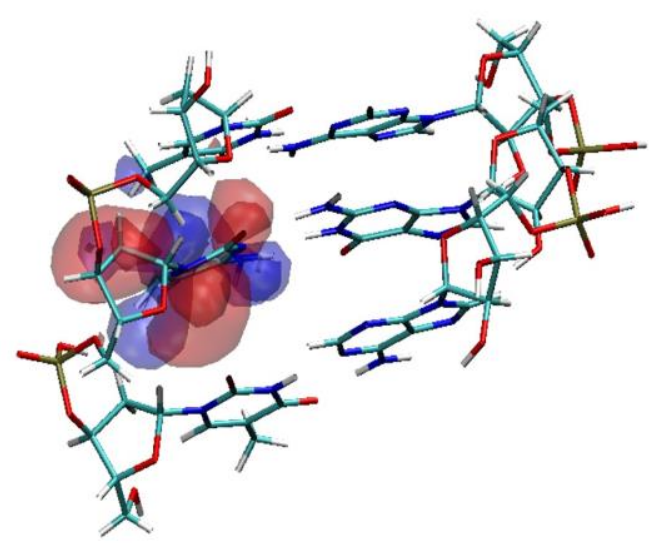

(a)

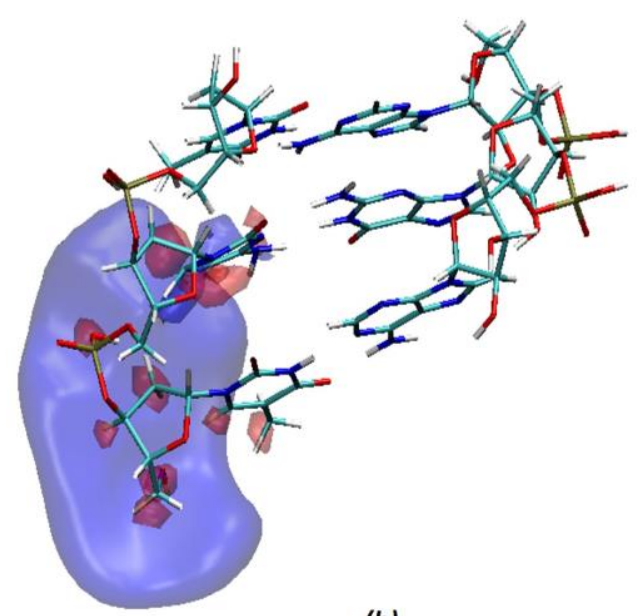

(b)

Figure 3: The natural orbitals corresponding to the (a) valence bound and (b) dipole bound state of the model DNA system

We calculated the VDE of the DNA model system treating the entire molecule in standard EAEOM-DLPNO-CCSD/ma-def2-SVP method using NORMALPNO settings. We consider this result as our 
benchmark VDE for the model system. The system consists of 652 correlated electrons and 2556 basis functions and the correlation calculation took 4640 minutes. We obtained two bound anionic states. One can see from Figure 3 that the natural orbital corresponding to the state-I (Figure 3(a)) is located over the cytosine base and the natural orbital corresponding to the state-II (Figure 3(b)) is delocalized away from the nuclear framework. Therefore, the state-I is valence bound and the state-II is dipole bound in nature. To investigate the effect of the DNA environment on the electron attachment to the cytosine base, we have performed three sets of multilayer calculations: (i) first taking the cytosine base as the main fragment and rest of the system as its environment, (ii) taking the cytosine and its complementary base guanine as the main fragment and rest of the system as its environment \& (iii) taking the hole chain containing the cytosine base as the main fragment and the other chain as its environment. The VDE values obtained in these different multilayer calculations are then compared with the VDE obtained from the full NORMALPNO calculation. All the results, along with the time taken for the correlation calculation are presented in Table 2. It can be observed that the neglect of inter-fragment and environmental interaction leads to only one bound anionic state (state-I) and it is valence bound in nature. The delocalized dipole bound state (state-II ) totally disappears in this case. Large error in the VDE is observed even for the valence bound state which is localized on the cytosine. The inclusion of inter-fragment interaction does not lead to any noticeable improvement. However, even a LOOSEPNO treatment of the environment can result in the significant improvement of the VDE values. The delocalized dipole-bound state also gets reproduced with sufficient accuracy and the computational timing is reduced to half compared to full NORMALPNO .

Table 2: VDE of the two lowest bound states of the DNA model system and the corresponding timings required for the correlation calculations $\left(T_{\text {Corr }}\right)$

\begin{tabular}{|c|c|c|c|c|c|c|c|c|c|}
\hline & \multirow{2}{*}{$\begin{array}{l}\text { Single } \\
\text { layer }\end{array}$} & \multicolumn{8}{|c|}{ Multilayer } \\
\hline & & \multicolumn{5}{|c|}{ Active region: Cytosine } & $\begin{array}{l}\text { Active region: } \\
\text { GC Basepair }\end{array}$ & \multicolumn{2}{|c|}{$\begin{array}{l}\text { Active region: Whole } \\
\text { chain }\end{array}$} \\
\hline & $\begin{array}{c}\text { Full } \\
\text { NPNO }\end{array}$ & $\begin{array}{l}\text { NPNO- } \\
\text { LPNO- } \\
\text { LPNO }\end{array}$ & $\begin{array}{c}\text { NPNO- } \\
\text { LPNO- } \\
\text { HF }\end{array}$ & $\begin{array}{l}\text { TPNO- } \\
\text { HF-HF }\end{array}$ & $\begin{array}{l}\text { NPNO- } \\
\text { HF-HF }\end{array}$ & $\begin{array}{c}\text { EF- } \\
\text { DLPNO }\end{array}$ & $\begin{array}{c}\text { NPNO- } \\
\text { HF- } \\
\text { HF }\end{array}$ & $\begin{array}{l}\text { NPNO- } \\
\text { HF-HF }\end{array}$ & QM/MM \\
\hline$\overline{T_{\text {corr }}}$ & $4640 \mathrm{~m}$ & $2088 \mathrm{~m}$ & $676 \mathrm{~m}$ & $1270 \mathrm{~m}$ & $248 \mathrm{~m}$ & $903 \mathrm{~m}$ & $1026 \mathrm{~m}$ & $1308 \mathrm{~m}$ & 6687m \\
\hline State-I & 1.563 & 1.610 & 0.984 & 0.969 & 0.978 & 1.566 & 1.025 & 1.498 & 1.203 \\
\hline State-II & 0.210 & 0.247 & NA & NA & NA & 0.246 & NA & 0.195 & 0.059 \\
\hline
\end{tabular}


Increasing the size of the main fragment to the base-pair does not show any improvement in the calculated VDE values. The results significantly improve on taking the whole chain containing cytosine as the main fragment. In that case, one can neglect the inter-fragment and environmental interactions.

An interesting thing to notice that the inclusion of inter-fragment interaction leads to very little improvement of the VDE. It is in sharp contrast with that in the multi-layer implementation of IP-EOMDLPNO-CCSD, where the inclusion of inter-fragment interaction significantly improves the accuracy ${ }^{81}$. This can be attributed to two reasons. Firstly, in the EOM-CCSD method, the $\hat{R}$ operation brings both the correlation and the orbital relaxation effect. Therefore, the truncation of the $\hat{R}_{2}$ operator leads to the reduction of both correlation and relaxation effect in IP- and EA-EOM-DLPNO-CCSD. Now, in the case of ionization, the correlation and the relaxation effect tend to cancel each other to a large extent. Therefore, the error introduced by multi-layer truncation is generally small in the case of IP-EOM-DLPNO-CCSD method $^{81}$. However, in the case of the EA, the error due to missing correlation and relaxation effects reinforces each other, leading to higher truncation error in the multi-layer EA-EOM-DLPNO-CCSD method. Secondly, if a particular orbital is not localized on the main fragment, then all the contribution up to second-order involving that particular orbital in EA-EOM-DLPNO-CCSD get automatically neglected even when one includes the inter-fragment interaction term. The terms beyond second order in perturbation generally has a small contribution in the calculated EA (as discussed in section 2.3). Therefore, to get sufficient accuracy one needs to have at least a LOOSEPNO treatment of the environment interactions.

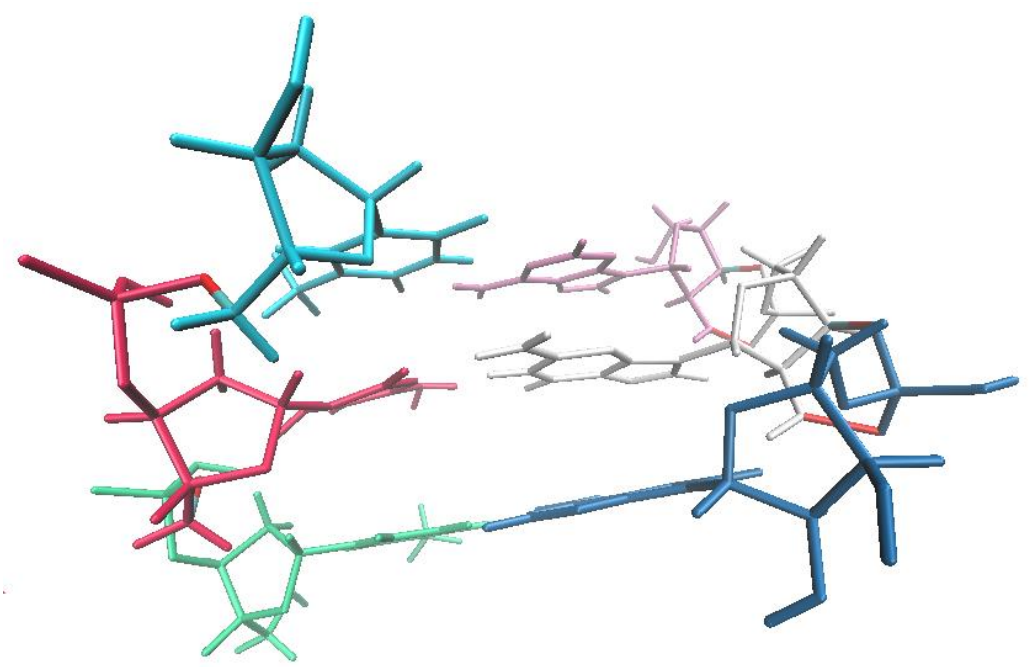

Figure 4: The explicit fragmentation scheme for DNA model system. Six different colors denote the six different fragments

In the case of EF-DLPNO calculation on the DNA model system the molecule is divided into six hypothetical fragments following the scheme suggested by Jensen and co-workers ${ }^{121}$. A pictorial representation of the fragments is presented in Figure 4. The fragment containing the cytosine is treated as 
the main fragment. It can be seen that the EF-DLPNO method gives very good agreement with the reference EA-EOM-DLPNO-CCSD and requires much less computational time than the multi-layer EA-EOMDLPNO-CCSD with NPNO-LPNO-LPNO setting.

We have also performed the EA-EOM-DLPNO-CCSD based QM/MM calculation on DNA model system by treating the whole chain containing the cytosine in the QM region and the other chain is treated with MM. The forcefield is generated using ORCA forcefield utility. The VDE for state-I in QM/MM is underestimated by $0.36 \mathrm{eV}$ whereas the state II shows a large error. Therefore, the QM/MM calculations may be more economical in terms of computational cost but much less accurate than the multi-layer EAEOM-DLPNO-CCSD with NPNO-LPNO-LPNO setting or EF-DLPNO method.

\subsection{Vertical Electron Affinity:}

To investigate the performance of the multi-layer method on VEA, we have studied the electron attachment to quinone in the photosynthetic reaction center (RC) from Rhodobacter Sphaeroides in the charge-neutral $\mathrm{DQ}_{\mathrm{A}} \mathrm{Q}_{\mathrm{B}}$ state ${ }^{122}$. The $\mathrm{PDB}$ structure of the $\mathrm{RC}$ is taken from the protein data bank ${ }^{123}$ (PDB ID: 1AIJ). Our focus is on the terminal electron acceptor $\mathrm{Q}_{B}$, which is a ubiquinone molecule. We have constructed the model system by cutting out the quinone molecule along with its immediate neighboring amino acids and discarded the rest of the RC. The position of the hydrogens is optimized using XTB. The geometry of the final model compound is provided in the supporting information. First, a full EA-EOMDLPNO-CCSD calculation is performed on the whole system using TIGHTPNO settings and ma-def2-SVP basis set, which is taken as the reference value for the multi-layer model. The correlation calculation took 14497 minutes. We have obtained two bound states and the natural orbital corresponding to them is plotted in Figure 5. The natural orbital corresponding to the lowest energy bound state is found to be located on the molecular framework of quinone (state-I) while that of the other one is located away from the nuclear framework of quinone (state-II). We have considered the quinone molecule as the central fragment while the rest of the system is considered as its environment for the multi-layer calculations. A multi-layer EAEOM-DLPNO-CCSD calculation using TIGHTPNO setting for the main fragment and LOOSEPNO for inter-fragment and environmental interaction gives very good agreement with the benchmark values. The errors are as small as $0.003 \mathrm{eV}$ and $0.059 \mathrm{eV}$ for state-I and state-II, respectively. The time required for the multi-layer calculation is fivefold less than that of the standard EA-EOM-DLPNO-CCSD method with TIGHTPNO settings. The same trend is observed for the NORMALPNO treatment of the main fragment and LOOSEPNO treatment of the inter-fragment and environmental interaction, where the error for state-I and state-II are 0.032 and $0.059 \mathrm{eV}$, respectively. The reduction in the time required for the correlation calculation, in this case, is 28 fold as compared to the benchmark calculation. The complete neglect of the inter-fragment interaction leads to large errors in the VEA for state-II (Table S1). We have also performed 
an EF-DLPNO calculation where each of the amino acids is considered as a separate fragment. The quinone moiety itself is treated as the main fragment. The EF-DLPNO method shows an even higher speed-up (55 fold) with a slight increase in the error for state-I. Figure 6 presents the errors in the peak separation between the state-I and state-II with respect to benchmark values. It can be seen that the error in the peak separation in the multi-layer EA-EOM-DLPNO-CCSD method with both TPNO-LPNO-LPNO and NPNO-LPNOLPNO is less than $0.05 \mathrm{eV}$. The peak separation error in EF-DLPNO method is slightly higher at $0.17 \mathrm{eV}$.

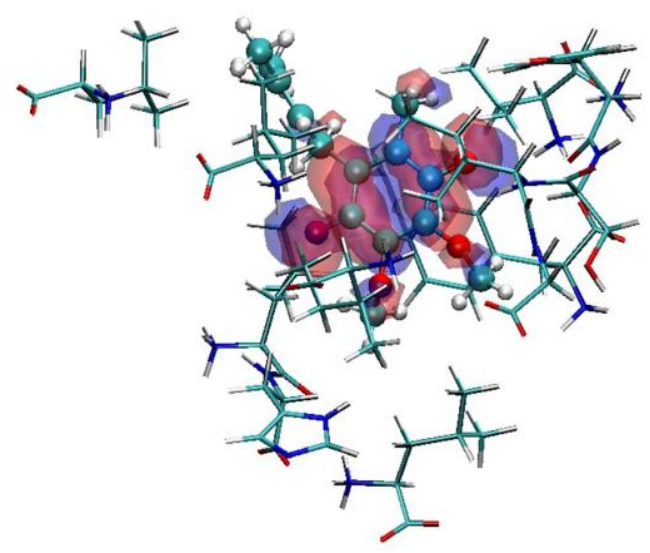

(a)

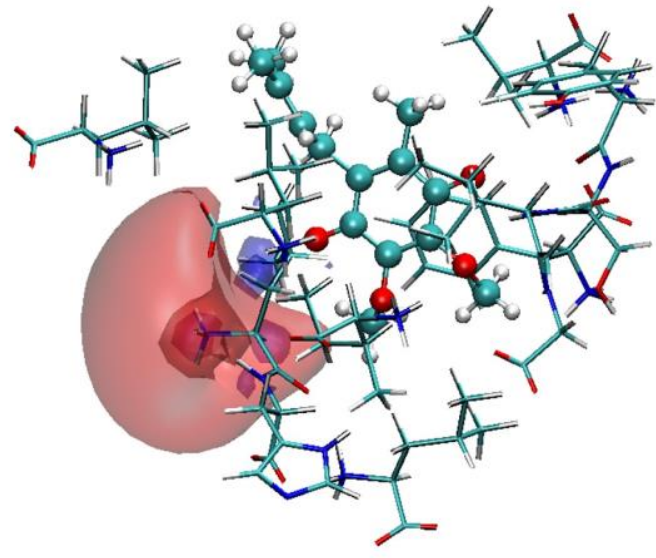

(b)

Figure 5: The natural orbitals corresponding to (a) state-I and (b) state-II of the $Q_{B}$ model system. The quinone is denoted with ball and stick model

However, they are much more accurate than the QM/MM result, where quinone is considered as QM and the environment is treated with MM using CHARM compatible forcefields. We have found that, although the state-I is reasonably reproduced in QM/MM method, the state-II is severely underestimated. It results in a large error of $1.1 \mathrm{eV}$ in the peak separation.

Table 3: The VEA corresponding to the two lowest bound states of $Q_{B}$ model system and corresponding computational timings

\begin{tabular}{|c|c|c|c|c|c|c|c|c|c|c|}
\hline \multirow{3}{*}{$\begin{array}{c}\text { Basis set: } \\
\text { ma-def2- } \\
\text { SVP }\end{array}$} & \multirow{3}{*}{\multicolumn{2}{|c|}{ Full TPNO }} & \multirow{3}{*}{\multicolumn{2}{|c|}{$\begin{array}{c}\text { TPNO-LPNO- } \\
\text { LPNO }\end{array}$}} & \multirow{3}{*}{\multicolumn{2}{|c|}{$\begin{array}{c}\text { NPNO-LPNO- } \\
\text { LPNO }\end{array}$}} & \multirow{3}{*}{\multicolumn{2}{|c|}{ EF-DLPNO }} & \multirow{3}{*}{\multicolumn{2}{|c|}{$\mathrm{QM} / \mathrm{MM}$}} \\
\hline & & & & & & & & & & \\
\hline & & & & & & & & & & \\
\hline $\mathrm{T}_{\text {tot }}$ & \multicolumn{2}{|c|}{$14604 \mathrm{~m}$} & \multicolumn{2}{|c|}{$2861 \mathrm{~m}$} & \multicolumn{2}{|c|}{$625 \mathrm{~m}$} & \multicolumn{2}{|c|}{$366 \mathrm{~m}$} & \multicolumn{2}{|c|}{$24 \mathrm{~min}$} \\
\hline $\mathrm{T}_{\text {corr }}$ & \multicolumn{2}{|c|}{$14497 \mathrm{~m}$} & \multicolumn{2}{|c|}{$2732 \mathrm{~m}$} & \multicolumn{2}{|c|}{$517 \mathrm{~m}$} & \multicolumn{2}{|c|}{$262 \mathrm{~m}$} & & \\
\hline State & I & I I & I & I I & I & I I & I & I I & I & I I \\
\hline VEA & 2.939 & 1.276 & 2.942 & 1.335 & 2.971 & 1.335 & 3.119 & 1.287 & 3.144 & 0.380 \\
\hline
\end{tabular}




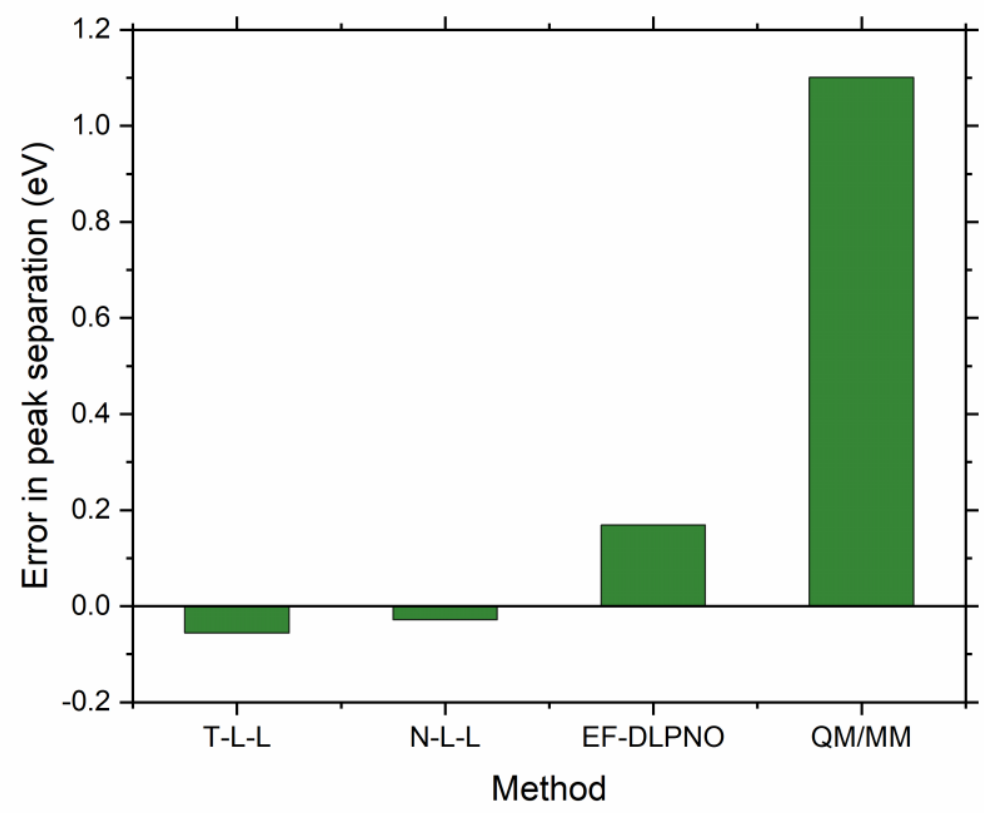

Figure 6: The errors in peak separation between the first two bound states of quinone with respect to the full EA-EOM-DLPNO-CCSD/ma-def2-SVP method with TIGHTPNO setting

\subsection{Adiabatic Electron Affinity of GC Base Pair:}

AEA is more challenging to calculate in an approximate method compared to the VDE or VEA. For the latter two, the energy of the neutral and anion species is calculated at the same geometry, which leads to better error cancellation. However, in the case of AEA, the neutral and the anion energy are calculated at their respective optimized geometries. Consequently, one needs to have a proper balance in the truncation of the neutral and anion state wave-function to get quantitive accuracy, which is difficult to achieve as the nature of the neutral and the anionic state is fundamentally different. Therefore, most of the multi-layer quantum chemical (and QM/MM) calculations focus solely on the vertical energy differences.

To investigate the performance of the multi-layer EA-EOM-DLPNO-CCSD method, we took a guanine-cytosine nucleic acid base pair (GC). The neutral and the anion geometry were optimized using B3LYP/6-31G ++ (d,p) method.

The EA-EOM-DLPNO-CCSD calculations are then performed using aug-cc-pVTZ basis set with an additional $5 \mathrm{~s} 5 \mathrm{p} 4 \mathrm{~d}$ diffuse function added to the positive end of the dipole. The electron attachment to

GC base-pair leads to two bound anionic states ${ }^{120}$. The first one is a dipole bound state which is vertically bound. The second bound anionic state is valence bound in nature, and it is bound adiabatically. The EAEOM-DLPNO-CCSD natural orbitals in Figure 7 shows the additional electron corresponding to the 
valence bound state is localized on cytosine. The cytosine is considered as the main fragment in multi-layer EA-EOM-DLPNO-CCSD calculation, and the results corresponding to different truncation thresholds are presented in Table 4. For the $\mathrm{QM} / \mathrm{MM}$ calculation, the cytosine is taken in the $\mathrm{QM}$ region and guanine is treated with MM. A CHARM compatible forcefield has been used for the MM part. The full NORMALPNO treatment gives an AEA value of $0.118 \mathrm{eV}$, which is taken as the benchmark. The AEA value gets reduced to half of the benchmark value when the environment and inter-fragment interactions are completely neglected. The inclusion of inter-fragment interaction actually leads to the deterioration of results. A LOOSEPNO treatment of the inter-fragment and environmental interaction does not show any appreciable improvement in AEA value. The EF-DLPNO method also fails to provide any appreciabe result. One at least needs to treat the inter-fragment interaction at NORMALPNO and environmental interaction at LOOSEPNO level to get acceptable accuracy. Therefore, the multi-layer EA-EOM-DLPNOCCSD methods cannot give quantitative accuracy for AEA. However, the results are much more accurate than a standard QM/MM calculation which shows an AEA value of $0.434 \mathrm{eV}$.

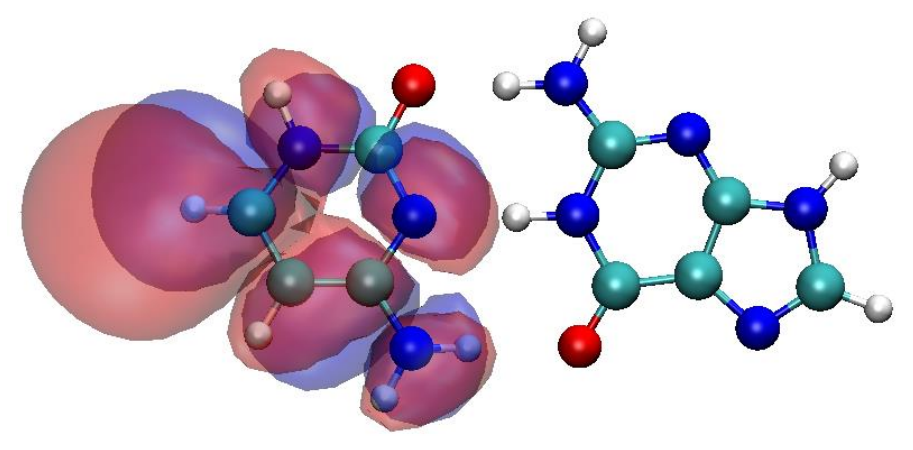

Figure 7: EA-EOM-DLPNO-CCSD natural orbital corresponding to the valence bound anionic state in GC base pair

Table 4: AEA of GC basepair in different approximations of the EA-EOM-DLPNO-CCSD/aug-cc$p V T Z+5 s 5 p 4$ method

\begin{tabular}{cc}
\hline Method & AEA (in eV) \\
\hline \hline Full NPNO & 0.118 \\
NPNO-HF-HF & 0.067 \\
NPNO-NPNO-HF & 0.002 \\
NPNO-LPNO-LPNO & 0.036 \\
NPNO-NPNO-LPNO & 0.082 \\
EF-DLPNO & 0.006
\end{tabular}




\subsection{Potential Energy Surface:}

The electron attachment to adenine-thymine (AT) base-pair gives rise to two kinds of anions similar to GC: one is a dipole bound state, which is vertically bound and another is a valence bound state which is bound adiabatically. Figure 8 represents the natural orbital corresponding to the valence and dipole bound state of AT base pair.

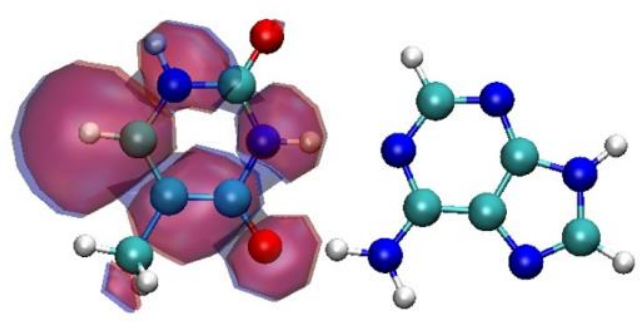

(a)

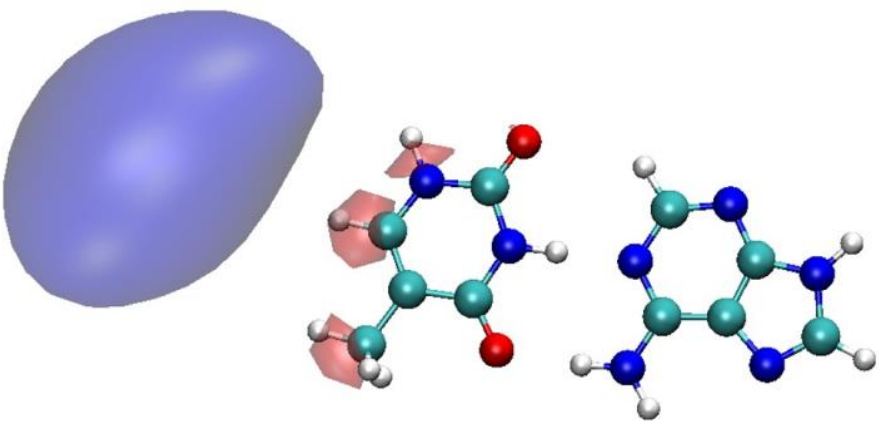

(b)

Figure 8: EA-EOM-DLPNO-CCSD natural orbital corresponding to the (a) valence and (b) dipole bound anionic state in AT basepair

The electron attachment to AT base pair in the gas phase happens through a doorway mechanism. The initial electron attachment leads to the formation of the dipole bound state, which then gets converted into a valence bound state through the mixing of electronic and nuclear degrees of freedom ${ }^{124-126}$. Figure 9 presents the adiabatic potential energy surface (PES) corresponding to the ground and first excited state of the AT anion along a linear transit from the dipole bound to valence bound geometry in different approximations to the EA-EOM-DLPNO-CCSD method. The aug-cc-pVTZ basis set with additional $5 \mathrm{~s} 5 \mathrm{p} 4 \mathrm{~d}$ functions placed at the positive end of the dipole has been used for the calculations. The intermediate geometries are generated using the following expression

$$
\mathrm{R}=(1-\lambda) \mathrm{R}_{\mathrm{DB}}+\lambda \mathrm{R}_{\mathrm{VB}}
$$

where $\mathrm{R}$ is the geometrical parameter (bond length, bond angle and dihedral) at the intermediate geometry, the $\mathrm{R}_{\mathrm{DB}}$ is the geometrical parameters at dipole bound geometry and $\mathrm{R}_{\mathrm{VB}}$ is the geometrical parameters at the valence bound geometry. The value of $\lambda$ varies from 0 to 1 . Setting $\lambda=0$ gives rise to dipole bound geometry while $\lambda=1$ leads to valence bound geometry. The lowest energy value in each method has been scaled to zero for the representation purpose. It can be seen from Figure 9 that the valence bound state, in the multi-layer EA-EOM-DLPNO-CCSD and EF-DLPNO method, becomes progressively 
less stabilized form the dipole-bound to the valence bound geometry, which is consistent with our observation in case of AEA. One can see that the adiabatic potential energy surfaces corresponding to the ground and the first excited state of the anion in all the methods exhibit an avoided crossing, which indicates the breakdown of the Born-Oppenheimer approximation. In such cases, one needs to use the so-called diabatic basis which substitutes the electron-nuclear coupling by electronic coupling. We have used the valence bound and dipole bound nature of the state as the diabetic basis and calculated the coupling element between the two diabetic surfaces by fitting a simple avoided crossing model potential (Figure 10)

$$
V=\left(\begin{array}{ll}
V_{1} & W \\
W & V_{2}
\end{array}\right)
$$

where the diagonal elements are defined by the harmonic potential

$$
V_{i}=\frac{1}{2} \omega_{i}\left(\lambda-\lambda_{i}^{0}\right)^{2}+v_{i}^{0}
$$

And the off-diagonal elements are assumed to be constant. One can also calculate the rate of transition of the electron from the dipole bound to the valence bound state using the Marcus formula ${ }^{127}$

$$
k=\frac{2 \pi}{\hbar}|W|^{2} \sqrt{\frac{1}{4 \pi k_{B} T \lambda_{R}}} e^{\frac{-\left(\lambda_{R}+\Delta G^{0}\right)^{2}}{4 \lambda_{R} k_{B} T}}
$$

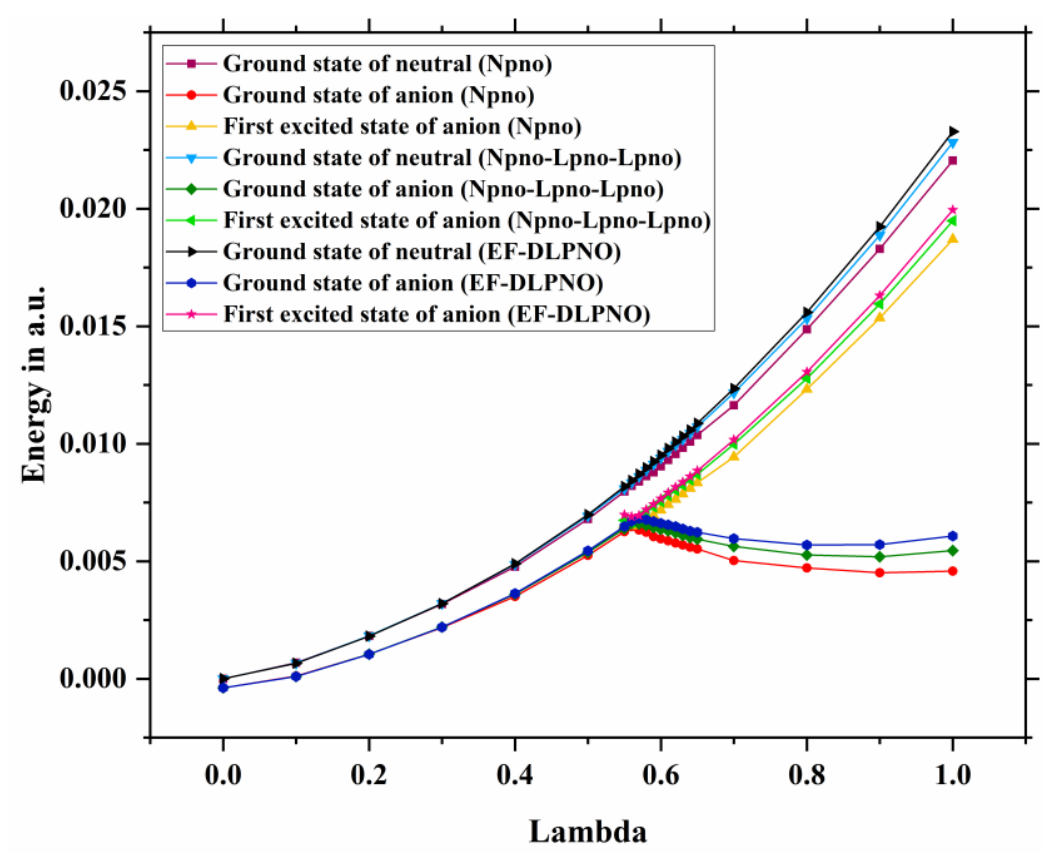

Figure 9: The adiabatic potential energy surface corresponding to the ground and first excited state of AT base pair anion in single-layer and different approximations to the multi-layer EA-EOM-DLPNO- 
The rate of transition from the dipole-bound to the valence bound state in the standard EA-EOMDLPNO-CCSD method with NORMALPNO setting is $3.37 \times 10^{11} \mathrm{sec}^{-1}$. The rate obtained in multi-layer EAEOM-CCSD-DLPNO with NPNO-LPNO-LPNO setting is two orders of magnitude less at 7.9x10 $\mathrm{sec}^{-1}$. The rate in the EF-DLPNO method is even lower at $2.42 \times 10^{9} \mathrm{sec}^{-1}$. The valence bound state in both multilayer EA-EOM-CCSD-DLPNO and EF-DLPNO is much less stabilized as compared to that of the standard EA-EOM-DLPNO-CCSD method, which leads to a lower rate of electron transfer from the dipole bound to valence bound state. Therefore, the multi-layer EA-EOM-DLPNO-CCSD methods cannot give quantitative accuracy for potential energy surfaces of anions.

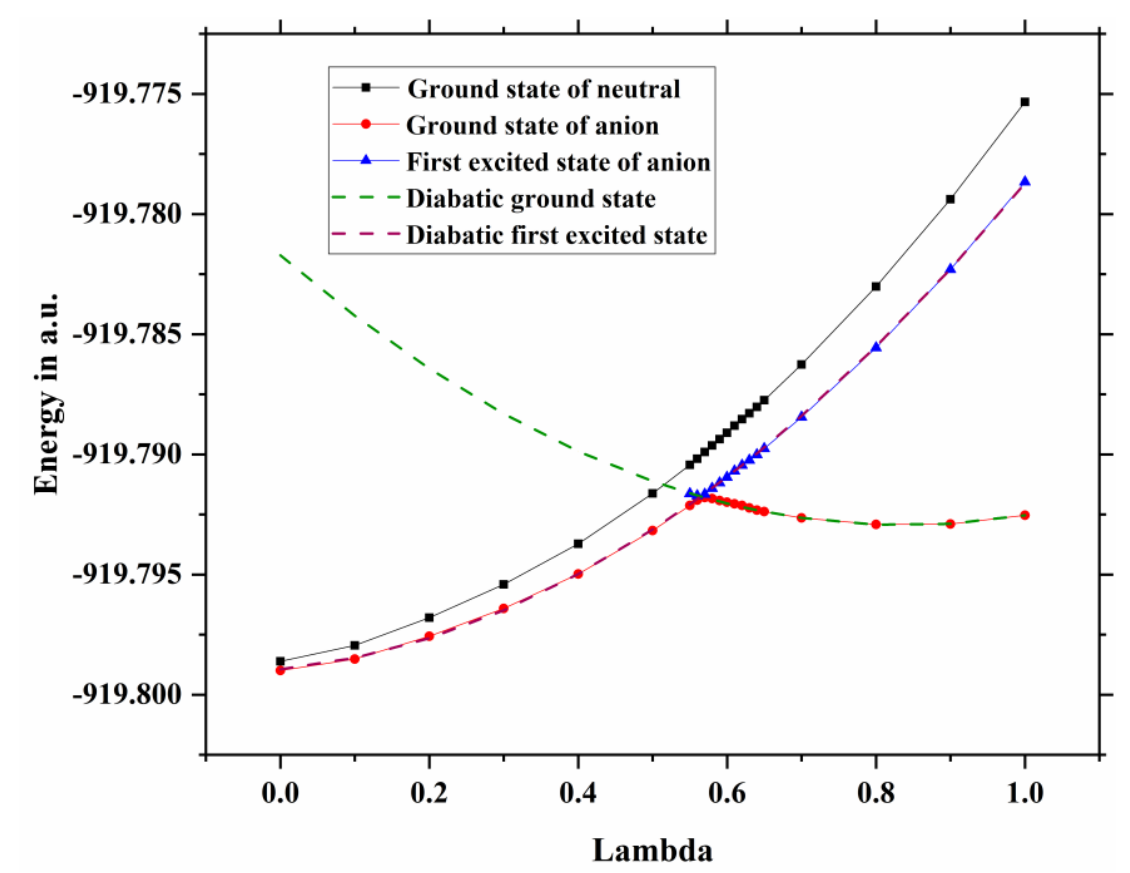

Figure 10: The diabatic potential energy surface corresponding to the dipole and valence bound surface of AT base pair anion in standard EA-EOM-DLPNO-CCSD method

\subsection{Computational Timing:}

From the VDE and VEA studies in the previous subsections, we have seen that the use of multi-layer EA-EOM-DLPNO-CCSD can give significant computation advantage over standard EA-EOM-DLPNOCCSD method. To understand the systematic trend in the reduction of computation time in the multi-layer EA-EOM-DLPNO-CCSD method, we have taken a series of thymine-(glycine $)_{n}$ cluster, with $n=1$ to 5 . The motivation behind choosing such a system is that, some specific proteins are known to stabilize the anionic state of DNA by hydrogen bonding and prevent the radiation-induced DNA strand breaking ${ }^{128,129}$. DNA nucleobase thymine, solvated by amorphous glycine, is protectded from radiation damage by formation of 
H-bonding with the glycine which stabilizes the excess electron captured by thymine. Glycine can also act as an electron scavenger by directly capturing the excess electron itself.

The geometries of the thymine-(glycine) $)_{\mathrm{n}}$ anion are optimized using RI-BP86/6-31G* level of theory. The optimized geometries are provided in the supporting information.

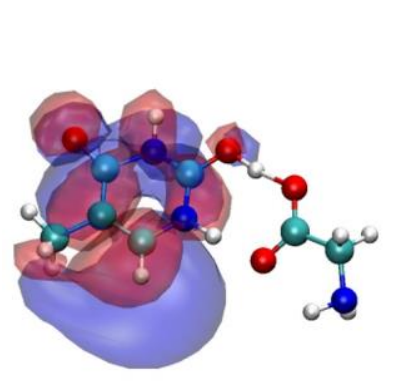

Thy- $(G l y)_{1}$

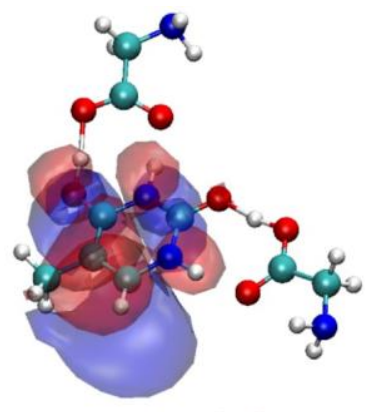

Thy- $(G \mid y)_{2}$

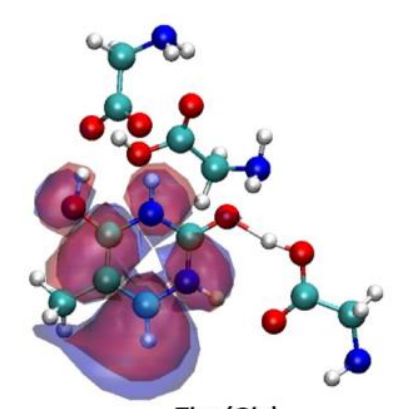

Thy- $(G / y)_{3}$

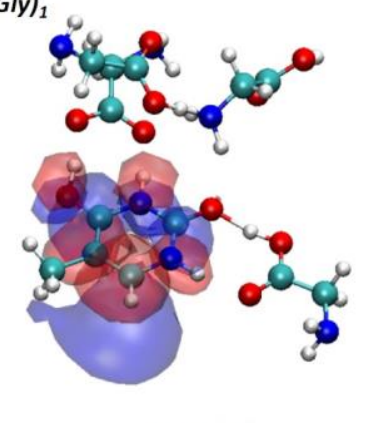

Thy- $(G / y)_{4}$

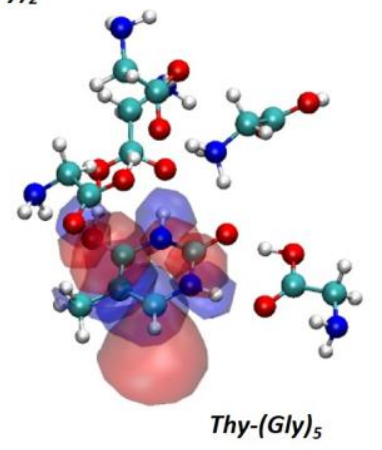

Figure 11: EA-EOM-DLPNO-CCSD natural orbital corresponding to the valence bound anionic state in Thy- $(\text { Gly })_{n}$ clusters

The single point EA-EOM-DLPNO-CCSD calculations are performed using an ma-def2-TZVP basis set and the thymine is considered as the main fragment in multi-layer calculations. From Figure 11 one can see that the lowest energy anionic state in all the clusters is valence bound in nature and the extraelectron is localized on thymine. The VDE and the time taken by the correlation module are presented in Table S2. As the multi-layer EA-EOM-DLPNO-CCSD with TPNO-LPNO-LPNO setting and the EFDLPNO calculations can provide sufficient accuracy in VDE, the timings for only these two methods are compared with full calculation. Figure 12 shows that the time required for the correlation calculation rises less steeply in the multi-layer EA-EOM-DLPNO-CCSD method than that in the standard variant. The timing advantages are even higher in the EF-DLPNO method than that in the multi-layer EA-EOMDLPNO-CCSD method.

The error in VDE in multi-layer and EF-DLPNO method with respect to the standard EA-EOMDLPNO-CCSD is plotted in Figure 13. One can see that the error in both multi-layer and EF-DLPNO 
method is quite small and less than $0.015 \mathrm{eV}$. Although there is no systematic trends in the results, it is gratifying to note that the error does not increase with an increase in the system size.

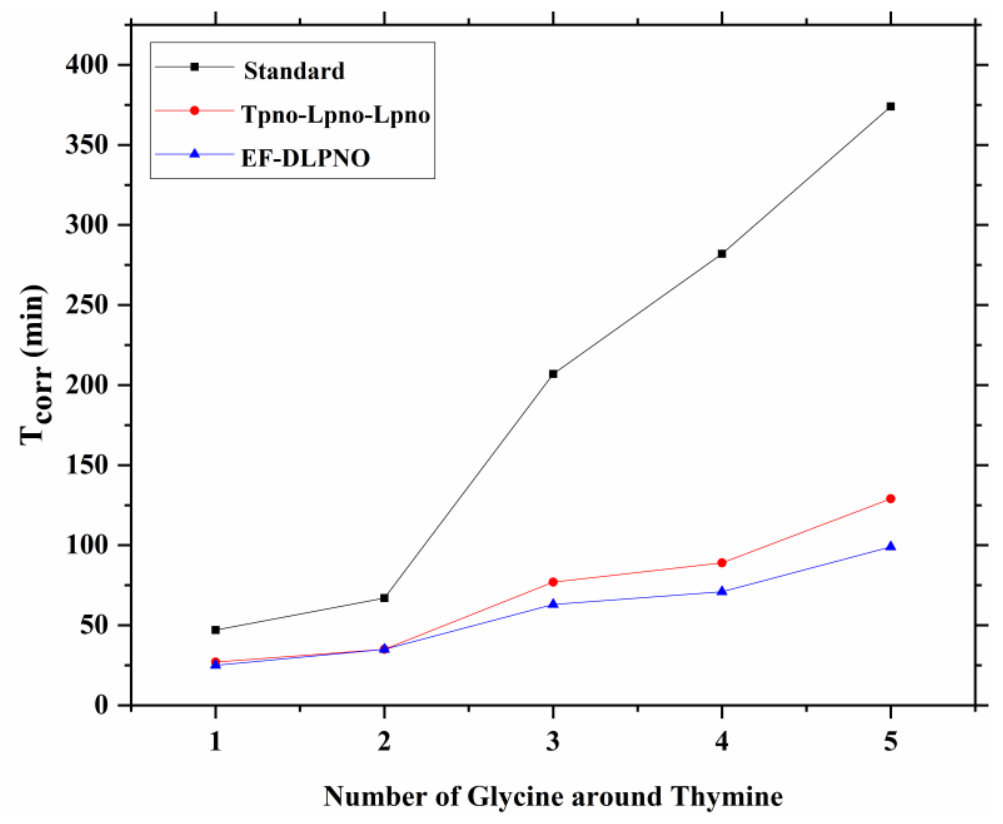

Figure 12: Increase in the time taken in the correlation calculation in standard, multii-layer, and EFDLPNO EA-EOM-DLPNO-CCSD method

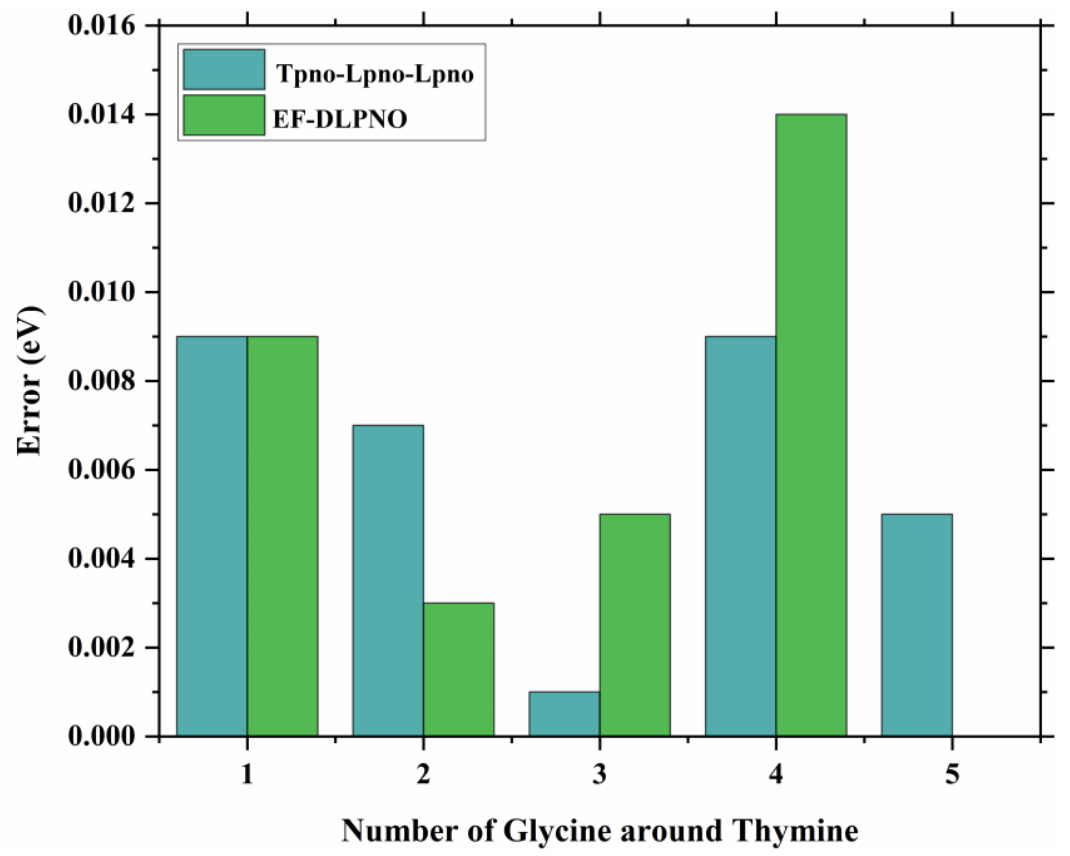

Figure 13: The error in VDE in multi-layer and EF-DLPNO method compared to the standard EA-EOMDLPNO-CCSD with increasing no of glycine molecules 


\section{Conclusion:}

In this study, we have presented the implementation and benchmarking of a multi-layer EA-EOMDLPNO-CCSD method. The method can treat environmental effects of both bonded and non-bonded nature. It allows the mutual polarization of the main fragment and the environment during the electron attachment process and can describe anionic states with both localized and delocalized electron density.

The complete neglect of environment interaction leads to significant errors in the multi-layer EAEOM-DLPNO-CCSD method, which is in contrast with the IP variant where the environmental interactions are shown to be not so important ${ }^{81}$. However, even a LOOSEPNO treatment of the environmental interaction leads to an accuracy comparable to the standard EA-EOM-DLPNO-CCSD method for VDE and VEA. The multi-layer EA-EOM-DLPNO-CCSD method with NPNO-LPNO-LPNO setting leads to several fold speed-up with respect to the standard EA-EOM-DLPNO-CCSD method with very little loss in accuracy. We have also developed an explicit fragment version of the EA-EOM-DLPNO-CCSD method, where the entire molecule is explicitly divided into several fragments and the interaction among the different fragments is neglected. The resulting EF-DLPNO method shows even larger reduction in the computational cost as compared to the multi-layer EA-EOM-DLPNO-CCSD method with almost similar accuracy. Both the multi-layer EA-EOM-DLPNO-CCSD and EF-DLPNO method cannot give quantitative accuracy for AEA or potential energy surfaces. However, the results are in much better agreement with the benchmark values than that observed for the QM/MM based method. Therefore, for accurate simulation of electron attachment induced phenomenon, one needs to combine the multi-layer DLPNO and QM/MM method. It will allow one to have a much larger QM region in the QM/MM calculations and will remove many of the artifacts associated with the standard QM/MM calculations. Work is in progress towards that direction.

\section{Supporting Information:}

The Supporting Information is available

Cartesian coordinates of all the examples used, ORCA EF-DLPNO input file for DNA and quinone model system, additional results on quinone model systems and the timing data for the thymine-(glycine $)_{\mathrm{n}}$ clusters are provided in the supporting information.

\section{Acknowledgment:}


The authors acknowledge the support from the IIT Bombay, IIT Bombay Seed Grant project, DST-Inspire Faculty Fellowship for financial support, IIT Bombay supercomputational facility and CDAC Supercomputing resources (PARAM Yuva-II) for computational time.

The authors declare no competing financial interest.

\section{References:}

(1) Voora, V. K.; Jordan, K. D. Nonvalence Correlation-Bound Anion State of C6F6: Doorway to Low-Energy Electron Capture. J. Phys. Chem. A 2014, 118 (35), 7201-7205. https://doi.org/10.1021/jp408386f.

(2) Cederbaum, L. S.; Domcke, W. Theoretical Aspects of Ionization Potentials and Photoelectron Spectroscopy: A Green's Function Approach. In Advances in Chemical Physics; Wiley-Blackwell, 2007, pp 205-344. https://doi.org/10.1002/9780470142554.ch4.

(3) Trofimov, A. B.; Schirmer, J. An Efficient Polarization Propagator Approach to Valence Electron Excitation Spectra. J. Phys. B At. Mol. Opt. Phys. 1995, 28 (12), 2299.

(4) Dreuw, A.; Wormit, M. The Algebraic Diagrammatic Construction Scheme for the Polarization Propagator for the Calculation of Excited States. Wiley Interdiscip. Rev. Comput. Mol. Sci. 2015, 5 (1), 82-95. https://doi.org/10.1002/wcms.1206.

(5) Sekino, H.; Bartlett, R. J. A Linear Response, Coupled-Cluster Theory for Excitation Energy. Int. J. Quantum Chem. 1984, 26 (S18), 255-265. https://doi.org/10.1002/qua.560260826.

(6) ROWE, D. J. Equations-of-Motion Method and the Extended Shell Model. Rev. Mod. Phys. 1968, $40(1), 153-166$.

(7) Krylov, A. I. Equation-of-Motion Coupled-Cluster Methods for Open-Shell and Electronically Excited Species: The Hitchhiker's Guide to Fock Space. Annu. Rev. Phys. Chem. 2008, 59 (1), 433-462. https://doi.org/10.1146/annurev.physchem.59.032607.093602.

(8) Nooijen, M.; Bartlett, R. J. Equation of Motion Coupled Cluster Method for Electron Attachment. J. Chem. Phys. 1995, 102 (9), 3629-3647.

(9) Stanton, J. F.; Bartlett, R. J. The Equation of Motion Coupled-cluster Method. A Systematic Biorthogonal Approach to Molecular Excitation Energies, Transition Probabilities, and Excited State Properties. J. Chem. Phys. 1993, 98 (9), 7029-7039. 
(10) Musiał, M.; Bartlett, R. J. Equation-of-Motion Coupled Cluster Method with Full Inclusion of Connected Triple Excitations for Electron-Attached States: EA-EOM-CCSDT. J. Chem. Phys. 2003, 119 (4), 1901-1908. https://doi.org/10.1063/1.1584657.

(11) Kowalski, K.; Piecuch, P. The Active-Space Equation-of-Motion Coupled-Cluster Methods for Excited Electronic States: Full EOMCCSDt. J. Chem. Phys. 2001, 115 (2), 643-651. https://doi.org/10.1063/1.1378323.

(12) Jagau, T.-C. Non-Iterative Triple Excitations in Equation-of-Motion Coupled-Cluster Theory for Electron Attachment with Applications to Bound and Temporary Anions. J. Chem. Phys. 2018, 148 (2), 24104. https://doi.org/10.1063/1.5006374.

(13) Izsák, R. Single-Reference Coupled Cluster Methods for Computing Excitation Energies in Large Molecules: The Efficiency and Accuracy of Approximations. Wiley Interdiscip. Rev. Comput. Mol. Sci. 2019, e1445.

(14) Dutta, A. K.; Pal, S.; Ghosh, D. Perturbative Approximations to Single and Double Spin Flip Equation of Motion Coupled Cluster Singles Doubles Methods. J. Chem. Phys. 2013, 139 (12), 124116. https://doi.org/http://dx.doi.org/10.1063/1.4821936.

(15) Dutta, A. K.; Gupta, J.; Pathak, H.; Vaval, N.; Pal, S. Partitioned EOMEA-MBPT (2): An Efficient N 5 Scaling Method for Calculation of Electron Affinities. J. Chem. Theory Comput. 2014, 10 (5), 1923-1933.

(16) Dutta, A. K.; Vaval, N.; Pal, S. Performance of the EOMIP-CCSD (2) Method for Determining the Structure and Properties of Doublet Radicals: A Benchmark Investigation. J. Chem. Theory Comput. 2013, 9 (10), 4313-4331.

(17) Dutta, A. K.; Vaval, N.; Pal, S. EOMIP-CCSD(2)*: An Efficient Method for the Calculation of Ionization Potentials. J. Chem. Theory Comput. 2015, 11 (6), 2461-2472. https://doi.org/10.1021/ct500927h.

(18) Nooijen, M.; Snijders, J. G. Second Order Many-body Perturbation Approximations to the Coupled Cluster Green's Function. J. Chem. Phys. 1995, 102 (4), 1681-1688.

(19) Stanton, J. F.; Gauss, J. Perturbative Treatment of the Similarity Transformed Hamiltonian in Equation-of-motion Coupled-cluster Approximations. J. Chem. Phys. 1995, 103 (3), 1064-1076.

(20) Weigend, F.; Häser, M.; Patzelt, H.; Ahlrichs, R. RI-MP2: Optimized Auxiliary Basis Sets and 
Demonstration of Efficiency. Chem. Phys. Lett. 1998, 294 (1-3), 143-152.

https://doi.org/10.1016/S0009-2614(98)00862-8.

(21) Whitten, J. L. Coulombic Potential Energy Integrals and Approximations. J. Chem. Phys. 1973, 58 (10), 4496-4501.

(22) Feyereisen, M.; Fitzgerald, G.; Komornicki, A. Use of Approximate Integrals in Ab Initio Theory. An Application in MP2 Energy Calculations. Chem. Phys. Lett. 1993, 208 (5-6), 359-363. https://doi.org/10.1016/0009-2614(93)87156-W.

(23) Vahtras, O.; Almlöf, J.; Feyereisen, M. W. Integral Approximations for LCAO-SCF Calculations. Chem. Phys. Lett. 1993, 213 (5-6), 514-518. https://doi.org/10.1016/0009-2614(93)89151-7.

(24) Neese, F. An Improvement of the Resolution of the Identity Approximation for the Formation of the Coulomb Matrix. J. Comput. Chem. 2003, 24 (14), 1740-1747. https://doi.org/10.1002/jcc.10318.

(25) Epifanovsky, E.; Zuev, D.; Feng, X.; Khistyaev, K.; Shao, Y.; Krylov, A. I. General Implementation of the Resolution-of-the-Identity and Cholesky Representations of Electron Repulsion Integrals within Coupled-Cluster and Equation-of-Motion Methods: Theory and Benchmarks. J. Chem. Phys. 2013, 139 (13), 134105. https://doi.org/http://dx.doi.org/10.1063/1.4820484.

(26) Hattig, C.; Weigend, F. CC2 Excitation Energy Calculations on Large Molecules Using the Resolution of the Identity Approximation. J. Chem. Phys. 2000, 113 (13), 5154-5161. https://doi.org/10.1063/1.1290013.

(27) Hohenstein, E. G.; Kokkila, S. I. L.; Parrish, R. M.; Martínez, T. J. Tensor Hypercontraction Equation-of-Motion Second-Order Approximate Coupled Cluster: Electronic Excitation Energies in O(N4) Time. J. Phys. Chem. B 2013, 117 (42), 12972-12978. https://doi.org/10.1021/jp4021905.

(28) Dutta, A. K.; Neese, F.; Izsák, R. Speeding up Equation of Motion Coupled Cluster Theory with the Chain of Spheres Approximation. J. Chem. Phys. 2016, 144 (3). https://doi.org/http://dx.doi.org/10.1063/1.4939844.

(29) Dutta, A. K.; Neese, F.; Izsák, R. Accelerating the Coupled-Cluster Singles and Doubles Method Using the Chain-of-Sphere Approximation. Mol. Phys. 2018, 116 (11), 1428-1434. 
(30) Crawford, T. D.; King, R. A. Locally Correlated Equation-of-Motion Coupled Cluster Theory for the Excited States of Large Molecules. Chem. Phys. Lett. 2002, 366 (5), 611-622.

(31) Korona, T.; Werner, H.-J. Local Treatment of Electron Excitations in the EOM-CCSD Method. $J$. Chem. Phys. 2003, 118 (7), 3006-3019. https://doi.org/http://dx.doi.org/10.1063/1.1537718.

(32) Kats, D.; Korona, T.; Schütz, M. Local CC2 Electronic Excitation Energies for Large Molecules with Density Fitting. J. Chem. Phys. 2006, 125 (10), 104106.

(33) Mata, R. A.; Stoll, H. An Incremental Correlation Approach to Excited State Energies Based on Natural Transition-Localized Orbitals. J. Chem. Phys. 2011, 134 (3), 034122. https://doi.org/http://dx.doi.org/10.1063/1.3522881.

(34) Baudin, P.; Kristensen, K. LoFEx - A Local Framework for Calculating Excitation Energies: Illustrations Using RI-CC2 Linear Response Theory. J. Chem. Phys. 2016, 144 (22), 224106. https://doi.org/http://dx.doi.org/10.1063/1.4953360.

(35) Hofener, S.; Klopper, W. Natural Transition Orbitals for the Calculation of Correlation and Excitation Energies. Chem. Phys. Lett. 2017, 679 (Supplement C), 52-59. https://doi.org/https://doi.org/10.1016/j.cplett.2017.04.083.

(36) Hoyvik, I.-M.; Myhre, R. H.; Koch, H. Correlated Natural Transition Orbitals for Core Excitation Energies in Multilevel Coupled Cluster Models. J. Chem. Phys. 2017, 146 (14), 144109. https://doi.org/10.1063/1.4979908.

(37) Mester, D.; Nagy, P. R.; Kallay, M. Reduced-Cost Linear-Response CC2 Method Based on Natural Orbitals and Natural Auxiliary Functions. J. Chem. Phys. 2017, 146 (19), 194102. https://doi.org/10.1063/1.4983277.

(38) Park, Y. C.; Perera, A.; Bartlett, R. J. Low Scaling EOM-CCSD and EOM-MBPT (2) Method with Natural Transition Orbitals. J. Chem. Phys. 2018, 149 (18), 184103.

(39) Landau, A.; Khistyaev, K.; Dolgikh, S.; Krylov, A. I. Frozen Natural Orbitals for Ionized States within Equation-of-Motion Coupled-Cluster Formalism. J. Chem. Phys. 2010, 132 (1), 14109.

(40) Dutta, A. K.; Gupta, J.; Pathak, H.; Vaval, N.; Pal, S. Partitioned EOMEA-MBPT(2): An Efficient N5 Scaling Method for Calculation of Electron Affinities. J. Chem. Theory Comput. 2014, 10 (5), 1923-1933. https://doi.org/10.1021/ct4009409. 
(41) Korona, T. The Effect of Local Approximations in the Ground-State Coupled Cluster Wave Function on Electron Affinities of Large Molecules. Mol. Phys. 2012, 110 (4), 199-205. https://doi.org/10.1080/00268976.2011.638330.

(42) Riplinger, C.; Sandhoefer, B.; Hansen, A.; Neese, F. Natural Triple Excitations in Local Coupled Cluster Calculations with Pair Natural Orbitals. J. Chem. Phys. 2013, 139 (13), 134101. https://doi.org/http://dx.doi.org/10.1063/1.4821834.

(43) Guo, Y.; Riplinger, C.; Becker, U.; Liakos, D. G.; Minenkov, Y.; Cavallo, L.; Neese, F. Communication: An Improved Linear Scaling Perturbative Triples Correction for the Domain Based Local Pair-Natural Orbital Based Singles and Doubles Coupled Cluster Method [DLPNOCCSD(T)]. J. Chem. Phys. 2018, 148 (1), 11101. https://doi.org/10.1063/1.5011798.

(44) Saitow, M.; Becker, U.; Riplinger, C.; Valeev, E. F.; Neese, F. A New Near-Linear Scaling, Efficient and Accurate, Open-Shell Domain-Based Local Pair Natural Orbital Coupled Cluster Singles and Doubles Theory. J. Chem. Phys. 2017, 146 (16), 164105. https://doi.org/10.1063/1.4981521.

(45) Pinski, P.; Riplinger, C.; Valeev, E. F.; Neese, F. Sparse Maps:A Systematic Infrastructure for Reduced-Scaling Electronic Structure Methods. I. An Efficient and Simple Linear Scaling Local MP2 Method That Uses an Intermediate Basis of Pair Natural Orbitals. J. Chem. Phys. 2015, 143 (3). https://doi.org/http://dx.doi.org/10.1063/1.4926879.

(46) Pinski, P.; Neese, F. Analytical Gradient for the Domain-Based Local Pair Natural Orbital Second Order Møller-Plesset Perturbation Theory Method (DLPNO-MP2). J. Chem. Phys. 2019, 150 (16), 164102 .

(47) Guo, Y.; Sivalingam, K.; Valeev, E. F.; Neese, F. SparseMapsâ $\square$ ”A Systematic Infrastructure for Reduced-Scaling Electronic Structure Methods. III. Linear-Scaling Multireference Domain-Based Pair Natural Orbital N-Electron Valence Perturbation Theory. J. Chem. Phys. 2016, 144 (9), 94111. https://doi.org/10.1063/1.4942769.

(48) Brabec, J.; Lang, J.; Saitow, M.; Pittner, J.; Neese, F.; Demel, O. Domain-Based Local Pair Natural Orbital Version of Mukherjee's State-Specific Coupled Cluster Method. J. Chem. Theory Comput. 2018, 14 (3), 1370-1382.

(49) Guo, Y.; Becker, U.; Neese, F. Comparison and Combination of "Direct" and Fragment Based Local Correlation Methods: Cluster in Molecules and Domain Based Local Pair Natural Orbital 
Perturbation and Coupled Cluster Theories. J. Chem. Phys. 2018, 148 (12), 124117.

(50) Guo, Y.; Riplinger, C.; Liakos, D. G.; Becker, U.; Saitow, M.; Neese, F. Linear Scaling Perturbative Triples Correction Approximations for Open-Shell Domain-Based Local Pair Natural Orbital Coupled Cluster Singles and Doubles Theory [DLPNO-CCSD (T0/T)]. J. Chem. Phys. 2020, 152 (2), 24116.

(51) Dutta, A. K.; Saitow, M.; Demoulin, B.; Neese, F.; Izsák, R. A Domain-Based Local Pair Natural Orbital Implementation of the Equation of Motion Coupled Cluster Method for Electron Attached States. J. Chem. Phys. 2019, 150 (16), 164123. https://doi.org/10.1063/1.5089637.

(52) Cramer, C. J.; Truhlar, D. G. Implicit Solvation Models: Equilibria, Structure, Spectra, and Dynamics. Chem. Rev. 1999, 99 (8), 2161-2200.

(53) Tomasi, J.; Mennucci, B.; Cammi, R. Quantum Mechanical Continuum Solvation Models. Chem. Rev. 2005, 105 (8), 2999-3094. https://doi.org/10.1021/cr9904009.

(54) Mennucci, B. Polarizable Continuum Model. Wiley Interdiscip. Rev. Comput. Mol. Sci. 2012, 2 (3), 386-404.

(55) Klamt, A.; Schüürmann, G. COSMO: A New Approach to Dielectric Screening in Solvents with Explicit Expressions for the Screening Energy and Its Gradient. J. Chem. Soc. Perkin Trans. 2 1993, No. 5, 799-805.

(56) Gordon, M. S.; Fedorov, D. G.; Pruitt, S. R.; Slipchenko, L. V. Fragmentation Methods: A Route to Accurate Calculations on Large Systems. Chem. Rev. 2012, 112 (1), 632-672. https://doi.org/10.1021/cr200093j.

(57) Ferré, N.; Olivucci, M. The Amide Bond: Pitfalls and Drawbacks of the Link Atom Scheme. $J$. Mol. Struct. THEOCHEM 2003, 632 (1), 71-82. https://doi.org/https://doi.org/10.1016/S01661280(03)00289-6.

(58) Lin, H.; Truhlar, D. G. QM/MM: What Have We Learned, Where Are We, and Where Do We Go from Here? Theor. Chem. Acc. 2006, 117 (2), 185. https://doi.org/10.1007/s00214-006-0143-z.

(59) Zhang, Y.; Lee, T.-S.; Yang, W. A Pseudobond Approach to Combining Quantum Mechanical and Molecular Mechanical Methods. J. Chem. Phys. 1999, 110 (1), 46-54.

(60) DiLabio, G. A.; Hurley, M. M.; Christiansen, P. A. Simple One-Electron Quantum Capping 
Potentials for Use in Hybrid QM/MM Studies of Biological Molecules. J. Chem. Phys. 2002, 116 (22), 9578-9584.

(61) Slipchenko, L. V. Solvation of the Excited States of Chromophores in Polarizable Environment: Orbital Relaxation versus Polarization. J. Phys. Chem. A 2010, 114 (33), 8824-8830. https://doi.org/10.1021/jp101797a.

(62) Ghosh, D.; Kosenkov, D.; Vanovschi, V.; Williams, C. F.; Herbert, J. M.; Gordon, M. S.; Schmidt, M. W.; Slipchenko, L. V; Krylov, A. I. Noncovalent Interactions in Extended Systems Described by the Effective Fragment Potential Method: Theory and Application to Nucleobase Oligomers. $J$. Phys. Chem. A 2010, 114 (48), 12739-12754.

(63) Ghosh, D.; Kosenkov, D.; Vanovschi, V.; Flick, J.; Kaliman, I.; Shao, Y.; Gilbert, A. T. B.; Krylov, A. I.; Slipchenko, L. V. Effective Fragment Potential Method in Q-CHEM: A Guide for Users and Developers. J. Comput. Chem. 2013, 34 (12), 1060-1070.

(64) Ghosh, D. Hybrid Equation-of-Motion Coupled-Cluster/Effective Fragment Potential Method: A Route toward Understanding Photoprocesses in the Condensed Phase. J. Phys. Chem. A 2017, 121 (4), 741-752. https://doi.org/10.1021/acs.jpca.6b08263.

(65) Day, P. N.; Jensen, J. H.; Gordon, M. S.; Webb, S. P.; Stevens, W. J.; Krauss, M.; Garmer, D.; Basch, H.; Cohen, D. An Effective Fragment Method for Modeling Solvent Effects in Quantum Mechanical Calculations. J. Chem. Phys. 1996, 105 (5), 1968-1986.

(66) Gordon, M. S.; Freitag, M. A.; Bandyopadhyay, P.; Jensen, J. H.; Kairys, V.; Stevens, W. J. The Effective Fragment Potential Method: A QM-Based MM Approach to Modeling Environmental Effects in Chemistry. J. Phys. Chem. A 2001, 105 (2), 293-307.

(67) Gordon, M. S.; Slipchenko, L.; Li, H.; Jensen, J. H. The Effective Fragment Potential: A General Method for Predicting Intermolecular Interactions. Annu. Rep. Comput. Chem. 2007, 3, 177-193.

(68) Nanda, K.; Krylov, A. Non-Linear Properties of Chromophores in Solution Using Equation-ofMotion Coupled Cluster (EOM-CC) and Effective Fragment Potential (EFP): A QM/MM Approach. In ABSTRACTS OF PAPERS OF THE AMERICAN CHEMICAL SOCIETY; 2016, 251.

(69) Neugebauer, J.; Louwerse, M. J.; Baerends, E. J.; Wesolowski, T. A. The Merits of the FrozenDensity Embedding Scheme to Model Solvatochromic Shifts. J. Chem. Phys. 2005, 122 (9), 94115. 
(70) Prager, S.; Zech, A.; Wesolowski, T. A.; Dreuw, A. Implementation and Application of the Frozen Density Embedding Theory with the Algebraic Diagrammatic Construction Scheme for the Polarization Propagator up to Third Order. J. Chem. Theory Comput. 2017, 13 (10), 4711-4725.

(71) Wesolowski, T. A.; Warshel, A. Frozen Density Functional Approach for Ab Initio Calculations of Solvated Molecules. J. Phys. Chem. 1993, 97 (30), 8050-8053.

(72) Lee, S. J. R.; Welborn, M.; Manby, F. R.; Miller, T. F. Projection-Based Wavefunction-in-DFT Embedding. Acc. Chem. Res. 2019, 52 (5), 1359-1368.

https://doi.org/10.1021/acs.accounts.8b00672.

(73) Bennie, S. J.; Curchod, B. F. E.; Manby, F. R.; Glowacki, D. R. Pushing the Limits of EOMCCSD with Projector-Based Embedding for Excitation Energies. J. Phys. Chem. Lett. 2017, 8 (22), 5559-5565. https://doi.org/10.1021/acs.jpclett.7b02500.

(74) Manby, F. R.; Stella, M.; Goodpaster, J. D.; Miller III, T. F. A Simple, Exact Density-FunctionalTheory Embedding Scheme. J. Chem. Theory Comput. 2012, 8 (8), 2564-2568.

(75) Coughtrie, D. J.; Giereth, R.; Kats, D.; Werner, H.-J.; Köhn, A. Embedded Multireference Coupled Cluster Theory. J. Chem. Theory Comput. 2018, 14 (2), 693-709.

(76) Hegely, B.; Nagy, P. R.; Kallay, M. Dual Basis Set Approach for Density Functional and Wave Function Embedding Schemes. J. Chem. Theory Comput. 2018, 14 (9), 4600-4615.

(77) Hégely, B.; Nagy, P. R.; Ferenczy, G. G.; Kállay, M. Exact Density Functional and Wave Function Embedding Schemes Based on Orbital Localization. J. Chem. Phys. 2016, 145 (6), 64107.

(78) Sparta, M.; Retegan, M.; Pinski, P.; Riplinger, C.; Becker, U.; Neese, F. Multilevel Approaches within the Local Pair Natural Orbital Framework. J. Chem. Theory Comput. 2017, 13 (7), 31983207. https://doi.org/10.1021/acs.jctc.7b00260.

(79) Barnes, A. L.; Bykov, D.; Lyakh, D. I.; Straatsma, T. P. Multilayer Divide-Expand-Consolidate Coupled-Cluster Method: Demonstrative Calculations of the Adsorption Energy of Carbon Dioxide in the Mg-MOF-74 Metal--Organic Framework. J. Phys. Chem. A 2019, 123 (40), 87348743.

(80) Folkestad, S. D.; Koch, H. Multilevel CC2 and CCSD Methods with Correlated Natural Transition Orbitals. J. Chem. Theory Comput. 2020, 16 (1), 179-189. 
https://doi.org/10.1021/acs.jctc.9b00701.

(81) Haldar, S.; Riplinger, C.; Demoulin, B.; Neese, F.; Izsak, R.; Dutta, A. K. Multilayer Approach to the IP-EOM-DLPNO-CCSD Method: Theory, Implementation, and Application. J. Chem. Theory Comput. 2019, 15 (4), 2265-2277. https://doi.org/10.1021/acs.jctc.8b01263.

(82) Riplinger, C.; Neese, F. An Efficient and near Linear Scaling Pair Natural Orbital Based Local Coupled Cluster Method. J. Chem. Phys. 2013, 138 (3), 034106.

https://doi.org/http://dx.doi.org/10.1063/1.4773581.

(83) Schwilk, M.; Usvyat, D.; Werner, H.-J. Communication: Improved Pair Approximations in Local Coupled-Cluster Methods. J. Chem. Phys. 2015, 142 (12), 121102. https://doi.org/10.1063/1.4916316.

(84) Werner, H.-J.; Pflüger, K. On the Selection of Domains and Orbital Pairs in Local Correlation Treatments. Annu. Rep. Comput. Chem. 2006, 2, 53-80.

(85) Schutz, M.; Werner, H.-J. Low-Order Scaling Local Electron Correlation Methods. IV. Linear Scaling Local Coupled-Cluster (LCCSD). J. Chem. Phys. 2001, 114 (2), 661-681. https://doi.org/10.1063/1.1330207.

(86) SAEBO, S.; PULAY, P. LOCAL TREATMENT OF ELECTRON CORRELATION. Annu. Rev. Phys. Chem. 1993, 44, 213-236. https://doi.org/10.1146/annurev.pc.44.100193.001241.

(87) Subotnik, J. E.; Sodt, A.; Head-Gordon, M. A near Linear-Scaling Smooth Local Coupled Cluster Algorithm for Electronic Structure. J. Chem. Phys. 2006, 125 (7), 74116. https://doi.org/10.1063/1.2336426.

(88) Schuetz, M.; Rauhut, G.; Werner, H.-J. Local Treatment of Electron Correlation in Molecular Clusters: Structures and Stabilities of (H2O) n, N=2- 4. J. Phys. Chem. A 1998, 102 (29), 59976003.

(89) Subotnik, J. E.; Head-Gordon, M. A Local Correlation Model That Yields Intrinsically Smooth Potential-Energy Surfaces. J. Chem. Phys. 2005, 123 (6), 64108. https://doi.org/10.1063/1.2000252.

(90) Fink, R.; Staemmler, V. A Multi-Configuration Reference CEPA Method Based on Pair Natural Orbitals. Theor. Chim. Acta 1993, 87 (1), 129-145. https://doi.org/10.1007/BF01113534. 
(91) Pipek, J.; Mezey, P. G. A Fast Intrinsic Localization Procedure Applicable for Ab Initio and Semiempirical Linear Combination of Atomic Orbital Wave Functions. J. Chem. Phys. 1989, 90 (9), 4916-4926. https://doi.org/10.1063/1.456588.

(92) Foster, J. M.; Boys, S. F. Canonical Configurational Interaction Procedure. Rev. Mod. Phys. 1960, 32 (2), 300-302. https://doi.org/10.1103/RevModPhys.32.300.

(93) Jung, Y.; Sodt, A.; Gill, P. M. W.; Head-Gordon, M. Auxiliary Basis Expansions for Large-Scale Electronic Structure Calculations. Proc. Natl. Acad. Sci. United States Am. 2005, 102 (19), 66926697. https://doi.org/10.1073/pnas.0408475102.

(94) Liakos, D. G.; Sparta, M.; Kesharwani, M. K.; Martin, J. M. L.; Neese, F. Exploring the Accuracy Limits of Local Pair Natural Orbital Coupled-Cluster Theory. J. Chem. Theory Comput. 2015, 11 (4), 1525-1539. https://doi.org/10.1021/ct501129s.

(95) Werner, H.-J. Communication: Multipole Approximations of Distant Pair Energies in Local Correlation Methods with Pair Natural Orbitals. J. Chem. Phys. 2016, 145 (20), 201101.

(96) Schwilk, M.; Ma, Q.; Köppl, C.; Werner, H.-J. Scalable Electron Correlation Methods. 3. Efficient and Accurate Parallel Local Coupled Cluster with Pair Natural Orbitals (PNO-LCCSD). J. Chem. Theory Comput. 2017, 13 (8), 3650-3675.

(97) Ma, Q.; Schwilk, M.; Köppl, C.; Werner, H.-J. Scalable Electron Correlation Methods. 4. Parallel Explicitly Correlated Local Coupled Cluster with Pair Natural Orbitals (PNO-LCCSD-F12). J. Chem. Theory Comput. 2017, 13 (10), 4871-4896.

(98) Ma, Q.; Werner, H.-J. Scalable Electron Correlation Methods. 5. Parallel Perturbative Triples Correction for Explicitly Correlated Local Coupled Cluster with Pair Natural Orbitals. J. Chem. Theory Comput. 2017, 14 (1), 198-215.

(99) Werner, H.-J.; Knizia, G.; Krause, C.; Schwilk, M.; Dornbach, M. Scalable Electron Correlation Methods I.: PNO-LMP2 with Linear Scaling in the Molecular Size and near-Inverse-Linear Scaling in the Number of Processors. J. Chem. Theory Comput. 2015, 11 (2), 484-507.

(100) Ma, Q.; Werner, H.-J. Scalable Electron Correlation Methods. 2. Parallel PNO-LMP2-F12 with near Linear Scaling in the Molecular Size. J. Chem. Theory Comput. 2015, 11 (11), 5291-5304.

(101) Helmich, B.; Hättig, C. A Pair Natural Orbital Based Implementation of ADC(2)-x: Perspectives and Challenges for Response Methods for Singly and Doubly Excited States in Large Molecules. 
Comput. Theor. Chem. 2014, 1040-1041, 35-44. https://doi.org/10.1016/j.comptc.2014.03.004.

(102) Helmich, B.; Hättig, C. A Pair Natural Orbital Implementation of the Coupled Cluster Model CC2 for Excitation Energies. J. Chem. Phys. 2013, 139 (8), 084114. https://doi.org/http://dx.doi.org/10.1063/1.4819071.

(103) Helmich, B.; Hättig, C. Local Pair Natural Orbitals for Excited States. J. Chem. Phys. 2011, 135 (21), 214106. https://doi.org/http://dx.doi.org/10.1063/1.3664902.

(104) Schmitz, G.; Hättig, C. Perturbative Triples Correction for Local Pair Natural Orbital Based Explicitly Correlated CCSD (F12*) Using Laplace Transformation Techniques. J. Chem. Phys. 2016, 145 (23), 234107.

(105) Schmitz, G.; Hattig, C.; Tew, D. P. Explicitly Correlated PNO-MP2 and PNO-CCSD and Their Application to the S66 Set and Large Molecular Systems. Phys. Chem. Chem. Phys. 2014, 16 (40), 22167-22178. https://doi.org/10.1039/C4CP03502J.

(106) Schmitz, G.; Hattig, C. Accuracy of Explicitly Correlated Local PNO-CCSD(T). J. Chem. Theory Comput. 2017, 13 (6), 2623-2633. https://doi.org/10.1021/acs.jctc.7b00180.

(107) Tew, D. P.; Hättig, C. Pair Natural Orbitals in Explicitly Correlated Second-Order Møller--Plesset Theory. Int. J. Quantum Chem. 2013, 113 (3), 224-229.

(108) Frank, M. S.; Schmitz, G.; Hättig, C. The PNO--MP2 Gradient and Its Application to Molecular Geometry Optimisations. Mol. Phys. 2017, 115 (3), 343-356.

(109) Ni, Z.; Li, W.; Li, S. Fully Optimized Implementation of the Cluster-in-Molecule Local Correlation Approach for Electron Correlation Calculations of Large Systems. J. Comput. Chem. 2019, 40 (10), 1130-1140.

(110) Li, S.; Ma, J.; Jiang, Y. Linear Scaling Local Correlation Approach for Solving the Coupled Cluster Equations of Large Systems. J. Comput. Chem. 2002, 23 (2), 237-244. https://doi.org/10.1002/jcc.10003.

(111) Neese, F. Software Update: The ORCA Program System, Version 4.0. Wiley Interdiscip. Rev. Comput. Mol. Sci. 2017, e1327--n/a. https://doi.org/10.1002/wcms.1327.

(112) Mukherjee, M.; Tripathi, D.; Dutta, A. K. Water Mediated Electron Attachment to Nucleobases: Surface-Bound vs Bulk Solvated Electrons. arXiv Prepr. arXiv1911.00335 2019. 
(113) Hanwell, M. D.; Curtis, D. E.; Lonie, D. C.; Vandermeersch, T.; Zurek, E.; Hutchison, G. R. Avogadro: An Advanced Semantic Chemical Editor, Visualization, and Analysis Platform. $J$. Cheminform. 2012, 4 (1), 17.

(114) Bannwarth, C.; Ehlert, S.; Grimme, S. GFN2-XTB—An Accurate and Broadly Parametrized SelfConsistent Tight-Binding Quantum Chemical Method with Multipole Electrostatics and DensityDependent Dispersion Contributions. J. Chem. Theory Comput. 2019, 15 (3), 1652-1671.

(115) Kumar, A.; Sevilla, M. D. Low-Energy Electron (LEE)-Induced DNA Damage: Theoretical Approaches to Modeling Experiment. In Handbook of Computational Chemistry; Leszczynski, J., Kaczmarek-Kedziera, A., Puzyn, T., G. Papadopoulos, M., Reis, H., K. Shukla, M., Eds.; Springer International Publishing: Cham, 2017; pp 1741-1802. https://doi.org/10.1007/978-3-319-272825_34.

(116) Téoule, R. Radiation-Induced DNA Damage and Its Repair. Int. J. Radiat. Biol. Relat. Stud. Physics, Chem. Med. 1987, 51 (4), 573-589. https://doi.org/10.1080/09553008414552111.

(117) Barrios, R.; Skurski, P.; Simons, J. Mechanism for Damage to DNA by Low-Energy Electrons. J. Phys. Chem. B 2002, 106 (33), 7991-7994. https://doi.org/10.1021/jp013861i.

(118) Boudaïfa, B.; Cloutier, P.; Hunting, D.; Huels, M. A.; Sanche, L. Resonant Formation of DNA Strand Breaks by Low-Energy (3 to 20 EV) Electrons. Science (80-. ). 2000, 287 (5458), $1658-$ 1660. https://doi.org/10.1126/science.287.5458.1658.

(119) Gu, J.; Leszczynski, J.; Henry F. Schaefer, I. I. I. Interactions of Electrons with Bare and Hydrated Biomolecules: From Nucleic Acid Bases to DNA Segments. Chem. Rev. 2012, 112 (11), 56035640. https://doi.org/10.1021/cr3000219.

(120) Tripathi, D.; Dutta, A. K. Electron Attachment to DNA Base Pairs: An Interplay of Dipole-and Valence-Bound States. J. Phys. Chem. A 2019, 123 (46), 10131-10138.

(121) Steinmann, C.; Ibsen, M. W.; Hansen, A. S.; Jensen, J. H. FragIt: A Tool to Prepare Input Files for Fragment Based Quantum Chemical Calculations. PLoS One 2012, 7 (9), e44480. https://doi.org/10.1371/journal.pone.0044480.

(122) Stowell, M. H. B.; McPhillips, T. M.; Rees, D. C.; Soltis, S. M.; Abresch, E.; Feher, G. LightInduced Structural Changes in Photosynthetic Reaction Center: Implications for Mechanism of Electron-Proton Transfer. Science (80-. ). 1997, 276 (5313), 812-816. 
(123) Berman, H. M.; Bourne, P. E.; Westbrook, J.; Zardecki, C. The Protein Data Bank. In Protein Structure; CRC Press, 2003, pp 394-410.

(124) Sommerfeld, T. Coupling between Dipole-Bound and Valence States: The Nitromethane Anion. Phys. Chem. Chem. Phys. (Incorporating Faraday Trans. 2002, 4, 2511-2516. https://doi.org/10.1039/B202143A.

(125) Sommerfeld, T. Intramolecular Electron Transfer from Dipole-Bound to Valence Orbitals: Uracil and 5-Chlorouracil. J. Phys. Chem. A 2004, 108 (42), 9150-9154. https://doi.org/10.1021/jp049082u.

(126) Sommerfeld, T. Dipole-Bound States as Doorways in (Dissociative) Electron Attachment. J. Phys. Conf. Ser. 2005, 4 (1), 245.

(127) Marcus, R. A. On the Theory of Oxidation-Reduction Reactions Involving Electron Transfer. I. $J$. Chem. Phys. 1956, 24 (5), 966-978.

(128) Solomun, T.; Skalický, T. The Interaction of a Protein-DNA Surface Complex with Low-Energy Electrons. Chem. Phys. Lett. 2008, 453 (1-3), 101-104. https://doi.org/10.1016/J.CPLETT.2007.12.078.

(129) Gu, B.; Smyth, M.; Kohanoff, J. Protection of DNA against Low-Energy Electrons by Amino Acids: A First-Principles Molecular Dynamics Study. Phys. Chem. Chem. Phys. 2014, 16 (44), 24350-24358. 


\section{Supporting Information}

\section{A Multi-layer Approach to the Equation of Motion Coupled- Cluster Method for Electron affinity}

Soumi Haldarl, Achintya Kumar Dutta ${ }^{1}$

${ }^{1}$ Department of Chemistry, Indian Institute of Technology Bombay, Powai, Mumbai 400 076, India

- Optimized geometry of monohydrated uracil system:
C -0.38641544862718
1.75686793631220
$-0.09535289150661$
C $\quad 0.75736749257069$
0.95299449730829
$-0.34941984071355$
C $\quad 0.66645867328888$
$-0.43227805417882$
$-0.46240098476578$
C -1.75255659142815
$-0.28030746589438$
0.17689016343378
N -1.55764786320432
1.05827427930401
0.32176967601147
newgto
S 8
19046.0000000
0.0007000
$2 \quad 1357.0000000$
0.0053890
$3 \quad 309.3000000$
0.0274060
$4 \quad 87.7300000$
0.1032070
$\begin{array}{ll}5 & 28.5600000\end{array}$
0.2787230
$\begin{array}{ll}6 & 10.2100000\end{array}$
0.4485400
$7 \quad 3.8380000$
0.2782380
$8 \quad 0.7466000$
0.0154400

S 8
19046.0000000
$-0.0001530$
$2 \quad 1357.0000000$
$-0.0012080$
$3 \quad 309.3000000$
$-0.0059920$ 


\begin{tabular}{|c|c|c|}
\hline 4 & 87.7300000 & -0.0245440 \\
\hline 5 & 28.5600000 & -0.0674590 \\
\hline 6 & 10.2100000 & -0.1580780 \\
\hline 7 & 3.8380000 & -0.1218310 \\
\hline$\varepsilon$ & 0.7466000 & 0.5490030 \\
\hline \multicolumn{3}{|c|}{$\begin{array}{ll}S & 1\end{array}$} \\
\hline 1 & 0.2248000 & 1.0000000 \\
\hline \multicolumn{3}{|c|}{ S 1} \\
\hline 1 & 0.0612400 & 1.0000000 \\
\hline \multicolumn{3}{|c|}{ S 1} \\
\hline 1 & 0.0191375 & 1.0000000 \\
\hline \multicolumn{3}{|c|}{ S 1} \\
\hline 1 & 0.0059805 & 1.0000000 \\
\hline \multicolumn{3}{|c|}{ S 1} \\
\hline 1 & 0.0018689 & 1.0000000 \\
\hline \multicolumn{3}{|c|}{ S 1} \\
\hline 1 & 0.0005840 & 1.0000000 \\
\hline \multicolumn{3}{|c|}{ S 1} \\
\hline 1 & 0.0001825 & 1.0000000 \\
\hline \multicolumn{3}{|c|}{ P 3} \\
\hline 1 & 13.5500000 & 0.0399190 \\
\hline 2 & 2.9170000 & 0.2171690 \\
\hline 3 & 0.7973000 & 0.5103190 \\
\hline \multicolumn{3}{|c|}{ P 1} \\
\hline 1 & 0.2185000 & 1.0000000 \\
\hline \multicolumn{3}{|c|}{ P 1} \\
\hline 1 & 0.0561100 & 1.0000000 \\
\hline
\end{tabular}




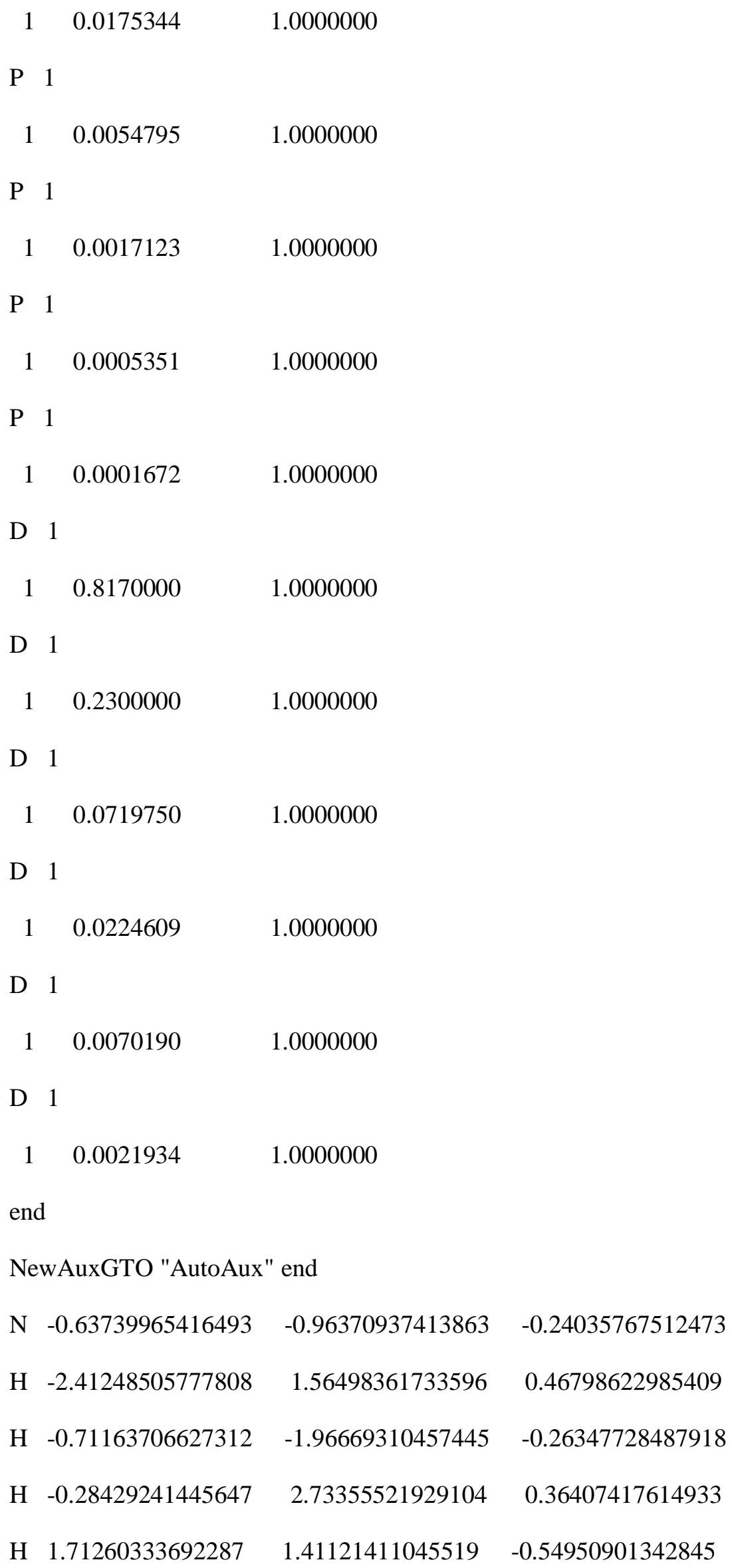



$\begin{array}{llll}\text { O } & -2.83317626125925 & -0.83700560289344 & 0.40142049791344\end{array}$
$\begin{array}{llll}\text { O } & 1.55811011235493 & -1.28227958753467 & -0.72854358410901\end{array}$
$\begin{array}{llll}\text { H } & 3.09163243041321 & -0.65424012755456 & -0.17787847229303\end{array}$
$\begin{array}{llll}\text { O } & 3.85112003969333 & -0.21171821226622 & 0.26881099899277\end{array}$
$\begin{array}{llll}\text { H } & 3.38009736107191 & 0.37235012185024 & 0.86725386941822\end{array}$

- Optimized geometry of DNA double-helix model system:
$\begin{array}{llll}\mathrm{H} & -5.632 & 8.586 & -0.713\end{array}$
$\begin{array}{llll}O & -5.137 & 8.216 & 0.073\end{array}$
C $\quad-6.077 \quad 7.969 \quad 1.148$
$\begin{array}{llll}H & -6.714 & 7.252 & 0.865\end{array}$
$\begin{array}{llll}\text { H } & -6.459 & 8.841 & 1.453\end{array}$
$\begin{array}{llll}\text { C } & -5.347 & 7.408 & 2.349\end{array}$
$\begin{array}{llll}\text { H } & -5.969 & 7.583 & 3.234\end{array}$
$\begin{array}{llll}\text { O } & -5.137 & 5.975 & 2.138\end{array}$
$\begin{array}{llll}\text { C } & -3.777 & 5.731 & 1.834\end{array}$
$\begin{array}{llll}\mathrm{H} & -3.314 & 5.145 & 2.641\end{array}$
$\begin{array}{llll}\mathrm{N} & -3.727 & 4.934 & 0.580\end{array}$
$\begin{array}{llll}\text { C } & -3.827 & 5.550 & -0.643\end{array}$
$\begin{array}{llll}\mathrm{H} & -3.948 & 6.632 & -0.691\end{array}$
$\begin{array}{llll}\text { C } & -3.577 & 3.569 & 0.702\end{array}$
$\begin{array}{llll}\text { O } & -3.487 & 3.012 & 1.781\end{array}$
$\begin{array}{llll}\text { N } & -3.537 & 2.871 & -0.489\end{array}$
$\begin{array}{llll}\mathrm{H} & -3.431 & 1.879 & -0.424\end{array}$
$\begin{array}{llll}\text { C } & -3.627 & 3.402 & -1.753\end{array}$
$\begin{array}{llll}O & -3.577 & 2.673 & -2.751\end{array}$
$\begin{array}{llll}\text { C } & -3.777 & 4.836 & -1.785\end{array}$
$\begin{array}{llll}\text { C } & -3.887 & 5.458 & -3.144\end{array}$
$\begin{array}{llll}\mathrm{H} & -2.918 & 5.895 & -3.429\end{array}$ 


$$
\begin{aligned}
& \begin{array}{llll}
\mathrm{H} & -4.655 & 6.243 & -3.127
\end{array} \\
& \begin{array}{llll}
\mathrm{H} & -4.167 & 4.687 & -3.878
\end{array} \\
& \begin{array}{llll}
\text { C } & -3.067 & 7.074 & 1.739
\end{array} \\
& \begin{array}{llll}
\mathrm{H} & -3.113 & 7.398 & 0.794
\end{array} \\
& \begin{array}{llll}
H & -2.165 & 6.994 & 2.163
\end{array} \\
& \begin{array}{llll}
\text { C } & -3.947 & 7.959 & 2.610
\end{array} \\
& \begin{array}{llll}
\text { H } & -3.877 & 9.016 & 2.309
\end{array} \\
& \begin{array}{llll}
\text { O } & -3.557 & 7.818 & 3.970
\end{array} \\
& \begin{array}{llll}
\mathrm{P} & -2.007 & 7.909 & 4.121
\end{array} \\
& \begin{array}{llll}
\text { O } & -1.787 & 8.539 & 5.439
\end{array} \\
& \begin{array}{llll}
\text { O } & -1.217 & 8.460 & 2.997
\end{array} \\
& \begin{array}{llll}
O & -1.757 & 6.336 & 4.225
\end{array} \\
& \begin{array}{llll}
\text { C } & -2.697 & 5.527 & 4.974
\end{array} \\
& \begin{array}{llll}
H & -3.334 & 5.094 & 4.336
\end{array} \\
& \begin{array}{llll}
\text { H } & -3.079 & 6.076 & 5.718
\end{array} \\
& \begin{array}{llll}
\text { C } & -1.967 & 4.387 & 5.649
\end{array} \\
& \text { H } \quad-2.589 \quad 4.033 \quad 6.480 \\
& \begin{array}{llll}
\text { O } & -1.757 & 3.322 & 4.669
\end{array} \\
& \begin{array}{llll}
\text { C } & -0.397 & 3.291 & 4.280
\end{array} \\
& \text { H } \quad 0.066 \quad 2.353 \quad 4.617 \\
& \begin{array}{llll}
\mathrm{N} & -0.280 & 3.447 & 2.783
\end{array} \\
& \begin{array}{llll}
\text { C } & -0.133 & 4.802 & 2.341
\end{array} \\
& \begin{array}{llll}
\mathrm{H} & -0.860 & 5.480 & 2.848
\end{array} \\
& \begin{array}{llll}
\text { C } & 0.137 & 4.912 & 0.928
\end{array} \\
& \begin{array}{llll}
\mathrm{H} & 0.108 & 5.898 & 0.427
\end{array} \\
& \begin{array}{llll}
\text { C } & 0.127 & 2.338 & 2.039
\end{array} \\
& \begin{array}{llll}
\text { O } & 0.201 & 1.219 & 2.618
\end{array} \\
& \begin{array}{llll}
\mathrm{N} & 0.423 & 2.489 & 0.710
\end{array}
\end{aligned}
$$



C $\quad 0.398 \quad 3.756 \quad 0.172$
N $\quad 0.716 \quad 3.816 \quad-1.199$
$\begin{array}{llll}\text { H } & 0.602 & 2.907 & -1.680\end{array}$
$\begin{array}{llll}\text { H } & 0.199 & 4.548 & -1.695\end{array}$
C $\quad 0.313 \quad 4.454 \quad 4.958$
$\begin{array}{llll}\mathrm{H} & 0.267 & 5.254 & 4.360\end{array}$
H $\quad 1.215 \quad 4.148 \quad 5.264$
$\begin{array}{llll}C & -0.567 & 4.695 & 6.175\end{array}$
$\begin{array}{llll}\mathrm{H} & -0.497 & 5.738 & 6.523\end{array}$
$\begin{array}{llll}\text { O } & -0.177 & 3.812 & 7.220\end{array}$
$\begin{array}{llll}P & 1.373 & 3.802 & 7.396\end{array}$
$\begin{array}{llll}O & 1.593 & 3.581 & 8.840\end{array}$
$\begin{array}{llll}\text { O } & 2.163 & 4.891 & 6.778\end{array}$
$\begin{array}{llll}O & 1.623 & 2.444 & 6.596\end{array}$
C $\quad 0.683 \quad 1.354 \quad 6.759$
H $\quad 0.046 \quad 1.356 \quad 5.989$
$\begin{array}{llll}\mathrm{H} & 0.302 & 1.388 & 7.683\end{array}$
$\begin{array}{llll}\text { C } & 1.413 & 0.031 & 6.674\end{array}$
H $\quad 0.791 \quad-0.729 \quad 7.161$
$\begin{array}{llll}O & 1.623 & -0.296 & 5.265\end{array}$
C $\quad 2.983 \quad-0.102 \quad 4.926$
H $3.446 \quad-1.068 \quad 4.675$
N $3.033 \quad 0.774 \quad 3.725$
C $2.933 \quad 2.137 \quad 3.853$
H $2.812 \quad 2.578 \quad 4.842$
C $3.183 \quad 0.161 \quad 2.500$
$\begin{array}{llll}\text { O } & 3.273 & -1.046 & 2.375\end{array}$
N $3.223 \quad 1.016 \quad 1.415$ 

$\begin{array}{llll}\text { H } & 3.329 & 0.592 & 0.515\end{array}$
C $3.133 \quad 2.386 \quad 1.447$
$\begin{array}{llll}\text { O } & 3.183 & 3.049 & 0.404\end{array}$

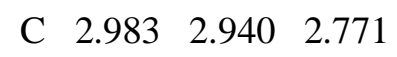
C $2.873 \quad 4.432 \quad 2.853$
H $3.842 \quad 4.857 \quad 3.156$
H $\quad 2.105 \quad 4.703 \quad 3.590$
H $2.593 \quad 4.834 \quad 1.867$

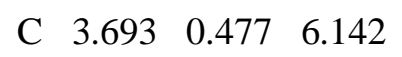
H $3.647 \quad 1.475 \quad 6.098$
$\begin{array}{llll}\text { H } & 4.595 & 0.052 & 6.222\end{array}$
$\begin{array}{llll}\text { C } & 2.813 & -0.010 & 7.283\end{array}$
H $2.883 \quad 0.656 \quad 8.157$
$\begin{array}{llll}\text { O } & 3.203 & -1.328 & 7.649\end{array}$
$\begin{array}{llll}\text { H } & 4.144 & -1.505 & 7.583\end{array}$
H $\quad \begin{array}{lll}5.777 & -1.173 & -8.754\end{array}$
$\begin{array}{llll}\text { O } & 5.283 & -1.873 & -8.239\end{array}$
$\begin{array}{llll}\text { C } & 6.223 & -2.883 & -7.793\end{array}$
$\begin{array}{llll}\text { H } & 6.862 & -2.469 & -7.145\end{array}$
$\begin{array}{llll}\text { H } & 6.602 & -3.350 & -8.592\end{array}$
$\begin{array}{llll}\text { C } & 5.493 & -3.953 & -7.010\end{array}$
$\begin{array}{llll}\text { H } & 6.116 & -4.855 & -7.013\end{array}$
$\begin{array}{llll}\text { O } & 5.283 & -3.472 & -5.645\end{array}$
$\begin{array}{llll}\text { C } & 3.923 & -3.127 & -5.463\end{array}$
$\begin{array}{llll}\text { H } & 3.461 & -3.807 & -4.734\end{array}$
N $3.873 \quad-1.740 \quad-4.924$

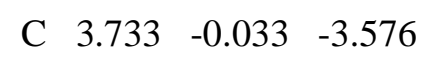
$\begin{array}{llll}\text { N } & 3.883 & 0.490 & -4.848\end{array}$ 

$\begin{array}{llll}\text { C } & 3.953 & -0.558 & -5.610\end{array}$
H $\quad 4.065 \quad-0.504 \quad-6.692$
N $3.483 \quad-0.240 \quad-1.246$
C $3.493 \quad-1.555 \quad-1.437$
$\begin{array}{llll}\text { H } & 3.387 & -2.153 & -0.540\end{array}$
$\begin{array}{llll}\mathrm{N} & 3.613 & -2.237 & -2.556\end{array}$
$\begin{array}{llll}\text { C } & 3.733 & -1.398 & -3.601\end{array}$
$\begin{array}{llll}\text { C } & 3.603 & 0.572 & -2.308\end{array}$
N $3.593 \quad 1.887 \quad-2.115$
H $3.684 \quad 2.526 \quad-2.916$
$\begin{array}{llll}\text { H } & 3.495 & 2.268 & -1.162\end{array}$
$\begin{array}{llll}\text { C } & 3.213 & -3.291 & -6.800\end{array}$
H $\quad 3.255 \quad-2.424 \quad-7.296$
$\begin{array}{llll}\text { O } & 1.923 & -3.830 & -6.545\end{array}$
$\begin{array}{llll}\text { H } & 1.494 & -3.499 & -5.753\end{array}$
$\begin{array}{llll}\text { C } & 4.093 & -4.308 & -7.506\end{array}$
$\begin{array}{llll}\text { H } & 4.024 & -4.222 & -8.597\end{array}$
$\begin{array}{llll}\text { O } & 3.703 & -5.623 & -7.103\end{array}$
$\begin{array}{llll}\text { P } & 2.153 & -5.787 & -7.164\end{array}$
$\begin{array}{llll}\text { O } & 1.933 & -7.202 & -7.531\end{array}$
$\begin{array}{llll}\text { O } & 1.363 & -4.789 & -7.920\end{array}$
$\begin{array}{llll}\text { O } & 1.903 & -5.588 & -5.601\end{array}$
C $\begin{array}{llll}2.843 & -6.171 & -4.663\end{array}$
H $3.482 \quad-5.464 \quad-4.361$
$\begin{array}{llll}\text { H } & 3.222 & -7.007 & -5.059\end{array}$
$\begin{array}{llll}\text { C } & 2.113 & -6.614 & -3.413\end{array}$
$\begin{array}{llll}\text { H } & 2.736 & -7.361 & -2.907\end{array}$
$\begin{array}{llll}\text { O } & 1.903 & -5.448 & -2.556\end{array}$ 

$\begin{array}{llll}\text { C } & 0.543 & -5.060 & -2.601\end{array}$
$\begin{array}{llll}\mathrm{H} & 0.081 & -5.213 & -1.615\end{array}$
$\begin{array}{llll}\mathrm{N} & 0.405 & -3.578 & -2.953\end{array}$
$\begin{array}{llll}\text { C } & 0.467 & -2.478 & -2.098\end{array}$
$\begin{array}{llll}\mathrm{N} & 0.562 & -1.102 & 1.137\end{array}$
$\begin{array}{llll}\mathrm{H} & 0.567 & -1.964 & 1.681\end{array}$
$\begin{array}{llll}\text { H } & 0.442 & -0.175 & 1.648\end{array}$
$\begin{array}{llll}\mathrm{N} & 0.539 & -2.488 & -0.750\end{array}$
$\begin{array}{llll}\text { C } & 0.512 & -1.253 & -0.200\end{array}$
$\begin{array}{llll}\mathrm{N} & 0.442 & -0.092 & -0.950\end{array}$
$\begin{array}{llll}\mathrm{H} & 0.440 & 0.832 & -0.427\end{array}$
$\begin{array}{llll}\text { C } & 0.407 & -0.021 & -2.363\end{array}$
$\begin{array}{llll}\mathrm{O} & 0.384 & 1.081 & -2.934\end{array}$
$\begin{array}{llll}\text { C } & 0.397 & -1.353 & -2.959\end{array}$
$\begin{array}{llll}\mathrm{N} & 0.288 & -1.748 & -4.285\end{array}$
$\begin{array}{llll}\text { C } & 0.294 & -3.069 & -4.244\end{array}$
$\begin{array}{llll}\text { H } & 0.139 & -3.740 & -5.107\end{array}$
$\begin{array}{llll}\text { C } & -0.167 & -5.949 & -3.612\end{array}$
$\begin{array}{llll}\mathrm{H} & -0.125 & -5.512 & -4.510\end{array}$
$\begin{array}{llll}\text { O } & -1.457 & -6.251 & -3.097\end{array}$
$\begin{array}{llll}\mathrm{H} & -1.885 & -5.530 & -2.628\end{array}$
$\begin{array}{llll}\text { C } & 0.713 & -7.187 & -3.623\end{array}$
H $\quad 0.644 \quad-7.731 \quad-4.573$
$\begin{array}{llll}O & 0.323 & -8.046 & -2.549\end{array}$
$\begin{array}{llll}P & -1.227 & -8.216 & -2.507\end{array}$
$\begin{array}{llll}\text { O } & -1.447 & -9.592 & -2.014\end{array}$
$\begin{array}{llll}\text { O } & -2.017 & -7.818 & -3.694\end{array}$
$\begin{array}{llll}\mathrm{O} & -1.477 & -7.171 & -1.328\end{array}$ 

$\begin{array}{llll}\text { C } & -0.537 & -7.124 & -0.224\end{array}$
$\begin{array}{llll}\text { H } & 0.102 & -6.369 & -0.372\end{array}$
$\begin{array}{llll}\text { H } & -0.157 & -8.038 & -0.081\end{array}$
$\begin{array}{llll}\text { C } & -1.267 & -6.787 & 1.058\end{array}$
$\begin{array}{llll}\mathrm{H} & -0.644 & -7.118 & 1.897\end{array}$
$\begin{array}{llll}\text { O } & -1.477 & -5.340 & 1.109\end{array}$
$\begin{array}{llll}\text { C } & -2.837 & -5.045 & 0.854\end{array}$
$\begin{array}{llll}H & -3.299 & -4.615 & 1.754\end{array}$
$\begin{array}{llll}\mathrm{N} & -2.887 & -4.036 & -0.240\end{array}$
$\begin{array}{llll}\text { C } & -3.027 & -2.158 & -1.336\end{array}$
$\begin{array}{llll}\mathrm{N} & -2.877 & -3.150 & -2.288\end{array}$
$\begin{array}{llll}\text { C } & -2.807 & -4.243 & -1.591\end{array}$
$\begin{array}{llll}\mathrm{H} & -2.695 & -5.231 & -2.037\end{array}$
$\begin{array}{llll}\text { N } & -3.277 & -0.064 & -0.293\end{array}$
$\begin{array}{llll}\text { C } & -3.267 & -0.723 & 0.862\end{array}$
$\begin{array}{llll}\text { H } & -3.373 & -0.106 & 1.746\end{array}$
$\begin{array}{llll}\mathrm{N} & -3.147 & -2.013 & 1.087\end{array}$
$\begin{array}{llll}\text { C } & -3.027 & -2.680 & -0.075\end{array}$
$\begin{array}{llll}\text { C } & -3.157 & -0.756 & -1.436\end{array}$
$\begin{array}{llll}\mathrm{N} & -3.167 & -0.096 & -2.590\end{array}$
$\begin{array}{llll}\mathrm{H} & -3.076 & -0.609 & -3.478\end{array}$
$\begin{array}{llll}\mathrm{H} & -3.265 & 0.930 & -2.596\end{array}$
$\begin{array}{llll}\text { C } & -3.547 & -6.349 & 0.519\end{array}$
$\begin{array}{llll}\mathrm{H} & -3.505 & -6.494 & -0.470\end{array}$
$\begin{array}{llll}\text { O } & -4.837 & -6.308 & 1.115\end{array}$
$\begin{array}{llll}H & -5.265 & -5.449 & 1.096\end{array}$
$\begin{array}{llll}\text { C } & -2.667 & -7.378 & 1.207\end{array}$
$\begin{array}{llll}\text { H } & -2.736 & -8.362 & 0.729\end{array}$ 


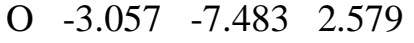
H $\quad-3.998 \quad-7.384 \quad 2.742$
$\mathrm{H} \quad-1.435 \quad 7.980 \quad 2.183$
H $1.946 \quad 4.953 \quad 5.835$
H $\quad 2.086 \quad-7.317 \quad-8.482$
$\begin{array}{llll}\mathrm{H} & -1.294 & -10.222 & -2.735\end{array}$

- Optimized geometry of ubiquinone model system:
$\begin{array}{llll}\mathrm{N} & 31.18900 & 37.67100 & 23.46300\end{array}$
$\begin{array}{llll}\mathrm{H} & 30.76300 & 38.57200 & 23.37900\end{array}$
$\begin{array}{llll}\mathrm{H} & 31.03400 & 37.30400 & 24.38000\end{array}$

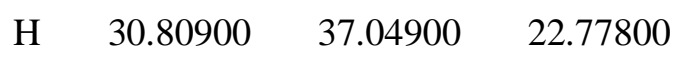
$\begin{array}{llll}\text { C } & 32.62400 & 37.80200 & 23.24100\end{array}$

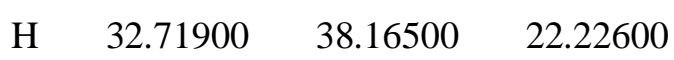

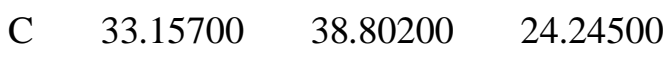

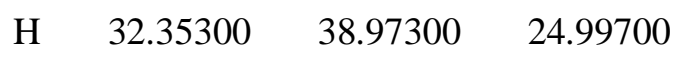
$\begin{array}{llll}\mathrm{H} & 34.00400 & 38.34100 & 24.80000\end{array}$

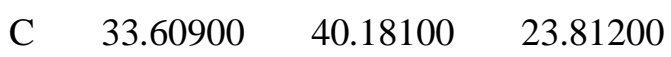

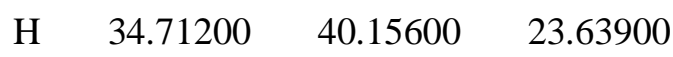

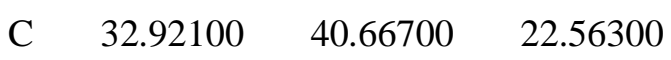
$\begin{array}{llll}\mathrm{H} & 33.24900 & 41.69900 & 22.31300\end{array}$
$\begin{array}{lll}\mathrm{H} & 33.16000 & 40.00700 \quad 21.70200\end{array}$
$\mathrm{H} \quad 31.81900 \quad 40.67800 \quad 22.70100$
$\begin{array}{llll}\text { C } & 33.34100 & 41.09400 & 24.97800\end{array}$

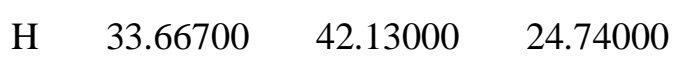

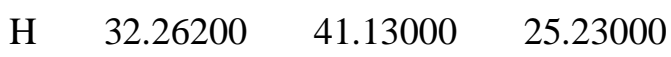

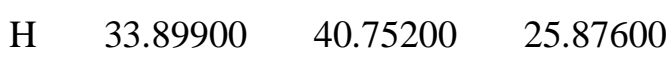
$\begin{array}{llll}\text { C } & 33.41000 & 36.49400 & 23.33900\end{array}$ 


\begin{tabular}{|c|c|c|c|}
\hline & 34.23300 & 36.20600 & 22.46000 \\
\hline & 33.17200 & 35.68300 & 24.37100 \\
\hline & 2.51900 & 5.91400 & 25.09100 \\
\hline & 33.84200 & 34.40200 & 24.53000 \\
\hline & 34.90300 & 34.59100 & 24.42600 \\
\hline & 33.53800 & 33.81700 & 25.90000 \\
\hline & 33.82600 & 34.55400 & 26.68100 \\
\hline F & 32.44200 & 33.65600 & 26.00100 \\
\hline 1 & 35.59300 & 32.33400 & 25.9700 \\
\hline $\mathrm{H}$ & 36.27700 & 33.04700 & 25.81000 \\
\hline C & 34.29100 & 32.51700 & 26.11300 \\
\hline C & 35.82800 & 31.07200 & 26.19100 \\
\hline I & 36.82200 & 30.62000 & 26.14500 \\
\hline $\mathrm{N}$ & 34.70100 & 30.46900 & 26.47500 \\
\hline C & 33.70800 & 31.31700 & 26.44300 \\
\hline $\mathrm{H}$ & 32.66400 & 31.07800 & 26.60900 \\
\hline C & 33.45400 & 33.38300 & 23.46300 \\
\hline C & 32.79400 & 33.80100 & 22.83900 \\
\hline & 33.94900 & 32.53000 & 23.63200 \\
\hline $\mathrm{N}$ & 35.13000 & 34.59000 & 20.17300 \\
\hline $\mathrm{H}$ & 34.89100 & 35.54600 & 20.34600 \\
\hline & 34.78800 & 34.01300 & 20.9150 \\
\hline $\mathrm{H}$ & 34.73800 & 34.29300 & 19.3020 \\
\hline C & 36.58300 & 34.46800 & 20.10700 \\
\hline $\mathrm{H}$ & 36.90300 & 35.06500 & 19.26300 \\
\hline C & 37.23600 & 34.95800 & 21.41200 \\
\hline & 36.77900 & 35.94400 & 21.6590 \\
\hline & 36.95100 & 34.27100 & 22.239 \\
\hline
\end{tabular}




\begin{tabular}{|c|c|c|c|}
\hline $\mathrm{C}$ & 38.77000 & 35.15500 & 21.45000 \\
\hline & 39.26800 & 34.15800 & 21.38400 \\
\hline C & 39.24000 & 36.06700 & 20.32000 \\
\hline $\mathrm{H}$ & 40.33600 & 36.23800 & 20.38800 \\
\hline & 39.01800 & 35.61100 & 19.33100 \\
\hline $\mathrm{H}$ & 38.73100 & 37.05300 & 20.37400 \\
\hline C & 39.15800 & 35.78500 & 22.76900 \\
\hline $\mathrm{H}$ & 40.26000 & 35.91800 & 22.8240 \\
\hline $\mathrm{H}$ & 38.69200 & 36.78200 & 22.90000 \\
\hline & 38.84400 & 35.13800 & 23.6170 \\
\hline C & 37.01500 & 33.03700 & 19.84600 \\
\hline $\mathrm{O}$ & 36.20200 & 32.46000 & 19.77100 \\
\hline O & 38.01400 & 33.00000 & 19.8090 \\
\hline $\mathrm{N}$ & 42.33800 & 40.21800 & 21.2920 \\
\hline & 41.64100 & 39.54500 & 21.04500 \\
\hline $\mathrm{H}$ & 43.15900 & 39.75300 & 21.62200 \\
\hline $\mathrm{H}$ & 42.56200 & 40.78400 & 20.49800 \\
\hline C & 41.82300 & 41.06500 & 22.34300 \\
\hline $\mathrm{H}$ & 40.97800 & 41.58600 & 21.90900 \\
\hline $\mathrm{C}$ & 41.40600 & 40.20800 & 23.52800 \\
\hline $\mathrm{H}$ & 41.55800 & 39.13600 & 23.2730 \\
\hline $\mathrm{H}$ & 42.03300 & 40.42500 & 24.41900 \\
\hline C & 39.92800 & 40.46000 & 23.77200 \\
\hline $\mathrm{C}$ & 38.97400 & 39.89500 & 22.91700 \\
\hline $\mathrm{H}$ & 39.29400 & 39.24500 & 22.11400 \\
\hline C & 37.62600 & 40.18200 & 23.1080 \\
\hline $\mathrm{H}$ & 36.88300 & 39.74700 & 22.4540 \\
\hline & 22500 & 41.02400 & 24.1440 \\
\hline
\end{tabular}




\begin{tabular}{|c|c|c|c|}
\hline $\mathrm{H}$ & 36.17600 & 41.23800 & 24.29000 \\
\hline $\mathrm{C}$ & 39.52900 & 41.30000 & 24.81400 \\
\hline $\mathrm{H}$ & 40.27000 & 41.74600 & 25.46200 \\
\hline $\mathrm{C}$ & 38.17400 & 41.58200 & 24.99700 \\
\hline $\mathrm{H}$ & 37.86400 & 42.23500 & 25.80100 \\
\hline $\mathrm{C}$ & 42.81800 & 42.12000 & 22.78200 \\
\hline $\mathrm{O}$ & 43.65600 & 42.02100 & 22.24500 \\
\hline $\mathrm{O}$ & 42.40800 & 42.67300 & 23.50700 \\
\hline $\mathrm{N}$ & 41.29800 & 45.89200 & 22.73900 \\
\hline $\mathrm{H}$ & 40.46200 & 45.78900 & 22.19900 \\
\hline $\mathrm{H}$ & 41.65500 & 44.99200 & 22.98900 \\
\hline $\mathrm{H}$ & 41.98300 & 46.39700 & 22.21400 \\
\hline $\mathrm{C}$ & 40.99100 & 46.63100 & 23.94800 \\
\hline $\mathrm{H}$ & 40.64400 & 47.60500 & 23.62600 \\
\hline $\mathrm{C}$ & 39.80900 & 45.83800 & 24.59800 \\
\hline $\mathrm{H}$ & 39.20100 & 45.39900 & 23.76900 \\
\hline $\mathrm{C}$ & 40.30300 & 44.70700 & 25.48600 \\
\hline $\mathrm{H}$ & 39.44400 & 44.18800 & 25.96300 \\
\hline $\mathrm{H}$ & 40.86700 & 43.94700 & 24.90600 \\
\hline $\mathrm{H}$ & 40.95900 & 45.09900 & 26.29300 \\
\hline $\mathrm{C}$ & 38.94000 & 46.82200 & 25.35200 \\
\hline $\mathrm{H}$ & 38.10600 & 46.29700 & 25.86500 \\
\hline $\mathrm{H}$ & 39.53700 & 47.36300 & 26.11800 \\
\hline $\mathrm{H}$ & 38.49200 & 47.57100 & 24.66600 \\
\hline $\mathrm{C}$ & 42.20000 & 46.85200 & 24.85900 \\
\hline $\mathrm{O}$ & 43.00500 & 46.43300 & 24.43900 \\
\hline $\mathrm{O}$ & 41.91000 & 47.36500 & 25.66600 \\
\hline $\mathrm{N}$ & 43.98100 & 44.32500 & 26.51400 \\
\hline
\end{tabular}




\begin{tabular}{|c|c|c|c|}
\hline $\mathrm{H}$ & 44.37600 & 45.19800 & 26.79800 \\
\hline $\mathrm{H}$ & 43.01500 & 44.44600 & 26.28700 \\
\hline $\mathrm{H}$ & 44.47600 & 43.96900 & 25.72100 \\
\hline $\mathrm{C}$ & 44.09500 & 43.37400 & 27.61000 \\
\hline $\mathrm{H}$ & 45.14800 & 43.19500 & 27.78900 \\
\hline $\mathrm{C}$ & 43.34400 & 43.89800 & 28.86400 \\
\hline $\mathrm{H}$ & 43.82000 & 44.84400 & 29.20500 \\
\hline $\mathrm{H}$ & 42.28500 & 44.13200 & 28.61900 \\
\hline $\mathrm{C}$ & 43.35700 & 42.96800 & 30.07800 \\
\hline $\mathrm{C}$ & 44.55800 & 42.62500 & 30.70600 \\
\hline $\mathrm{H}$ & 45.48900 & 43.04500 & 30.35100 \\
\hline $\mathrm{C}$ & 44.56200 & 41.72800 & 31.77300 \\
\hline $\mathrm{H}$ & 45.48800 & 41.45200 & 32.25600 \\
\hline $\mathrm{C}$ & 43.35900 & 41.18100 & 32.21000 \\
\hline $\mathrm{O}$ & 43.35300 & 40.26100 & 33.23600 \\
\hline $\mathrm{H}$ & 42.43700 & 40.06000 & 33.43700 \\
\hline $\mathrm{C}$ & 42.15700 & 42.42000 & 30.53100 \\
\hline $\mathrm{H}$ & 41.23000 & 42.65800 & 30.02800 \\
\hline $\mathrm{C}$ & 42.15600 & 41.52500 & 31.60100 \\
\hline $\mathrm{H}$ & 41.22600 & 41.09000 & 31.93500 \\
\hline $\mathrm{C}$ & 43.48900 & 42.06000 & 27.15200 \\
\hline $\mathrm{O}$ & 42.65500 & 42.02700 & 26.24600 \\
\hline $\mathrm{N}$ & 43.95300 & 40.95700 & 27.72200 \\
\hline $\mathrm{H}$ & 44.74000 & 40.94200 & 28.33800 \\
\hline $\mathrm{C}$ & 43.35200 & 39.66200 & 27.49800 \\
\hline $\mathrm{H}$ & 42.32900 & 39.80400 & 27.17600 \\
\hline $\mathrm{C}$ & 44.19900 & 38.83000 & 26.55800 \\
\hline $\mathrm{H}$ & 44.20900 & 39.33300 & 25.56400 \\
\hline
\end{tabular}




\begin{tabular}{|c|c|c|c|}
\hline & 45.25300 & 38.79200 & 26.91600 \\
\hline C & 43.63900 & 37.53300 & 26.4240 \\
\hline & 44.06500 & 7.11800 & 25.6630 \\
\hline 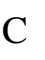 & 43.30800 & 39.01100 & 28.8670 \\
\hline 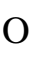 & 44.34500 & 38.89600 & 29.5200 \\
\hline & 42.14900 & 38.58100 & 29.3710 \\
\hline I & 41.26100 & 38.65200 & 28.92100 \\
\hline $\mathrm{C}$ & 42.10500 & 37.94600 & 30.6820 \\
\hline I & 42.80100 & 38.49200 & 31.3060 \\
\hline 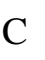 & 40.63800 & 38.07700 & 31.2280 \\
\hline I & 40.37300 & 39.15200 & 31.0620 \\
\hline 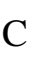 & 39.69700 & 37.10300 & 30.5430 \\
\hline $\mathrm{F}$ & 38.64400 & 37.31300 & 30.8240 \\
\hline $\mathrm{F}$ & 39.77400 & 37.18800 & 29.4390 \\
\hline $\mathrm{F}$ & 39.93000 & 36.05600 & 30.8310 \\
\hline C & 40.64600 & 37.83600 & 32.7320 \\
\hline $\mathrm{H}$ & 40.94200 & 36.78400 & 32.9430 \\
\hline & 41.41400 & 38.49400 & 33.1990 \\
\hline $\mathrm{C}$ & 39.30200 & 38.11800 & 33.4240 \\
\hline $\mathrm{F}$ & 39.39700 & 37.97800 & 34.5230 \\
\hline $\mathrm{H}$ & 38.97500 & 39.16300 & 33.2340 \\
\hline & 38.51300 & 37.42900 & 33.0570 \\
\hline C & 42.60700 & 36.49600 & 30.6210 \\
\hline C & 42.96100 & 35.93900 & 31.6610 \\
\hline$\Gamma$ & 42.71600 & 35.86300 & 29.4470 \\
\hline $\mathrm{H}$ & 42.45800 & 36.29000 & 28.5810 \\
\hline & 43.22200 & 34.50000 & 29.351 \\
\hline & 43.74700 & 34.30000 & 30.27 \\
\hline
\end{tabular}




\begin{tabular}{|c|c|c|c|}
\hline & 43.84500 & 34.45900 & 28.46800 \\
\hline$C$ & 42.11800 & 33.45300 & 29.19800 \\
\hline & 41.23100 & 33.91400 & 29.19200 \\
\hline & 42.53500 & 32.54600 & 29.13800 \\
\hline & 38.57000 & 33.94000 & 31.42100 \\
\hline & 39.19100 & 34.61100 & 31.01500 \\
\hline & 38.85500 & 33.01500 & 31.16900 \\
\hline F & 38.56800 & 34.03700 & 32.41600 \\
\hline C & 37.22200 & 34.17500 & 30.9180 \\
\hline $\mathrm{H}$ & 36.94700 & 35.15900 & 31.27500 \\
\hline$C$ & 37.24800 & 34.14700 & 29.34300 \\
\hline $\mathrm{F}$ & 37.93500 & 34.98400 & 29.05900 \\
\hline$C$ & 37.66100 & 32.77200 & 28.83500 \\
\hline $\mathrm{H}$ & 37.83000 & 32.79500 & 27.73800 \\
\hline H & 38.60600 & 32.44000 & 29.31400 \\
\hline $\mathrm{H}$ & 36.87500 & 32.01700 & 29.04900 \\
\hline$C$ & 35.86500 & 34.49600 & 28.78200 \\
\hline & 35.88500 & 34.44300 & 27.67000 \\
\hline $\mathrm{H}$ & 35.13100 & 33.73600 & 29.13400 \\
\hline $\mathrm{C}$ & 35.29600 & 35.87500 & 29.17000 \\
\hline $\mathrm{H}$ & 34.27100 & 35.99900 & 28.75900 \\
\hline F & 35.24300 & 35.98000 & 30.2750 \\
\hline $\mathrm{H}$ & 35.92800 & 36.69400 & 28.76800 \\
\hline C & 36.19200 & 33.19400 & 31.48400 \\
\hline $\mathrm{O}$ & 36.65300 & 32.56200 & 32.10700 \\
\hline $\mathrm{O}$ & 35.29300 & 33.40900 & 31.10100 \\
\hline & 35.61700 & 34.46200 & 34.8870 \\
\hline & 36.56900 & 34.70100 & 35.076 \\
\hline
\end{tabular}




\begin{tabular}{|c|c|c|c|}
\hline & 35.55800 & 33.95100 & 34.03000 \\
\hline $\mathrm{H}$ & 35.24700 & 33.91400 & 35.63700 \\
\hline & 4.83500 & 5.68700 & 34.76400 \\
\hline F & 34.88400 & 36.18200 & 35.72500 \\
\hline$C$ & 35.34500 & 36.59200 & 33.63500 \\
\hline & 36.41200 & 36.82400 & 33.85600 \\
\hline & 35.34700 & 36.01700 & 32.68300 \\
\hline C & 34.64100 & 37.94500 & 33.38000 \\
\hline $\mathrm{H}$ & 33.57000 & 37.75500 & 33.12900 \\
\hline$C$ & 34.72900 & 38.83000 & 34.61900 \\
\hline $\mathrm{H}$ & 34.26600 & 39.82100 & 34.42400 \\
\hline $\mathrm{F}$ & 34.19800 & 38.36000 & 35.47400 \\
\hline $\mathrm{H}$ & 35.78800 & 38.99300 & 34.91000 \\
\hline$C$ & 35.28700 & 38.63000 & 32.1920 \\
\hline H & 34.78100 & 39.59700 & 31.98200 \\
\hline $\mathrm{H}$ & 36.35900 & 38.84400 & 32.37600 \\
\hline H & 35.20800 & 37.99200 & 31.28500 \\
\hline C & 33.37900 & 35.39000 & 34.47600 \\
\hline $\mathrm{O}$ & 33.25200 & 34.39900 & 34.42900 \\
\hline $\mathrm{O}$ & 32.88000 & 36.25300 & 34.39900 \\
\hline $\mathrm{N}$ & 30.42800 & 36.67700 & 36.85100 \\
\hline $\mathrm{H}$ & 31.33900 & 37.07500 & 36.74700 \\
\hline H & 30.33600 & 35.87600 & 36.2600 \\
\hline $\mathrm{H}$ & 30.27700 & 36.41600 & 37.80400 \\
\hline $\mathrm{C}$ & 29.43300 & 37.66500 & 36.46700 \\
\hline $\mathrm{H}$ & 29.53100 & 38.48900 & 37.16200 \\
\hline C & 29.67100 & 38.12400 & 35.0280 \\
\hline & 29.64300 & 37.21500 & 34.384 \\
\hline
\end{tabular}




\begin{tabular}{|c|c|c|c|}
\hline $\mathrm{H}$ & 28.81600 & 38.75800 & 34.70400 \\
\hline $\mathrm{C}$ & 30.97500 & 38.85900 & 34.71600 \\
\hline $\mathrm{H}$ & 31.83600 & 38.22000 & 35.02600 \\
\hline $\mathrm{C}$ & 31.05100 & 39.11800 & 33.21700 \\
\hline $\mathrm{H}$ & 31.96700 & 39.69400 & 32.96700 \\
\hline $\mathrm{H}$ & 31.07700 & 38.16000 & 32.65500 \\
\hline $\mathrm{H}$ & 30.17000 & 39.70200 & 32.87400 \\
\hline $\mathrm{C}$ & 31.04800 & 40.15800 & 35.49900 \\
\hline $\mathrm{H}$ & 32.00400 & 40.68300 & 35.28700 \\
\hline $\mathrm{H}$ & 30.22000 & 40.84500 & 35.23100 \\
\hline $\mathrm{H}$ & 30.99700 & 39.95700 & 36.59100 \\
\hline $\mathrm{C}$ & 28.02100 & 37.11400 & 36.60500 \\
\hline $\mathrm{O}$ & 28.07000 & 36.17200 & 36.93600 \\
\hline $\mathrm{O}$ & 27.36800 & 37.82000 & 36.33300 \\
\hline $\mathrm{C}$ & 37.73500 & 40.74500 & 28.66700 \\
\hline $\mathrm{C}$ & 38.80100 & 39.90200 & 28.30700 \\
\hline $\mathrm{C}$ & 38.58900 & 38.71800 & 27.59000 \\
\hline $\mathrm{C}$ & 37.28700 & 38.35700 & 27.21500 \\
\hline $\mathrm{C}$ & 36.20300 & 39.19400 & 27.56700 \\
\hline $\mathrm{C}$ & 36.41100 & 40.39800 & 28.28500 \\
\hline $\mathrm{C}$ & 38.03900 & 42.00300 & 29.47800 \\
\hline $\mathrm{C}$ & 40.15700 & 37.66800 & 25.99400 \\
\hline $\mathrm{C}$ & 36.59400 & 37.16500 & 25.17800 \\
\hline $\mathrm{C}$ & 35.21200 & 41.33000 & 28.53500 \\
\hline $\mathrm{C}$ & 34.84300 & 41.34300 & 29.94000 \\
\hline $\mathrm{C}$ & 34.14400 & 42.38500 & 30.53300 \\
\hline $\mathrm{C}$ & 33.69900 & 43.60500 & 29.73200 \\
\hline $\mathrm{C}$ & 33.85900 & 42.35000 & 32.02700 \\
\hline
\end{tabular}




\begin{tabular}{|c|c|c|c|}
\hline $\mathrm{O}$ & 39.94900 & 40.21500 & 28.62000 \\
\hline $\mathrm{O}$ & 39.67400 & 37.89200 & 27.30900 \\
\hline $\mathrm{O}$ & 37.08700 & 37.16400 & 26.51400 \\
\hline $\mathrm{O}$ & 35.04800 & 38.86100 & 27.26400 \\
\hline $\mathrm{H}$ & 37.12900 & 42.53300 & 29.66900 \\
\hline $\mathrm{H}$ & 38.70700 & 42.63000 & 28.92600 \\
\hline $\mathrm{H}$ & 38.49300 & 41.72800 & 30.40700 \\
\hline $\mathrm{H}$ & 40.99300 & 37.00100 & 26.03000 \\
\hline $\mathrm{H}$ & 40.46100 & 38.59900 & 25.56200 \\
\hline $\mathrm{H}$ & 39.38100 & 37.23500 & 25.39800 \\
\hline $\mathrm{H}$ & 36.51400 & 36.15800 & 24.82700 \\
\hline $\mathrm{H}$ & 37.26800 & 37.70900 & 24.55000 \\
\hline $\mathrm{H}$ & 35.63000 & 37.62900 & 25.15400 \\
\hline $\mathrm{H}$ & 34.37800 & 40.98900 & 27.95800 \\
\hline $\mathrm{H}$ & 35.48800 & 42.32300 & 28.24700 \\
\hline $\mathrm{H}$ & 35.11400 & 40.53800 & 30.52600 \\
\hline $\mathrm{H}$ & 33.97100 & 43.47600 & 28.70500 \\
\hline $\mathrm{H}$ & 34.17700 & 44.48000 & 30.12000 \\
\hline $\mathrm{H}$ & 32.63700 & 43.71400 & 29.80900 \\
\hline $\mathrm{H}$ & 33.31500 & 43.22800 & 32.30700 \\
\hline $\mathrm{H}$ & 34.78300 & 42.31600 & 32.56600 \\
\hline $\mathrm{H}$ & 33.27900 & 41.48100 & 32.25900 \\
\hline
\end{tabular}

- Fragmentation scheme of ORCA EF-DLPNO calculation of DNA model system:

\#multilayer input

! EA-EOM-DLPNO-CCSD NORMALPNO SP ma-def2-SVP RIJCOSX autoaux def2/J Pa12

$\%$ maxcore 50000

$\%$ mdci 
printlevel 3

nroots 2

FollowCIS true

TCutPNOSingles $1 \mathrm{e}-12$

Maxiter 2000

DTO1 1e-5

NDAV 10

NormalPNOFragInter $\left\{\begin{array}{ll}1 & 1\end{array}\right\}$

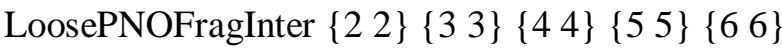

HFFRAGMENTINTERACTION $\{12\}\{13\}\{14\}\{15\}\{16\}\left\{\begin{array}{ll}2 & 3\end{array}\right\}\{24\}\{25\}\{26\}\{34\}\{35\}$ $\{36\}\{45\}\{46\}\left\{\begin{array}{ll}5 & 6\end{array}\right\}$

end

\#QM/MM input

*xyz 01

$\begin{array}{llll}H(2) & -5.632 & 8.586 & -0.713\end{array}$

$\mathrm{O}(2) \quad-5.137 \quad 8.216 \quad 0.073$

$\begin{array}{llll}C(2) & -6.077 & 7.969 & 1.148\end{array}$

$H(2) \quad-6.714 \quad 7.252 \quad 0.865$

$\begin{array}{llll}H(2) & -6.459 & 8.841 & 1.453\end{array}$

$\begin{array}{llll}C(2) & -5.347 & 7.408 & 2.349\end{array}$

$\begin{array}{llll}H(2) & -5.969 & 7.583 & 3.234\end{array}$

$\mathrm{O}(2) \quad-5.137 \quad 5.975 \quad 2.138$

$\begin{array}{llll}C(2) & -3.777 & 5.731 & 1.834\end{array}$

$\begin{array}{llll}H(2) & -3.314 & 5.145 & 2.641\end{array}$

$\mathrm{N}(2) \quad-3.727 \quad 4.934 \quad 0.580$

$\begin{array}{llll}C(2) & -3.827 & 5.550 & -0.643\end{array}$

$\begin{array}{llll}H(2) & -3.948 & 6.632 & -0.691\end{array}$

$\begin{array}{llll}C(2) & -3.577 & 3.569 & 0.702\end{array}$ 


$$
\begin{array}{llll}
\mathrm{O}(2) & -3.487 & 3.012 & 1.781 \\
\mathrm{~N}(2) & -3.537 & 2.871 & -0.489 \\
\mathrm{H}(2) & -3.431 & 1.879 & -0.424 \\
\mathrm{C}(2) & -3.627 & 3.402 & -1.753 \\
\mathrm{O}(2) & -3.577 & 2.673 & -2.751 \\
\mathrm{C}(2) & -3.777 & 4.836 & -1.785 \\
\mathrm{C}(2) & -3.887 & 5.458 & -3.144 \\
\mathrm{H}(2) & -2.918 & 5.895 & -3.429 \\
\mathrm{H}(2) & -4.655 & 6.243 & -3.127 \\
\mathrm{H}(2) & -4.167 & 4.687 & -3.878 \\
\mathrm{C}(2) & -3.067 & 7.074 & 1.739 \\
\mathrm{H}(2) & -3.113 & 7.398 & 0.794 \\
\mathrm{H}(2) & -2.165 & 6.994 & 2.163 \\
\mathrm{C}(2) & -3.947 & 7.959 & 2.610 \\
\mathrm{H}(2) & -3.877 & 9.016 & 2.309 \\
\mathrm{O}(2) & -3.557 & 7.818 & 3.970 \\
\mathrm{C}(2) & -2.007 & 7.909 & 4.121 \\
\mathrm{H}(1) & 0.066 & 2.353 & 4.617 \\
\mathrm{O}(2) & -1.787 & 8.539 & 5.439 \\
\mathrm{O}(2) & -1.217 & 8.460 & 2.997 \\
\mathrm{O}(2) & -1.757 & 6.336 & 4.225 \\
\mathrm{C}(1) & -2.697 & 5.527 & 4.974 \\
\mathrm{H}(1) & -3.334 & 5.094 & 4.336 \\
\mathrm{H}(1) & -3.079 & 6.076 & 5.718 \\
\mathrm{C}(1) & -1.967 & 4.387 & 5.649 \\
\hline & & & \\
\hline
\end{array}
$$




$$
\begin{aligned}
& \begin{array}{llll}
\mathrm{N}(1) & -0.280 & 3.447 & 2.783
\end{array} \\
& \begin{array}{llll}
C(1) & -0.133 & 4.802 & 2.341
\end{array} \\
& \begin{array}{llll}
\mathrm{H}(1) & -0.860 & 5.480 & 2.848
\end{array} \\
& \begin{array}{llll}
C(1) & 0.137 & 4.912 & 0.928
\end{array} \\
& \begin{array}{llll}
H(1) & 0.108 & 5.898 & 0.427
\end{array} \\
& \text { C(1) } \quad 0.127 \quad 2.338 \quad 2.039 \\
& \begin{array}{llll}
\mathrm{O}(1) & 0.201 & 1.219 & 2.618
\end{array} \\
& \begin{array}{llll}
\mathrm{N}(1) & 0.423 & 2.489 & 0.710
\end{array} \\
& \text { C(1) } \quad 0.398 \quad 3.756 \quad 0.172 \\
& \mathrm{~N}(1) \quad 0.716 \quad 3.816 \quad-1.199 \\
& \begin{array}{llll}
H(1) & 0.602 & 2.907 & -1.680
\end{array} \\
& \begin{array}{llll}
H(1) & 0.199 & 4.548 & -1.695
\end{array} \\
& \text { C(1) } \quad 0.313 \quad 4.454 \quad 4.958 \\
& H(1) \quad 0.267 \quad 5.254 \quad 4.360 \\
& \mathrm{H}(1) \quad 1.215 \quad 4.148 \quad 5.264 \\
& \begin{array}{llll}
C(1) & -0.567 & 4.695 & 6.175
\end{array} \\
& \begin{array}{llll}
H(1) & -0.497 & 5.738 & 6.523
\end{array} \\
& \begin{array}{llll}
\mathrm{O}(1) & -0.177 & 3.812 & 7.220
\end{array} \\
& \mathrm{P}(1) \quad 1.373 \quad 3.802 \quad 7.396 \\
& \text { O(1) } \quad 1.593 \quad 3.581 \quad 8.840 \\
& \text { O(1) } \quad 2.163 \quad 4.891 \quad 6.778 \\
& \text { O(1) } 1.623 \quad 2.444 \quad 6.596 \\
& \text { C(3) } \quad 0.683 \quad 1.354 \quad 6.759 \\
& \mathrm{H}(3) \quad 0.046 \quad 1.356 \quad 5.989 \\
& \mathrm{H}(3) \quad 0.302 \quad 1.388 \quad 7.683 \\
& \text { C(3) } \quad 1.413 \quad 0.031 \quad 6.674 \\
& \begin{array}{llll}
\mathrm{H}(3) & 0.791 & -0.729 & 7.161
\end{array} \\
& \begin{array}{llll}
\mathrm{O}(3) & 1.623 & -0.296 & 5.265
\end{array}
\end{aligned}
$$



$\begin{array}{llll}C(3) & 2.983 & -0.102 & 4.926\end{array}$
H(3) $3.446 \quad-1.068 \quad 4.675$
$\mathrm{N}(3) \quad 3.033 \quad 0.774 \quad 3.725$
C(3) $\quad 2.933 \quad 2.137 \quad 3.853$
H(3) $2.812 \quad 2.578 \quad 4.842$
$\begin{array}{llll}C(3) & 3.183 & 0.161 & 2.500\end{array}$
O(3) $\quad 3.273 \quad-1.046 \quad 2.375$
$\mathrm{N}(3) \quad 3.223 \quad 1.016 \quad 1.415$
$\mathrm{H}(3) \quad 3.329 \quad 0.592 \quad 0.515$
C(3) $3.133 \quad 2.386 \quad 1.447$
$\begin{array}{llll}\mathrm{O}(3) & 3.183 & 3.049 & 0.404\end{array}$
C(3) $\quad 2.983 \quad 2.940 \quad 2.771$
C(3) $\quad 2.873 \quad 4.432 \quad 2.853$
H(3) $3.842 \quad 4.857 \quad 3.156$
H(3) $\quad 2.105 \quad 4.703 \quad 3.590$
H(3) $2.593 \quad 4.834 \quad 1.867$
C(3) $3.693 \quad 0.477 \quad 6.142$
H(3) $3.647 \quad 1.475 \quad 6.098$
H(3) $\quad 4.595 \quad 0.052 \quad 6.222$
C(3) $\quad 2.813 \quad-0.010 \quad 7.283$
H(3) $2.883 \quad 0.656 \quad 8.157$
O(3) $3.203 \quad-1.328 \quad 7.649$
$\mathrm{H}(3) \quad 4.144 \quad-1.505 \quad 7.583$
H(4) $\quad 5.777 \quad-1.173 \quad-8.754$
$\begin{array}{llll}\mathrm{O}(4) & 5.283 & -1.873 & -8.239\end{array}$
$\begin{array}{llll}C(4) & 6.223 & -2.883 & -7.793\end{array}$
$\begin{array}{llll}H(4) & 6.862 & -2.469 & -7.145\end{array}$
$\mathrm{H}(4) \quad 6.602 \quad-3.350 \quad-8.592$ 


$$
\begin{array}{llll}
\mathrm{C}(4) & 5.493 & -3.953 & -7.010 \\
\mathrm{H}(4) & 6.116 & -4.855 & -7.013 \\
\mathrm{O}(4) & 5.283 & -3.472 & -5.645 \\
\mathrm{C}(4) & 3.923 & -3.127 & -5.463 \\
\mathrm{H}(4) & 3.461 & -3.807 & -4.734 \\
\mathrm{~N}(4) & 3.873 & -1.740 & -4.924 \\
\mathrm{C}(4) & 3.733 & -0.033 & -3.576 \\
\mathrm{~N}(4) & 3.883 & 0.490 & -4.848 \\
\mathrm{C}(4) & 3.953 & -0.558 & -5.610 \\
\mathrm{H}(4) & 4.065 & -0.504 & -6.692 \\
\mathrm{~N}(4) & 3.483 & -0.240 & -1.246 \\
\mathrm{C}(4) & 3.493 & -1.555 & -1.437 \\
\mathrm{H}(4) & 3.387 & -2.153 & -0.540 \\
\mathrm{~N}(4) & 3.613 & -2.237 & -2.556 \\
\mathrm{C}(4) & 3.733 & -1.398 & -3.601 \\
\mathrm{O}(5) & 1.933 & -7.202 & -7.531 \\
\mathrm{C}(4) & 3.603 & 0.572 & -2.308 \\
\mathrm{~N}(4) & 3.593 & 1.887 & -2.115 \\
\mathrm{H}(4) & 3.684 & 2.526 & -2.916 \\
\mathrm{H}(4) & 3.495 & 2.268 & -1.162 \\
\mathrm{C}(4) & 3.213 & -3.291 & -6.800 \\
\mathrm{H}(4) & 3.255 & -2.424 & -7.296 \\
\mathrm{O}(4) & 1.923 & -3.830 & -6.545 \\
\mathrm{H}(4) & 1.494 & -3.499 & -5.753 \\
& 4.093 & -4.308 & -7.506 \\
& & -4.222 & -8.597 \\
& -5.623 & -7.103 \\
\mathrm{H} & -5.787 & -7.164 \\
\mathrm{H} & & \\
\hline
\end{array}
$$




$$
\begin{aligned}
& \begin{array}{llll}
\mathrm{O}(5) & 1.363 & -4.789 & -7.920
\end{array} \\
& \text { O(5) } 1.903 \quad-5.588 \quad-5.601 \\
& \text { C(5) } 2.843 \quad-6.171 \quad-4.663 \\
& \begin{array}{llll}
H(5) & 3.482 & -5.464 & -4.361
\end{array} \\
& \begin{array}{llll}
H(5) & 3.222 & -7.007 & -5.059
\end{array} \\
& \begin{array}{llll}
C(5) & 2.113 & -6.614 & -3.413
\end{array} \\
& \begin{array}{llll}
H(5) & 2.736 & -7.361 & -2.907
\end{array} \\
& \begin{array}{llll}
\mathrm{O}(5) & 1.903 & -5.448 & -2.556
\end{array} \\
& \begin{array}{llll}
C(5) & 0.543 & -5.060 & -2.601
\end{array} \\
& \begin{array}{llll}
H(5) & 0.081 & -5.213 & -1.615
\end{array} \\
& \begin{array}{llll}
N(5) & 0.405 & -3.578 & -2.953
\end{array} \\
& \begin{array}{llll}
C(5) & 0.467 & -2.478 & -2.098
\end{array} \\
& \begin{array}{llll}
\mathrm{N}(5) & 0.562 & -1.102 & 1.137
\end{array} \\
& \begin{array}{llll}
H(5) & 0.567 & -1.964 & 1.681
\end{array} \\
& \begin{array}{llll}
H(5) & 0.442 & -0.175 & 1.648
\end{array} \\
& \mathrm{~N}(5) \quad 0.539 \quad-2.488 \quad-0.750 \\
& \begin{array}{llll}
C(5) & 0.512 & -1.253 & -0.200
\end{array} \\
& \begin{array}{llll}
\mathrm{N}(5) & 0.442 & -0.092 & -0.950
\end{array} \\
& \begin{array}{llll}
H(5) & 0.440 & 0.832 & -0.427
\end{array} \\
& \begin{array}{llll}
C(5) & 0.407 & -0.021 & -2.363
\end{array} \\
& \begin{array}{llll}
\mathrm{O}(5) & 0.384 & 1.081 & -2.934
\end{array} \\
& \begin{array}{llll}
C(5) & 0.397 & -1.353 & -2.959
\end{array} \\
& \begin{array}{llll}
\mathrm{N}(5) & 0.288 & -1.748 & -4.285
\end{array} \\
& \begin{array}{llll}
C(5) & 0.294 & -3.069 & -4.244
\end{array} \\
& \begin{array}{llll}
H(5) & 0.139 & -3.740 & -5.107
\end{array} \\
& \begin{array}{llll}
C(5) & -0.167 & -5.949 & -3.612
\end{array} \\
& \mathrm{H}(5) \quad-0.125 \quad-5.512 \quad-4.510 \\
& \begin{array}{llll}
\mathrm{O}(5) & -1.457 & -6.251 & -3.097
\end{array}
\end{aligned}
$$




$$
\begin{array}{llll}
\mathrm{H}(5) & -1.885 & -5.530 & -2.628 \\
\mathrm{C}(5) & 0.713 & -7.187 & -3.623 \\
\mathrm{H}(5) & 0.644 & -7.731 & -4.573 \\
\mathrm{O}(6) & 0.323 & -8.046 & -2.549 \\
\mathrm{P}(6) & -1.227 & -8.216 & -2.507 \\
\mathrm{O}(6) & -1.447 & -9.592 & -2.014 \\
\mathrm{O}(6) & -2.017 & -7.818 & -3.694 \\
\mathrm{O}(6) & -1.477 & -7.171 & -1.328 \\
\mathrm{C}(6) & -0.537 & -7.124 & -0.224 \\
\mathrm{H}(6) & 0.102 & -6.369 & -0.372 \\
\mathrm{H}(6) & -0.157 & -8.038 & -0.081 \\
\mathrm{C}(6) & -1.267 & -6.787 & 1.058 \\
\mathrm{H}(6) & -0.644 & -7.118 & 1.897 \\
\mathrm{C}(6) & -3.157 & -0.756 & -1.436 \\
\mathrm{~N}(6) & -3.167 & -0.096 & -2.590 \\
\mathrm{C}(6) & -2.837 & -5.045 & 0.854 \\
\mathrm{H}(6) & -3.147 & -2.013 & 1.087 \\
\mathrm{H}(6) & -3.299 & -4.615 & 1.754 \\
\mathrm{~N}(6) & -2.887 & -4.036 & -0.240 \\
\mathrm{C}(6) & -3.027 & -2.158 & -1.336 \\
\mathrm{~N}(6) & -2.877 & -3.150 & -2.288 \\
\mathrm{C}(6) & -2.807 & -4.243 & -1.591 \\
\mathrm{H}(6) & -2.695 & -5.231 & -2.037 \\
\mathrm{~N}(6) & -3.277 & -0.064 & -0.293 \\
\mathrm{C}(6) & -3.267 & -0.723 & 0.862 \\
& -2.680 & -0.075 \\
\hline
\end{array}
$$




$$
\begin{array}{llll}
\mathrm{H}(6) & -3.076 & -0.609 & -3.478 \\
\mathrm{H}(6) & -3.265 & 0.930 & -2.596 \\
\mathrm{C}(6) & -3.547 & -6.349 & 0.519 \\
\mathrm{H}(6) & -3.505 & -6.494 & -0.470 \\
\mathrm{O}(6) & -4.837 & -6.308 & 1.115 \\
\mathrm{H}(6) & -5.265 & -5.449 & 1.096 \\
\mathrm{C}(6) & -2.667 & -7.378 & 1.207 \\
\mathrm{H}(6) & -2.736 & -8.362 & 0.729 \\
\mathrm{O}(6) & -3.057 & -7.483 & 2.579 \\
\mathrm{H}(6) & -3.998 & -7.384 & 2.742 \\
\mathrm{H}(2) & -1.435 & 7.980 & 2.183 \\
\mathrm{H}(1) & 1.946 & 4.953 & 5.835 \\
\mathrm{H}(5) & 2.086 & -7.317 & -8.482 \\
\mathrm{H}(6) & -1.294 & -10.222 & -2.735
\end{array}
$$

- Fragmentation scheme of ORCA EF-DLPNO calculation of ubiquinone model system:

! EA-EOM-DLPNO-CCSD NORMALPNO ma-def2-SVP RIJCOSX autoaux def2/J pal8 $\%$ maxcore 20000

\%mdci

printlevel 3

nroots 2

FollowCIS true

TCutPNOSingles $1 \mathrm{e}-12$

Maxiter 2000

DTO1 1e-5

NormalPNOFragInter $\left\{\begin{array}{ll}1 & 1\end{array}\right\}$

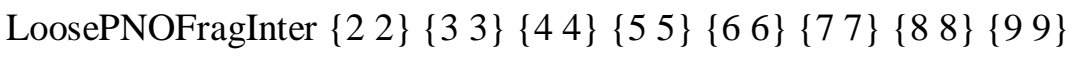


HFFRAGMENTINTERACTION $\{12\}\{13\}\{14\}\{15\}\{16\}\{17\}\{18\}\{19\}\{23\}\{24\}\{25\}$ $\{26\}\{27\}\{28\}\{29\}\{34\}\{35\}\{36\}\{37\}\{38\}\{39\}\{45\}\{46\}\{47\}\{48\}\{49\}\{56\}\{5$

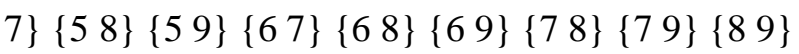

end

\#QM/MM input

*xyz 01

$\mathrm{N}(1) \quad 31.189 \quad 37.671 \quad 23.463$

$\mathrm{H}(1) \quad 30.763 \quad 38.572 \quad 23.379$

$H(1) \quad 31.034 \quad 37.304 \quad 24.380$

$H(1) \quad 30.809 \quad 37.049 \quad 22.778$

C(1) $\quad 32.624 \quad 37.802 \quad 23.241$

$H(1) \quad 32.719 \quad 38.165 \quad 22.226$

C(1) $\quad 33.157 \quad 38.802 \quad 24.245$

H(1) $\quad 32.353 \quad 38.973 \quad 24.997$

H(1) $\quad 34.004 \quad 38.341 \quad 24.800$

C(1) $\quad 33.609 \quad 40.181 \quad 23.812$

$H(1) \quad 34.712 \quad 40.156 \quad 23.639$

C(1) $\quad 32.921 \quad 40.667 \quad 22.563$

H(1) $\quad 33.249 \quad 41.699 \quad 22.313$

$H(1) \quad 33.160 \quad 40.007 \quad 21.702$

$H(1) \quad 31.819 \quad 40.678 \quad 22.701$

C(1) $\quad 33.341 \quad 41.094 \quad 24.978$

$H(1) \quad 33.667 \quad 42.130 \quad 24.740$

$H(1) \quad 32.262 \quad 41.130 \quad 25.230$

$H(1) \quad 33.899 \quad 40.752 \quad 25.876$

C(1) $\quad 33.410 \quad 36.494 \quad 23.339$

O(1) $\quad 34.233 \quad 36.206 \quad 22.460$

$\mathrm{N}(1) \quad 33.172 \quad 35.683 \quad 24.371$ 

H(1) $\quad 32.519 \quad 35.914 \quad 25.091$
C(1) $\quad 33.842 \quad 34.402 \quad 24.530$
H(1) $34.903 \quad 34.591 \quad 24.426$
C(1) $33.538 \quad 33.817 \quad 25.900$
$H(1) \quad 33.826 \quad 34.554 \quad 26.681$
$\mathrm{H}(1) \quad 32.442 \quad 33.656 \quad 26.001$
$\mathrm{N}(1) \quad 35.593 \quad 32.334 \quad 25.970$
$\begin{array}{llll}H(1) & 36.277 & 33.047 & 25.810\end{array}$
C(1) $\quad 34.291 \quad 32.517 \quad 26.113$
C(1) $\quad 35.828 \quad 31.072 \quad 26.191$
$H(1) \quad 36.822 \quad 30.620 \quad 26.145$
$\mathrm{N}(1) \quad 34.701 \quad 30.469 \quad 26.475$
C(1) $33.708 \quad 31.317 \quad 26.443$
H(1) $\quad 32.664 \quad 31.078 \quad 26.609$
C(1) $\quad 33.454 \quad 33.383 \quad 23.463$
$\begin{array}{llll}O(1) & 32.794 & 33.801 & 22.839\end{array}$
$\begin{array}{llll}O(1) & 33.949 & 32.530 & 23.632\end{array}$
$\mathrm{N}(2) \quad 35.130 \quad 34.590 \quad 20.173$
$H(2) \quad 34.891 \quad 35.546 \quad 20.346$
$H(2) \quad 34.788 \quad 34.013 \quad 20.915$
$H(2) \quad 34.738 \quad 34.293 \quad 19.302$
$\begin{array}{llll}C(2) & 36.583 & 34.468 & 20.107\end{array}$
$\begin{array}{llll}H(2) & 36.903 & 35.065 & 19.263\end{array}$
C(2) $\quad 37.236 \quad 34.958 \quad 21.412$
$H(2) \quad 36.779 \quad 35.944 \quad 21.659$
$\begin{array}{llll}H(2) & 36.951 & 34.271 & 22.239\end{array}$
C(2) $\quad 38.770 \quad 35.155 \quad 21.450$
$H(2) \quad 39.268 \quad 34.158 \quad 21.384$ 

$\begin{array}{llll}C(2) & 39.240 & 36.067 & 20.320\end{array}$
$H(2) \quad 40.336 \quad 36.238 \quad 20.388$
$H(2) \quad 39.018 \quad 35.611 \quad 19.331$
$H(2) \quad 38.731 \quad 37.053 \quad 20.374$
$\begin{array}{llll}C(2) & 39.158 & 35.785 & 22.769\end{array}$
$H(2) \quad 40.260 \quad 35.918 \quad 22.824$
$H(2) \quad 38.692 \quad 36.782 \quad 22.900$
$\begin{array}{llll}H(2) & 38.844 & 35.138 & 23.617\end{array}$
$\begin{array}{llll}C(2) & 37.015 & 33.037 & 19.846\end{array}$
$\mathrm{O}(2) \quad 36.202 \quad 32.460 \quad 19.771$
$\begin{array}{llll}O(2) & 38.014 & 33.000 & 19.809\end{array}$
$\mathrm{N}(3) \quad 42.338 \quad 40.218 \quad 21.292$
H(3) $41.641 \quad 39.545 \quad 21.045$
$H(3) \quad 43.159 \quad 39.753 \quad 21.622$
$H(3) \quad 42.562 \quad 40.784 \quad 20.498$
C(3) $\quad 41.823 \quad 41.065 \quad 22.343$
H(3) $40.978 \quad 41.586 \quad 21.909$
C(3) $41.406 \quad 40.208 \quad 23.528$
H(3) $\quad 41.558 \quad 39.136 \quad 23.273$
$H(3) \quad 42.033 \quad 40.425 \quad 24.419$
C(3) $\quad 39.928 \quad 40.460 \quad 23.772$
$\begin{array}{llll}C(3) & 38.974 & 39.895 & 22.917\end{array}$
$H(3) \quad 39.294 \quad 39.245 \quad 22.114$
C(3) $37.626 \quad 40.182 \quad 23.108$
$H(3) \quad 36.883 \quad 39.747 \quad 22.454$
C(3) $\quad 37.225 \quad 41.024 \quad 24.144$
$H(3) \quad 36.176 \quad 41.238 \quad 24.290$
C(3) $\quad 39.529 \quad 41.300 \quad 24.814$ 

$H(3) \quad 40.270 \quad 41.746 \quad 25.462$
C(3) $\quad 38.174 \quad 41.582 \quad 24.997$
$H(3) \quad 37.864 \quad 42.235 \quad 25.801$
C(3) $\quad 42.818 \quad 42.120 \quad 22.782$
$\mathrm{O}(3) \quad 43.656 \quad 42.021 \quad 22.245$
$\begin{array}{llll}O(3) & 42.408 & 42.673 & 23.507\end{array}$
$\mathrm{N}(4) \quad 41.298 \quad 45.892 \quad 22.739$
$H(4) \quad 40.462 \quad 45.789 \quad 22.199$
$H(4) \quad 41.655 \quad 44.992 \quad 22.989$
H(4) $\quad 41.983 \quad 46.397 \quad 22.214$
C(4) $\quad 40.991 \quad 46.631 \quad 23.948$
H(4) $40.644 \quad 47.605 \quad 23.626$
C(4) $39.809 \quad 45.838 \quad 24.598$
$H(4) \quad 39.201 \quad 45.399 \quad 23.769$
C(4) $\quad 40.303 \quad 44.707 \quad 25.486$
$H(4) \quad 39.444 \quad 44.188 \quad 25.963$
H(4) $40.867 \quad 43.947 \quad 24.906$
H(4) $40.959 \quad 45.099 \quad 26.293$
C(4) $\quad 38.940 \quad 46.822 \quad 25.352$
H(4) $\quad 38.106 \quad 46.297 \quad 25.865$
$H(4) \quad 39.537 \quad 47.363 \quad 26.118$
H(4) $38.492 \quad 47.571 \quad 24.666$
C(4) $\quad 42.200 \quad 46.852 \quad 24.859$
$\mathrm{O}(4) \quad 43.005 \quad 46.433 \quad 24.439$
$\mathrm{O}(4) \quad 41.910 \quad 47.365 \quad 25.666$
$\begin{array}{llll}\mathrm{N}(5) & 43.981 & 44.325 & 26.514\end{array}$
H(5) $44.376 \quad 45.198 \quad 26.798$
H(5) $\quad 43.015 \quad 44.446 \quad 26.287$ 

H(5) $44.476 \quad 43.969 \quad 25.721$
C(5) $\quad 44.095 \quad 43.374 \quad 27.610$
$H(5) \quad 45.148 \quad 43.195 \quad 27.789$
$\begin{array}{llll}C(5) & 43.344 & 43.898 & 28.864\end{array}$
$\begin{array}{llll}H(5) & 43.820 & 44.844 & 29.205\end{array}$
$H(5) \quad 42.285 \quad 44.132 \quad 28.619$
$\begin{array}{llll}C(5) & 43.357 & 42.968 & 30.078\end{array}$
C(5) $\quad 44.558 \quad 42.625 \quad 30.706$
$H(5) \quad 45.489 \quad 43.045 \quad 30.351$
C(5) $\quad 44.562 \quad 41.728 \quad 31.773$
$\mathrm{H}(5) \quad 45.488 \quad 41.452 \quad 32.256$
$\begin{array}{llll}C(5) & 43.359 & 41.181 \quad 32.210\end{array}$
O(5) $43.353 \quad 40.261 \quad 33.236$
$\begin{array}{llll}H(5) & 42.437 & 40.060 & 33.437\end{array}$
$\begin{array}{llll}C(5) & 42.157 & 42.420 & 30.531\end{array}$
H(5) $\quad 41.230 \quad 42.658 \quad 30.028$
C(5) $\quad 42.156 \quad 41.525 \quad 31.601$
$H(5) \quad 41.226 \quad 41.090 \quad 31.935$
$\begin{array}{llll}C(5) & 43.489 & 42.060 & 27.152\end{array}$
$\mathrm{O}(5) \quad 42.655 \quad 42.027 \quad 26.246$
N(5) $\quad 43.953 \quad 40.957 \quad 27.722$
$H(5) \quad 44.740 \quad 40.942 \quad 28.338$
C(5) $\quad 43.352 \quad 39.662 \quad 27.498$
H(5) $\quad 42.329 \quad 39.804 \quad 27.176$
$\begin{array}{llll}C(5) & 44.199 & 38.830 & 26.558\end{array}$
$H(5) \quad 44.209 \quad 39.333 \quad 25.564$
H(5) $\quad 45.253 \quad 38.792 \quad 26.916$
O(5) $\quad 43.639 \quad 37.533 \quad 26.424$ 

$H(5) \quad 44.065 \quad 37.118 \quad 25.663$
$\begin{array}{llll}C(5) & 43.308 & 39.011 & 28.867\end{array}$
$\begin{array}{llll}O(5) & 44.345 & 38.896 & 29.520\end{array}$
$\begin{array}{llll}N(5) & 42.149 & 38.581 & 29.371\end{array}$
H(5) $\quad 41.261 \quad 38.652 \quad 28.921$
C(5) $\quad 42.105 \quad 37.946 \quad 30.682$
$H(5) \quad 42.801 \quad 38.492 \quad 31.306$
$\begin{array}{llll}C(5) & 40.638 & 38.077 & 31.228\end{array}$
H(5) $\quad 40.373 \quad 39.152 \quad 31.062$
$\begin{array}{llll}C(5) & 39.697 & 37.103 & 30.543\end{array}$
$\begin{array}{llll}H(5) & 38.644 & 37.313 & 30.824\end{array}$
H(5) $\quad 39.774 \quad 37.188 \quad 29.439$
H(5) $39.930 \quad 36.056 \quad 30.831$
C(5) $\quad 40.646 \quad 37.836 \quad 32.732$
$H(5) \quad 40.942 \quad 36.784 \quad 32.943$
H(5) $\quad 41.414 \quad 38.494 \quad 33.199$
C(5) $\quad 39.302 \quad 38.118 \quad 33.424$
$\begin{array}{llll}H(5) & 39.397 & 37.978 & 34.523\end{array}$
$\begin{array}{llll}H(5) & 38.975 & 39.163 & 33.234\end{array}$
H(5) $\quad 38.513 \quad 37.429 \quad 33.057$
C(5) $\quad 42.607 \quad 36.496 \quad 30.621$
$\begin{array}{llll}O(5) & 42.961 & 35.939 & 31.661\end{array}$
$\mathrm{N}(5) \quad 42.716 \quad 35.863 \quad 29.447$
$H(5) \quad 42.458 \quad 36.290 \quad 28.581$
$\begin{array}{llll}C(5) & 43.222 & 34.500 & 29.351\end{array}$
$\begin{array}{llll}H(5) & 43.747 & 34.300 & 30.275\end{array}$
H(5) $\quad 43.845 \quad 34.459 \quad 28.468$
C(5) $\quad 42.118 \quad 33.453 \quad 29.198$ 

O(5) $\quad 41.231 \quad 33.914 \quad 29.192$
O(5) $\quad 42.535 \quad 32.546 \quad 29.138$
$\mathrm{N}(6) \quad 38.570 \quad 33.940 \quad 31.421$
H(6) $\quad 39.191 \quad 34.611 \quad 31.015$
H(6) $\quad 38.855 \quad 33.015 \quad 31.169$
H(6) $\quad 38.568 \quad 34.037 \quad 32.416$
$\begin{array}{llll}C(6) & 37.222 & 34.175 & 30.918\end{array}$
$\begin{array}{llll}H(6) & 36.947 & 35.159 & 31.275\end{array}$
$\begin{array}{llll}C(6) & 37.248 & 34.147 & 29.343\end{array}$
H(6) $\quad 37.935 \quad 34.984 \quad 29.059$
$\begin{array}{llll}C(6) & 37.661 & 32.772 & 28.835\end{array}$
$\begin{array}{llll}H(6) & 37.830 & 32.795 & 27.738\end{array}$
H(6) $38.606 \quad 32.440 \quad 29.314$
H(6) $\quad 36.875 \quad 32.017 \quad 29.049$
C(6) $\quad 35.865 \quad 34.496 \quad 28.782$
$H(6) \quad 35.885 \quad 34.443 \quad 27.670$
H(6) $\quad 35.131 \quad 33.736 \quad 29.134$
C(6) $\quad 35.296 \quad 35.875 \quad 29.170$
H(6) $\quad 34.271 \quad 35.999 \quad 28.759$
$\begin{array}{llll}H(6) & 35.243 & 35.980 & 30.275\end{array}$
H(6) $\quad 35.928 \quad 36.694 \quad 28.768$
$\begin{array}{llll}C(6) & 36.192 & 33.194 & 31.484\end{array}$
$\begin{array}{llll}\mathrm{O}(6) & 36.653 & 32.562 & 32.107\end{array}$
$\mathrm{O}(6) \quad 35.293 \quad 33.409 \quad 31.101$
N(7) $\quad 35.617 \quad 34.462 \quad 34.887$
H(7) $\quad 36.569 \quad 34.701 \quad 35.076$
$\mathrm{H}(7) \quad 35.558 \quad 33.951 \quad 34.030$
$\begin{array}{llll}H(7) & 35.247 & 33.914 & 35.637\end{array}$ 

C(7) $\quad 34.835 \quad 35.687 \quad 34.764$
H(7) $\quad 34.884 \quad 36.182 \quad 35.725$
C(7) $\quad 35.345 \quad 36.592 \quad 33.635$
$H(7) \quad 36.412 \quad 36.824 \quad 33.856$
$H(7) \quad 35.347 \quad 36.017 \quad 32.683$
C(7) $\quad 34.641 \quad 37.945 \quad 33.380$
$H(7) \quad 33.570 \quad 37.755 \quad 33.129$
$\begin{array}{llll}\text { C(7) } & 34.729 & 38.830 & 34.619\end{array}$
H(7) $\quad 34.266 \quad 39.821 \quad 34.424$
H(7) $\quad 34.198 \quad 38.360 \quad 35.474$
H(7) $\quad 35.788 \quad 38.993 \quad 34.910$
C(7) $\quad 35.287 \quad 38.630 \quad 32.192$
$\mathrm{H}(7) \quad 34.781 \quad 39.597 \quad 31.982$
H(7) $\quad 36.359 \quad 38.844 \quad 32.376$
$H(7) \quad 35.208 \quad 37.992 \quad 31.285$
C(7) $\quad 33.379 \quad 35.390 \quad 34.476$
$\begin{array}{llll}\mathrm{O}(7) & 33.252 & 34.399 & 34.429\end{array}$
$\begin{array}{llll}\mathrm{O}(7) & 32.880 & 36.253 & 34.399\end{array}$
$\mathrm{N}(8) \quad 30.428 \quad 36.677 \quad 36.851$
$\begin{array}{llll}H(8) & 31.339 & 37.075 & 36.747\end{array}$
H(8) $30.336 \quad 35.876 \quad 36.260$
H(8) $\quad 30.277 \quad 36.416 \quad 37.804$
C(8) $\quad 29.433 \quad 37.665 \quad 36.467$
$H(8) \quad 29.531 \quad 38.489 \quad 37.162$
C(8) $\quad 29.671 \quad 38.124 \quad 35.028$
$H(8) \quad 29.643 \quad 37.215 \quad 34.384$
H(8) $\quad 28.816 \quad 38.758 \quad 34.704$
C(8) $\quad 30.975 \quad 38.859 \quad 34.716$ 
H(8) $31.836 \quad 38.220 \quad 35.026$

$\begin{array}{llll}C(8) & 31.051 & 39.118 & 33.217\end{array}$

H(8) $31.967 \quad 39.694 \quad 32.967$

H(8) $31.077 \quad 38.160 \quad 32.655$

H(8) $\quad 30.170 \quad 39.702 \quad 32.874$

$\begin{array}{llll}C(8) & 31.048 & 40.158 \quad 35.499\end{array}$

H(8) $32.004 \quad 40.683 \quad 35.287$

$\mathrm{H}(8) \quad 30.220 \quad 40.845 \quad 35.231$

H(8) $30.997 \quad 39.957 \quad 36.591$

C(8) $\quad 28.021 \quad 37.114 \quad 36.605$

$\begin{array}{llll}\mathrm{O}(8) & 28.070 & 36.172 \quad 36.936\end{array}$

$\begin{array}{llll}\mathrm{O}(8) & 27.368 & 37.820 & 36.333\end{array}$

C(9) $\quad 37.735 \quad 40.745 \quad 28.667$

C(9) $38.801 \quad 39.902 \quad 28.307$

$\begin{array}{llll}C(9) & 38.589 & 38.718 & 27.590\end{array}$

$\begin{array}{llll}C(9) & 37.287 & 38.357 & 27.215\end{array}$

$\begin{array}{llll}C(9) & 36.203 & 39.194 & 27.567\end{array}$

C(9) $36.411 \quad 40.398 \quad 28.285$

C(9) $38.039 \quad 42.003 \quad 29.478$

C(9) $40.157 \quad 37.668 \quad 25.994$

C(9) $36.594 \quad 37.165 \quad 25.178$

C(9) $35.212 \quad 41.330 \quad 28.535$

C(9) $34.843 \quad 41.343 \quad 29.940$

C(9) $34.144 \quad 42.385 \quad 30.533$

C(9) $33.699 \quad 43.605 \quad 29.732$

C(9) $33.859 \quad 42.350 \quad 32.027$

$\begin{array}{lll}O(9) & 39.949 \quad 40.215 \quad 28.620\end{array}$

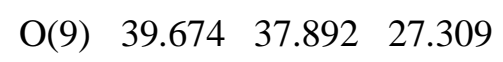




\begin{abstract}
$\begin{array}{llll}O(9) & 37.087 & 37.164 & 26.514\end{array}$
$\begin{array}{llll}\mathrm{O}(9) & 35.048 & 38.861 & 27.264\end{array}$

$H(9) \quad 37.129 \quad 42.533 \quad 29.669$

$H(9) \quad 38.707 \quad 42.630 \quad 28.926$

H(9) $38.493 \quad 41.728 \quad 30.407$

$H(9) \quad 40.993 \quad 37.001 \quad 26.030$

H(9) $\quad 40.461 \quad 38.599 \quad 25.562$

$H(9) \quad 39.381 \quad 37.235 \quad 25.398$

$\mathrm{H}(9) \quad 36.514 \quad 36.158 \quad 24.827$

$H(9) \quad 37.268 \quad 37.709 \quad 24.550$

$\mathrm{H}(9) \quad 35.630 \quad 37.629 \quad 25.154$

$H(9) \quad 34.378 \quad 40.989 \quad 27.958$

$\begin{array}{llll}H(9) & 35.488 & 42.323 & 28.247\end{array}$

$H(9) \quad 35.114 \quad 40.538 \quad 30.526$

$H(9) \quad 33.971 \quad 43.476 \quad 28.705$

$H(9) \quad 34.177 \quad 44.480 \quad 30.120$

$H(9) \quad 32.637 \quad 43.714 \quad 29.809$

$\begin{array}{llll}H(9) & 33.315 & 43.228 & 32.307\end{array}$

$H(9) \quad 34.783 \quad 42.316 \quad 32.566$

$\mathrm{H}(9) \quad 33.279 \quad 41.481 \quad 32.259$
\end{abstract}

- Optimized geometries of GC basepair:

- Neutral:
$\begin{array}{llll}\mathrm{N} & 4.67936 & 0.47473 & -0.00013\end{array}$
$\begin{array}{llll}\text { C } & 4.97546 & -0.88139 & 0.00047\end{array}$
$\begin{array}{llll}\mathrm{N} & 3.90645 & -1.63406 & -0.00015\end{array}$
$\begin{array}{llll}\text { C } & 2.84936 & -0.73871 & -0.00005\end{array}$
$\begin{array}{llll}\text { C } & 1.43502 & -0.95041 & -0.00011\end{array}$
$\begin{array}{llll}\text { O } & 0.80606 & -2.02243 & -0.00018\end{array}$ 


\begin{tabular}{|c|c|c|c|}
\hline $\mathrm{T}$ & 0.73128 & 0.26963 & -0.00006 \\
\hline $\mathrm{C}$ & 1.29484 & 1.52486 & 0.00001 \\
\hline 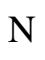 & 0.44336 & 2.57410 & 0.00002 \\
\hline$N$ & 2.60472 & 1.73235 & 0.00002 \\
\hline $\mathrm{C}$ & 3.31174 & 0.58309 & 0.00003 \\
\hline $\mathrm{H}$ & 5.99610 & -1.23819 & 0.00068 \\
\hline $\mathrm{H}$ & -0.29876 & 0.18357 & -0.00013 \\
\hline $\mathrm{H}$ & 0.85205 & 3.49447 & -0.00002 \\
\hline $\mathrm{H}$ & -0.57319 & 2.46560 & -0.00009 \\
\hline $\mathrm{N}$ & -4.34545 & 0.91595 & 0.00012 \\
\hline $\mathrm{C}$ & -2.94389 & 1.06258 & 0.00001 \\
\hline $\mathrm{O}$ & -2.47258 & 2.20777 & -0.00003 \\
\hline $\mathrm{N}$ & -2.19633 & -0.07107 & -0.00004 \\
\hline $\mathrm{C}$ & -2.77188 & -1.28162 & -0.00002 \\
\hline $\mathrm{N}$ & -1.96920 & -2.35185 & -0.00008 \\
\hline $\mathrm{C}$ & -4.20811 & -1.43832 & 0.00008 \\
\hline $\mathrm{C}$ & -4.95299 & -0.30331 & 0.00015 \\
\hline $\mathrm{H}$ & -6.03738 & -0.30607 & 0.00022 \\
\hline $\mathrm{H}$ & -4.67324 & -2.41575 & 0.00010 \\
\hline $\mathrm{H}$ & -0.93783 & -2.23851 & -0.00018 \\
\hline $\mathrm{H}$ & -2.36197 & -3.27980 & -0.00009 \\
\hline $\mathrm{H}$ & 5.32858 & 1.24777 & -0.00028 \\
\hline $\mathrm{H}$ & -4.87901 & 1.77503 & 0.00016 \\
\hline
\end{tabular}

- Anion:

* xyz 01

$\begin{array}{llll}\mathrm{N} & 4.63818 & 0.57343 & -0.00806 \\ \mathrm{C} & 4.99908 & -0.75653 & -0.17955 \\ \mathrm{~N} & 3.96461 & -1.55494 & -0.24531\end{array}$




$$
\begin{aligned}
& \begin{array}{llll}
\text { C } & 2.86378 & -0.72063 & -0.11208
\end{array} \\
& \begin{array}{llll}
\text { C } & 1.45124 & -1.00671 & -0.10040
\end{array} \\
& \begin{array}{llll}
\text { O } & 0.89765 & -2.10724 & -0.21151
\end{array} \\
& \begin{array}{llll}
\mathrm{N} & 0.68676 & 0.16555 & 0.06380
\end{array} \\
& \begin{array}{llll}
\text { C } & 1.19583 & 1.43483 & 0.19795
\end{array} \\
& \begin{array}{llll}
\mathrm{N} & 0.30841 & 2.43389 & 0.36629
\end{array} \\
& \begin{array}{llll}
\mathrm{N} & 2.50547 & 1.71246 & 0.18971
\end{array} \\
& \begin{array}{llll}
\text { C } & 3.26199 & 0.61022 & 0.03724
\end{array} \\
& \begin{array}{llll}
\mathrm{H} & 6.03538 & -1.05928 & -0.24709
\end{array} \\
& \begin{array}{llll}
\mathrm{H} & -0.37065 & 0.04641 & 0.08748
\end{array} \\
& \begin{array}{llll}
\text { H } & 0.70484 & 3.36064 & 0.35056
\end{array} \\
& \begin{array}{llll}
\mathrm{H} & -0.71421 & 2.31361 & 0.16142
\end{array} \\
& \begin{array}{llll}
\mathrm{N} & -4.22570 & 0.96952 & -0.36482
\end{array} \\
& \begin{array}{llll}
\text { C } & -2.85497 & 1.04652 & -0.15039
\end{array} \\
& \begin{array}{llll}
\text { O } & -2.32977 & 2.19910 & -0.22165
\end{array} \\
& \begin{array}{llll}
\mathrm{N} & -2.14625 & -0.06984 & 0.10033
\end{array} \\
& \begin{array}{llll}
\text { C } & -2.83037 & -1.27635 & 0.19573
\end{array} \\
& \begin{array}{llll}
\mathrm{N} & -2.02219 & -2.36751 & 0.53255
\end{array} \\
& \begin{array}{llll}
\text { C } & -4.20530 & -1.37849 & 0.06079
\end{array} \\
& \begin{array}{llll}
\text { C } & -4.97762 & -0.21242 & -0.14086
\end{array} \\
& \begin{array}{llll}
\mathrm{H} & -5.98091 & -0.22529 & -0.55568
\end{array} \\
& \begin{array}{llll}
\mathrm{H} & -4.69710 & -2.34250 & 0.15682
\end{array} \\
& \begin{array}{llll}
\mathrm{H} & -1.04760 & -2.28736 & 0.23843
\end{array} \\
& \begin{array}{llll}
\mathrm{H} & -2.42036 & -3.26458 & 0.28859
\end{array} \\
& \begin{array}{llll}
\mathrm{H} & 5.24506 & 1.37496 & 0.07171
\end{array} \\
& \begin{array}{llll}
\mathrm{H} & -4.68450 & 1.86807 & -0.37906
\end{array}
\end{aligned}
$$

- Optimized geometries of Thymine-(Glycine) $)_{n}$ clusters:

(i) Thy-(Gly)

$\begin{array}{llll}\mathrm{N} & -1.11396129228557 & -0.93358027963086 & -3.55407596312663\end{array}$ 

$\begin{array}{llll}\text { C } & -0.34348066536846 & -0.20180140748152 & -4.48306903271018\end{array}$
$\begin{array}{llll}\mathrm{H} & -0.66799426750991 & -0.31087254853657 & -5.51954799223705\end{array}$
$\begin{array}{llll}\text { C } & 0.63454479145479 & 1.10653770037031 & -2.63250339057824\end{array}$
$\begin{array}{llll}\text { O } & 1.24061156427092 & 2.01772113154361 & -2.01307401558582\end{array}$
$\begin{array}{llll}\text { N } & 0.02241438568207 & 0.05028784628259 & -1.77552356954048\end{array}$
$\begin{array}{llll}\mathrm{H} & -0.06919855251017 & 0.33885796467506 & -0.79998022714854\end{array}$
$\begin{array}{llll}\text { C } & -0.97529251393864 & -0.78153222571723 & -2.23284173477579\end{array}$
$\begin{array}{llll}\text { O } & -1.69737919140367 & -1.42245370915118 & -1.33269976213393\end{array}$
C $\quad 1.08669536369760 \quad 1.85193649427830 \quad-4.98588558673772$
$\begin{array}{llll}\mathrm{H} & 1.67331177783620 & 2.59360999848332 & -4.41758558048529\end{array}$
$\begin{array}{llll}\text { H } & 1.77147437909027 & 1.33980726123326 & -5.69718269369343\end{array}$
$\begin{array}{llll}\mathrm{H} & 0.34822070466688 & 2.40335218458476 & -5.60901457002097\end{array}$
$\begin{array}{llll}\mathrm{H} & -1.82285772499100 & -1.63534759855135 & -3.88751131194974\end{array}$
N $\quad-4.90422812790217 \quad-4.77278339488560 \quad-4.95774041815194$
H $\quad-4.63412854456081 \quad-3.98727779660936 \quad-5.57171373431425$
$\begin{array}{llll}\text { C } & -4.87521154681897 & -4.20084827255585 & -3.59926820121522\end{array}$
$\begin{array}{llll}\text { C } & -3.70402805584897 & -3.22580652606568 & -3.31015392948644\end{array}$
H $\quad-5.81827691231208 \quad-3.64586888217816 \quad-3.42284885292743$
$\begin{array}{llll}\mathrm{H} & -4.85917729649207 & -5.01193305181737 & -2.84986526229775\end{array}$
$\begin{array}{llll}\text { O } & -3.02617307411448 & -2.82586306333329 & -4.30064484832882\end{array}$
H $\quad-4.07816326127176 \quad-5.38553109449016 \quad-5.02925455478680$
$\begin{array}{llll}\text { O } & -3.55924250899494 & -2.89867693576345 & -2.07658884408433\end{array}$
$\begin{array}{llll}\mathrm{H} & -2.49398678613590 & -2.05745599259769 & -1.75445200651033\end{array}$
$\begin{array}{llll}\text { C } & 0.43951242576098 & 0.89778871791417 & -4.01792434717265\end{array}$

\section{(ii) Thy-(Gly $)_{2}$ :}
N -1.32678508137652
$-0.69074415738109$
$-3.31412535366465$
C -0.55203621802296
0.17823455133110
$-4.12843846836595$
H $\quad-0.94778394620138$
0.36303823777391
$-5.12844463704873$ 

C 0.60665857821904
0.88892119820115
$-2.12447752072689$
O 1.54017314301142
1.57308673769858
$-1.45590660000629$
N -0.17264379717461
$-0.04811875822599 \quad-1.38936794081155$
H $\quad 0.02882589379158$
$-0.18369718640914$
$-0.35902113661331$
C -1.12610200777370
$-0.84306971589893$
$-1.97499063130825$
O $\quad-1.78106331600181$
$-1.67978962507227$
$-1.27072248327215$
C 1.20202565047169
$2.01478359060515 \quad-4.29337038561463$
H 1.62026882433889
2.78762589235354
$-3.62868301880245$
H 2.05201044996184
1.54054706750389
$-4.82474284670781$
H $\quad 0.57666158920559$
2.50877510593378
$-5.06272213896409$
H -2.01397683501743
$-1.33534081810921$
$-3.74102322571123$
N $\quad-5.20923444482177$
$-4.44097484812777$
$-5.15919019480069$
H $\quad-4.33699797183644$
$-4.60797214666703$
$-5.68057813944795$
C -4.84681815298802
$-4.37043457427461$
$-3.73965614712900$
C -3.78051431583350
$-3.31800288017025$
$-3.37861916679831$
H $\quad-5.75077571818505$
$-4.16213407465126$
$-3.13710458871232$
H -4.48543791504107
$-5.35866667178592 \quad-3.39978357782199$
O $\quad-3.29743966764416$
$-2.58497980520924 \quad-4.26221731346611$
H $\quad-5.46144047955671$
$-3.48472644399283 \quad-5.44684206241723$
O $\quad-3.48268345791140$
$-3.30769205646032-2.09838163995775$
H $\quad-2.72948470659557$
$-2.55636215285322 \quad-1.83721865523744$
C 0.39618091384439
$1.02037659282583 \quad-3.49437347280017$
N 0.34990363075919
$0.02488694005161 \quad 4.07494724222311$
H -0.65782949447924
$0.22208307805249 \quad 3.98201315944051$
C 1.04588143401787
$1.04488810690320 \quad 3.26799559869470$
C 0.89010867271089
$0.89516539953136 \quad 1.73077186266312$
H $\quad 0.71587831397841$
$2.05599272047524 \quad 3.56567268949191$
H 2.13109598171749
$1.00279370962801 \quad 3.49320364466961$ 

O $\quad 0.43881523328399$
$-0.21202462109085$
1.30884395611374
H 0.44486419360973
$-0.83949724455923 \quad 3.51566080609564$
O 1.26313867293462
1.90331295345416
1.03414416942326
H 1.35035736060462
$1.65573040861622-0.40233980260865$

\section{(iii) Thy-(Gly)3:}
N -1.43835116390068
$-1.16054463718901$
$-2.85513862758778$
C -0.27981580014170
$-0.74603398370787$
$-3.56097772216104$
H $\quad-0.14443601173109$
$-1.18202385175520$
$-4.54975435965217$
C 0.48725092379220
$0.29815924918522-1.52634908630122$
O 1.35811967704233
0.97681737587145
$-0.76389730437498$
N $\quad-0.75039923759904$
$-0.05714601867250$
$-0.92075184264055$
H -1.00512328777881
0.41969107393885
$-0.02007915487649$
C -1.70137952258097
$-0.80885421686829$
$-1.56713686753537$
O $\quad-2.77143017449197$
$-1.15662087028845$
$-0.96566868815625$
C 2.04068802921624
0.30334126056303
$-3.50397913849544$
H 1.95540762776514
1.20514403018741
$-4.14305988440123$
H 2.80404667653818
0.51285344603985
$-2.73786020470011$
H 2.40336595858061
$-0.51951074758821$
$-4.14977676991934$
H -2.17218804347332
$-1.71719198193034 \quad-3.32665269947363$
N $\quad-5.84782903546701$
$-3.99178180059522 \quad-5.10705609861835$
H $\quad-5.29765358520718$
$-3.37510210292297$
$-5.72216058313721$
C -5.98064985871682
$-3.28789369099195$
$-3.82776238603662$
C -4.68486341389676
$-2.66022115824119$
$-3.28506251650432$
H -6.72515861584619
$-2.47465850163832 \quad-3.93064513835784$
H $\quad-6.38897957214339$
$-3.97207373859062 \quad-3.06276298694451$
O -3.65166233607311
$-2.64262897715939 \quad-3.97750713743487$
H $\quad-5.21304362904245$
$-4.78705598575788 \quad-4.95174344186311$
O $\quad-4.82565072321169$
$-2.15614391673371 \quad-2.07372072210853$ 

H $\quad-3.91875341273968 \quad-1.73578116165733 \quad-1.70126605425872$
$\begin{array}{llll}\text { C } & 0.73049648595423 & -0.05684987207155 & -2.84808179978691\end{array}$
$\begin{array}{llll}\mathrm{N} & -1.61215756534931 & 0.94156225926975 & 4.24593725965300\end{array}$
$\begin{array}{llll}\mathrm{H} & -2.18330437350048 & 1.50362492569579 & 3.59562247583878\end{array}$
$\begin{array}{llll}\text { C } & -0.23497061686219 & 1.07258901159759 & 3.74604638046962\end{array}$
C $\quad-0.09502830619291 \quad 0.97472771285415 \quad 2.21331418698898$
$\begin{array}{llll}\text { H } & 0.17417638869890 & 2.05757736424635 & 4.05539865409223\end{array}$
$\begin{array}{llll}\text { H } & 0.40405909598535 & 0.30512520622982 & 4.21267564953227\end{array}$
$\begin{array}{llll}\text { O } & -1.05864538553311 & 1.34941250828181 & 1.49856099109128\end{array}$
H $\quad-1.88213063254520 \quad-0.02601470437096 \quad 4.01259619576244$
$\begin{array}{llll}\text { O } & 1.04190625843211 & 0.51469540482168 & 1.76545828096038\end{array}$
$\begin{array}{llll}\mathrm{H} & 1.19107053325131 & 0.79009972483410 & 0.25392161987906\end{array}$
$\begin{array}{llll}\mathrm{N} & -2.35784426799089 & -3.78993614588819 & 1.08543042551494\end{array}$
H $\quad-2.73908375596055 \quad-3.45056060883996 \quad 1.98131399452105$
C $\quad-0.89742872765039 \quad-3.75134890902034 \quad 1.23515491671511$
C $\quad-0.38601385039806 \quad-2.46872546994076 \quad 1.91074053581268$
$\begin{array}{llll}\text { H } & -0.57048602188364 & -4.61315432016431 & 1.85273300990688\end{array}$
$\begin{array}{llll}\mathrm{H} & -0.41306424847314 & -3.86359394359588 & 0.25144333121884\end{array}$
$\begin{array}{llll}\text { O } & -1.05422401297906 & -1.87716322039778 & 2.76336645351617\end{array}$
H $\quad-2.60931641530747 \quad-3.04152825075975 \quad 0.41917526832453$
$\begin{array}{llll}\text { O } & 0.82274382733899 & -2.08682121900867 & 1.47728909253707\end{array}$
H $\quad 0.99360389207296 \quad-1.11958932726999 \quad 1.78087010299138$

\section{(iv) Thy-(Gly) 4:}
N $\quad-0.66733796616470 \quad-1.46620165776206 \quad-3.87538543929296$
$\begin{array}{llll}\text { C } & 0.25673683934636 & -1.05608963805299 & -4.87271017277654\end{array}$
$\begin{array}{llll}\mathrm{H} & -0.13575049350914 & -1.00955250090429 & -5.88948071036414\end{array}$
C $\quad 1.70686222565196 \quad-0.29276623301750 \quad-3.09674093322904$
$\begin{array}{llll}\text { O } & 2.84499519792640 & 0.22075670652624 & -2.61167344817242\end{array}$ 

N 0.75408462759165
$-0.78278851539451$
$-2.15870841505299$
H 1.00257816329352
$-0.75067135038631-1.13135740542845$
C -0.42840768136051
$-1.36081642011911$
$-2.54143499427675$
O $\quad-1.26310285123310$
$-1.78514619902308$
$-1.66842472647594$
C 2.43511125803799
0.11840029575680
$-5.46739867284739$
H 3.03775035486753
$0.92986304675990 \quad-5.02800811522291$
H 3.14014429333332
$-0.66419409889309$
$-5.81192905836102$
H 1.91801778185321
0.50872701553963
$-6.36391242722724$
H -1.55221215135952
$-1.93107574985992$
$-4.13876431086832$
N $\quad-5.63301678893756$
$-4.11650908256487$
$-4.88510340024583$
H $\quad-5.65930524659248$
$-3.18950878561133$
$-5.33188690256643$
C -5.15733544613609
$-3.91804491670437$
$-3.51324100354886$
C -3.81670975371050
$-3.17458183832159$
$-3.37750406198939$
H $\quad-5.91742998463772$
$-3.36110566423943$
H $\quad-5.05914364858558$
$-4.89732422048012$
$-2.93439829936349$
O $\quad-3.20985306448405$
$-2.76468560083484$
$-3.00939444399793$
H $\quad-4.88120926033614$
$-4.59710931766007$
$-4.38094550772932$
O $\quad-3.42875984350587$
$-3.04356855929171$
$-5.39832283163909$
H $\quad-2.50769335579773$
$-2.51894714129036$
$-2.12068268893800$
C 1.44491131545663
$-0.4066288470514$
$-2.03944719670011$
N 1.61729438887101
0.45204511450558
$-4.45754315050851$
H 0.86774409952413
1.12703259677865
3.18191723080817
C 2.67341362125314
0.70516269677080
2.96551700951646
C 2.32373259791027
0.39265655861983
2.19316288948169
H 2.99406651502724
1.75774873882239
0.71872511309673
H 3.56231787330716
0.09085094342688
2.26540276348240
O 1.46968956287766
$-0.53137629514548$
2.44572303446291
Н 1.21240913534932
$-0.46821101029244$
0.50836907700483
2.95301203661267 

O $2.94693043302135 \quad 1.05628447459845$
$-0.18148148410869$
H 2.78241842032124
$0.53904666781437 \quad-1.61150131698344$
N -1.31054462855145
$0.05581422952216 \quad 0.66451404193926$
H -0.34481486607958
$-0.18578960887281$
0.96938474524088
C -2.22143726553484
0.20387529332297
1.79108362027102
C -2.20108337169506
$-0.94126105079794$
2.79655152478962
H -1.93835660219272
1.12909192878523
2.33369804588296
H $\quad-3.25668097517400$
0.35028927058723
1.43643442901899
O $\quad-1.33451624731700$
$-1.79382410129550$
2.91187095375775
H - 1.57321160999941
$-0.69037953138214$
$-0.00267505630913$
O $\quad-3.29507210318602$
$-0.89030602163102$
3.62639939934375
H $\quad-3.15262461821754$
$-1.63257070936087$
4.26021202954481
N 2.23083423231178
4.13484244420179
0.48384684565958
H 2.11282822498363
4.06898516798549
1.50605710933972
C 0.87398422479477
$4.10143096940482 \quad-0.08355903477392$
C $\quad-0.00493528405411 \quad 2.97090155704301$
0.47973267850262
H $\quad 0.37039058937079$
5.06619678912929
0.13267902130984
H 0.93537284970975
4.00100109905094
$-1.17925250052251$
O 0.00166925007770
2.70082300271243
1.69586627335367
H 2.68608695389908
3.24155704020825
0.22328857403258
O $\quad-0.71858084839872$
2.33127803963956
$-0.43474337214696$
H -1.06929784321736
1.39588215872853
0.00256532521503

\section{(v) Thy-(Gly)5:}
N 0.00970867367555
$-3.16984905574423$
$-3.81025701390666$
C 1.15383948517913
$-3.36224251158238$
$-4.62951566513771$
H 0.95912053247559
$-3.73941276452026 \quad-5.63185453696878$
C 2.44319685353588
$-2.16414396754230 \quad-2.98051941507044$
O 3.57401201486856
$-1.63069041852439 \quad-2.48551346606144$ 

N $1.26905494635864 \quad-2.09453844612734 \quad-2.17135023649922$
H $\quad 1.32330369857011 \quad-1.63954645012389 \quad-1.22153608580783$
$\begin{array}{llll}\text { C } & 0.05226254948295 & -2.53869416588186 & -2.61373853279633\end{array}$
$\begin{array}{llll}\text { O } & -1.00537681282099 & -2.36032892590785 & -1.90234861581558\end{array}$
$\begin{array}{llll}\text { C } & 3.57506140052567 & -2.78249380565251 & -5.13903777034846\end{array}$
H $\quad 4.50930696434484 \quad-2.94462759949980 \quad-4.57560272435249$
$\begin{array}{llll}\text { H } & 3.48725745688204 & -3.57423512048187 & -5.90418015880520\end{array}$
H $3.66248602255343 \quad-1.81083792507623 \quad-5.66041816288749$
H $\quad-0.92242643472606 \quad-3.49153750779267 \quad-4.12138804637952$
$\begin{array}{llll}\mathrm{N} & -5.33424539433177 & -4.71064007220336 & -5.19717614458051\end{array}$
H $\quad-4.98044224067630 \quad-4.07903681391498 \quad-5.92860066171507$
C $\quad-5.05157686333938-4.08365255973505 \quad-3.90543236299751$
$\begin{array}{llll}\text { C } & -3.58076100303492 & -3.71795582396403 & -3.65082021288906\end{array}$
H $\quad-5.65599027572835 \quad-3.16411798558769-3.79912874314850$
$\begin{array}{llll}\mathrm{H} & -5.38202510241700 & -4.75192748668761 & -3.08830658796411\end{array}$
$\begin{array}{llll}\text { O } & -2.69692901559294 & -3.97252843079002 & -4.48296415433571\end{array}$
$\begin{array}{llll}\mathrm{H} & -4.72261211743610 & -5.53381429168645 & -5.27940567580997\end{array}$
O
$\begin{array}{llll}\mathrm{H} & -2.39015223340591 & -2.87587927812529 & -2.33209688807253\end{array}$
C $\quad 2.37564110965676 \quad-2.78343072666331 \quad-4.22328470562577$
$\begin{array}{llll}\mathrm{N} & 1.26919228677758 & 1.58422735865065 & 1.97831933355061\end{array}$
$\begin{array}{llll}\mathrm{H} & 0.75063279346331 & 2.12993584590941 & 1.27294599777905\end{array}$
C $\quad 2.52941405188442 \quad 1.12228534811643 \quad 1.38656016072706$
$\begin{array}{llll}\text { C } & 2.45933786898876 & 0.04221442036518 & 0.28030927438725\end{array}$
H $3.08538235768173 \quad 1.98552611598355 \quad 0.98272791665454$
H $3.17075724043335 \quad 0.70173701689024 \quad 2.18876876820006$
O $\quad 1.40646105638332 \quad-0.68963169614800 \quad 0.22126628985654$
$\begin{array}{llll}\mathrm{H} & 0.68670146901161 & 0.75790671649641 & 2.17331769335521\end{array}$ 

O 3.48026663433747
$-0.07693240193213$
$-0.46728107089412$
H 3.44378225782300
$-1.05175366352799-1.61146606039844$
N $\quad-0.94262166679138$
0.16862449339099
$-0.65616730619851$
H -0.16037528147554
$-0.01925460770585$
0.04046312962864
C -2.14335839071868
0.79695473160726
$-0.06978093025353$
C $\quad-2.51186043871599$
0.19235600718076
1.26681984163104
H $\quad-1.88367405579923$
1.87130184009853
0.06358105919021
H $\quad-2.98935625020436$
0.73132071282835
$-0.77226973962037$
O $\quad-1.76886395904189$
$-0.44156852303746$
2.00058401928291
H $\quad-1.11279806930225$
$-0.76563372113332$
$-1.11313340497555$
O $\quad-3.80623051196019$
0.48992220346564
1.59355529484468
H $\quad-3.92925652853899$
0.11072220281411
2.49537687275080
N 0.73861286911322
5.62471837747791
$-1.38504189438671$
H $\quad-0.18696357822058$
5.69412595539732
$-0.93753667008682$
C 0.69819057893812
4.41142865726099
$-2.21182759673393$
C 0.09025284124154
3.15547544567041
$-1.54361138663003$
H $\quad 0.11874619815170$
4.61488260674879
$-3.133458666698734$
H 1.72082831192515
4.16720801558381
$-2.55152028517911$
O $\quad-0.39087961355215$
3.26104405453739
$-0.38281400659563$
H 1.35438979433313
5.41733781094803
$-0.58612140070249$
O 0.10001902524051
2.0681001952975
$-2.25063639970956$
H $\quad-0.51040871035976$
0.86871665560973
$-1.37384888473105$
N 4.46305129771620
1.05457137242488
$-4.02921150298555$
H 4.57417095785936
0.93075789090165
$-5.04674896199668$
C 3.11546357756794
1.58876488143263
$-3.83838557011156$
C 2.12910959580081
$1.24484627466292 \quad-4.97287806412536$
H 2.71473739621191
$1.26254385783676 \quad-2.86361299245267$
H 3.14828294259380
2.70090456575537
$-3.79362856287436$ 

$\begin{array}{llll}\text { O } & 2.50929228480873 & 0.77836123898862 & -6.04542943533885\end{array}$
$\begin{array}{llll}\mathrm{H} & 4.46435333645831 & 0.10123558653379 & -3.63967597159381\end{array}$
$\begin{array}{llll}\text { O } & 0.83519164549036 & 1.56075384782645 & -4.77091664874156\end{array}$
$\begin{array}{llll}\mathrm{H} & 0.65946929032210 & 1.84243418230083 & -3.80977372692378\end{array}$

- Optimized geometries of AT basepair:

- Neutral:
C $\quad 0.000000 \quad 0.000000 \quad 0.000000$
C $\quad 0.000000 \quad 0.000000 \quad 1.367491$
C $\quad 1.296704 \quad 0.000000 \quad 2.047352$
$\begin{array}{llll}\mathrm{N} & 2.419148 & 0.000044 & 1.225547\end{array}$
C $\quad 2.439783 \quad 0.000048 \quad-0.158785$
N $\quad 1.170899 \quad 0.000025 \quad-0.733202$
$\mathrm{H} \quad 1.154685 \quad 0.000028 \quad-1.747273$
H $\quad-0.923724 \quad-0.000016 \quad-0.583384$
H $\quad-2.146622 \quad-0.000009 \quad 1.560696$
H $\quad-1.279025 \quad 0.885714 \quad 2.854367$
H $\quad-1.279017 \quad-0.885735 \quad 2.854346$
$\begin{array}{llll}\text { O } & 3.473211 & 0.000071 & -0.830619\end{array}$
N $\quad 4.934157 \quad 0.000089 \quad 2.476197$

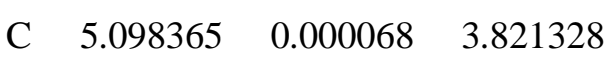
$\begin{array}{llll}\text { C } & 6.429437 & 0.000095 & 4.314499\end{array}$
$\begin{array}{llll}\text { N } & 6.933796 & 0.000085 & 5.606047\end{array}$
$\begin{array}{llll}\text { C } & 8.257330 & 0.000124 & 5.421991\end{array}$
$\begin{array}{llll}\text { N } & 8.623151 & 0.000159 & 4.092708\end{array}$
C $\quad 7.455908 \quad 0.000141 \quad 3.350208$
$\begin{array}{llll}\text { N } & 7.319540 & 0.000162 & 2.005354\end{array}$
$\begin{array}{llll}\text { C } & 6.022884 & 0.000133 & 1.658159\end{array}$
$\begin{array}{llll}\text { H } & 5.790969 & 0.000147 & 0.589573\end{array}$
$\begin{array}{llll}\mathrm{H} & 9.565205 & 0.000191 & 3.716467\end{array}$ 

$\begin{array}{llll}\text { H } & 8.996090 & 0.000129 & 6.220842\end{array}$
$\begin{array}{llll}\mathrm{N} & 4.012818 & 0.000023 & 4.625471\end{array}$
$\begin{array}{llll}\mathrm{H} & 4.153304 & 0.000009 & 5.627107\end{array}$
$\begin{array}{llll}\text { H } & 3.363590 & 0.000060 & 1.695667\end{array}$
H $\quad 3.070244 \quad 0.000005 \quad 4.221755$
$\begin{array}{llll}\text { O } & 1.417870 & 0.000055 & 3.288446\end{array}$
$\begin{array}{llll}\text { C } & -1.251589 & -0.000005 & 2.200683\end{array}$

- Anion:
$\begin{array}{llll}\text { C } & 0.000000 & 0.000000 & 0.000000\end{array}$
$\begin{array}{llll}\text { C } & 0.000000 & 0.000000 & 1.419896\end{array}$
$\begin{array}{llll}\text { C } & 1.205802 & 0.000000 & 2.120901\end{array}$
$\begin{array}{llll}\mathrm{N} & 2.402075 & -0.000287 & 1.353055\end{array}$
$\begin{array}{llll}\text { C } & 2.475567 & -0.000605 & -0.027130\end{array}$
$\begin{array}{llll}\mathrm{N} & 1.262734 & -0.000329 & -0.661858\end{array}$
$\begin{array}{llll}\mathrm{H} & 1.323365 & -0.000419 & -1.671377\end{array}$
$\begin{array}{llll}\text { H } & -0.885963 & 0.000062 & -0.629572\end{array}$
$\begin{array}{llll}\mathrm{H} & -2.151540 & -0.000153 & 1.501234\end{array}$
$\begin{array}{llll}\text { H } & -1.379733 & 0.886383 & 2.848639\end{array}$
$\begin{array}{llll}\text { H } & -1.379638 & -0.886671 & 2.848593\end{array}$
$\begin{array}{llll}\text { O } & 3.564783 & -0.000780 & -0.644057\end{array}$
$\begin{array}{llll}\mathrm{N} & 4.938951 & -0.002183 & 2.929482\end{array}$
$\begin{array}{llll}\text { C } & 4.807705 & 0.000012 & 4.284619\end{array}$
$\begin{array}{llll}\text { C } & 6.014998 & -0.001184 & 5.046866\end{array}$
$\begin{array}{llll}\mathrm{N} & 6.245145 & 0.000494 & 6.418775\end{array}$
$\begin{array}{llll}\text { C } & 7.577795 & -0.001984 & 6.514980\end{array}$
$\begin{array}{llll}\mathrm{N} & 8.210243 & -0.005025 & 5.289421\end{array}$
$\begin{array}{llll}\text { C } & 7.219146 & -0.004493 & 4.318212\end{array}$
$\begin{array}{llll}\text { N } & 7.375751 & -0.006623 & 2.975166\end{array}$ 

$\begin{array}{llll}\text { C } & 6.169100 & -0.005172 & 2.368098\end{array}$
H $\quad 6.171161 \quad-0.006772 \quad 1.274152$
$\begin{array}{llll}\text { H } & 9.207999 & -0.007201 & 5.112472\end{array}$
H $\quad 8.136577 \quad-0.001670 \quad 7.449005$
$\begin{array}{llll}\mathrm{N} & 3.579577 & 0.003829 & 4.820893\end{array}$
H $\quad 3.516642 \quad 0.005738 \quad 5.831652$
H $\quad 3.300222 \quad-0.000341 \quad 1.851541$
H $\quad 2.704893 \quad 0.005546 \quad 4.208179$
$\begin{array}{llll}\text { O } & 1.340092 & -0.000851 & 3.398585\end{array}$
$\begin{array}{llll}\text { C } & -1.293070 & -0.000115 & 2.194028\end{array}$

Table S1: The VEA corresponding to first two bound states of $Q_{B}$ model system and corresponding computational timings

\begin{tabular}{lcc|cc|cc}
\hline $\begin{array}{c}\text { Basis set: } m a- \\
\text { def2-SVP }\end{array}$ & Full NPNO & \multicolumn{2}{c}{$\begin{array}{c}\text { NPNO-LPNO- } \\
\text { HF }\end{array}$} \\
\hline \hline State & I & I I & I & I I & I & I I \\
\hline & 3.029 & 1.293 & 2.761 & 0.610 & 2.755 & 0.610 \\
\hline
\end{tabular}

Table S2:VDE of the Thymine-(Glycine $)_{n}$ cluster and the corresponding timings required for the correlation calculations $\left(\boldsymbol{T}_{\text {Corr }}\right)$

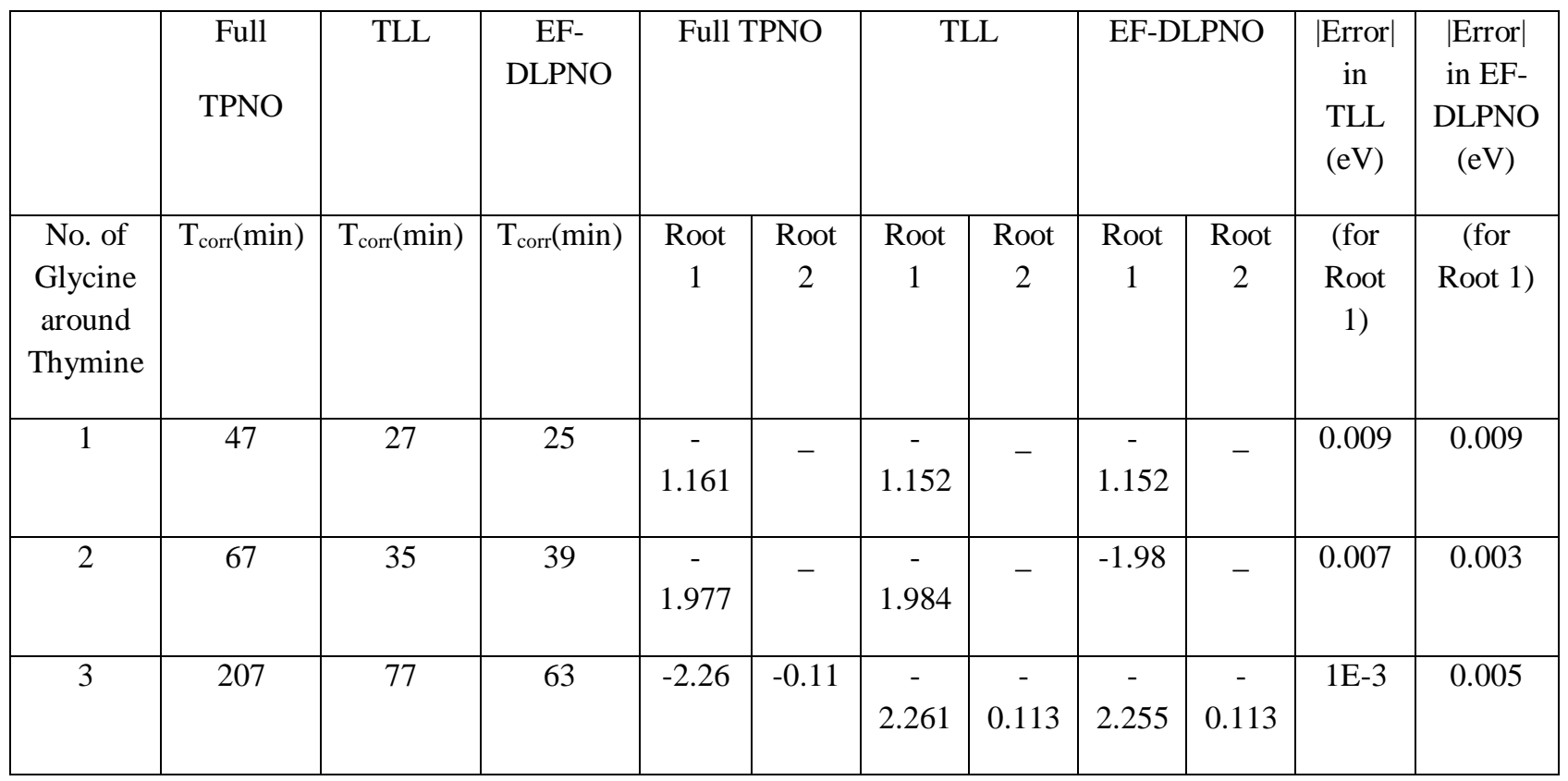




\begin{tabular}{|c|c|c|c|c|c|c|c|c|c|c|c|}
\hline 4 & 282 & 89 & 71 & - & - & - & - & - & - & 0.009 & 0.014 \\
& & & & 2.263 & 0.115 & 2.254 & 0.117 & 2.249 & 0.116 & \\
\hline 5 & 374 & 129 & 99 & - & - & - & - & - & - & 0.005 & 0 \\
\hline
\end{tabular}


